\title{
III. AUF DEM WEG ZUR KÖNIGLICHEN GUNST PRACHTBAU UND PROPAGANDA 1656-1661
}

Bereits wenige Jahre nach der Übernahme seines neuen Amtes schien Fouquets Position als Minister ernsthaft gefährdet. Im täglichen Ringen um die eigene Stellung waren sowohl das Wohlwollen eines höhergestellten Förderers als auch die Absicherung durch ein breit angelegtes Netz von Beziehungen, dessen Klienten die Interessen des Patrons auf vielfältiger Ebene vertraten, unabdingbar. Beides drohte der Finanzminister Mitte der fünfziger Jahre zu verlieren. Sein stärkster Konkurrent um die Protektion durch den Premierminister, Jean-Baptiste Colbert, trieb die Verleumdung Fouquets bei Mazarin seit 1655 mit zunehmendem Erfolg voran. Zugleich verlor der Finanzminister nach dem endgültigen Zerwürfnis mit seinem Bruder Basile im Jahr 1657 einen beträchtlichen Teil seiner Klienten und mit ihnen wichtige Informanten und Geldgeber.

Auf der anderen Seite blieb der Finanzminister für Mazarin so lange unentbehrlich, wie er die Beschaffung von Zahlungsmitteln in einer Zeit des chronischen Mangels garantierte. Nicht allein der Krieg gegen Spanien verschlang bis 1659 unaufhörlich nicht vorhandene Staatsgelder, auch der Premierminister selbst forderte große Summen zur Befriedigung seiner privaten Bedürfnisse.

Auf innenpolitischer Ebene ließ der sich verschlechternde Gesundheitszustand Mazarins in dieser Zeit die Frage nach der Nachfolge für den Premierminister aufkommen. Für diese war Nicolas Fouquet ein naheliegender Kandidat. Die Aussicht auf den begehrten Posten entfachte in ihm die Hoffnung auf einen weiteren Aufstieg.

Das politische Schicksal Nicolas Fouquets schien Mitte der fünfziger Jahre nach allen Seiten offen. Seine Laufbahn war bedroht, und er stand zugleich in der Erwartung von Mazarins Tod vor der Möglichkeit eines weiteren Aufstiegs. Für die Nachfolge des Premierministerpostens war das Wohlwollen Mazarins zwar nicht unerheblich, da dieser die Entscheidung des Königs bis zu seinem Ableben nachhaltig beeinflussen konnte, entscheidend aber war die Meinung des Monarchen selbst. Dieser hatte seit seiner Krönung im Juni 1654 politisch an Bedeutung gewonnen, wenngleich noch immer der Premierminister die Regierungsgeschäfte führte. Für Fouquet, der sich der Loyalität Mazarins nicht mehr sicher sein konnte, galt es in dieser Situation, die Gunst Ludwigs XIV. zu erlangen, um die eigene Position zu festigen und seine Interessen durchsetzen zu können.

Der Mäzen Nicolas Fouquet reagierte auf die Situation mit dem Bau eines neuen Schlosses, dessen ikonographisches Programm die Tugenden und Fähigkeiten des Finanzministers in Deckengemälden und Skulpturen inszenierte. Mit dem Bau der neuen Anlage änderte sich auch die Art der Literaturförderung durch Fouquet, der nun die Entstehung von Werken in Auftrag gab, die ihn und seinen Schlossbau zum Thema hatten. 


\section{Der zweite Schlossbau: Vaux-le-Vicomte}

Vaux-le-Vicomte gilt heute als eines der ersten und zugleich glänzendsten architektonischen Gesamtkunstwerke des 17. Jahrhunderts. Auch die Zeitgenossen versetzte seine Pracht in Staunen. In dem neuen Schloss sahen sie jedoch nicht nur das bauliche Kunstwerk, sondern auch eine politische Botschaft, mit deren Hilfe der Erbauer seinem Schicksal eine neue Wende zu geben hoffte.

\subsection{Die Baugeschichte}

Bereits im Februar 1641 hatte Nicolas Fouquet, damals noch Berichterstatter im Conseil d'État, von seinem Amtskollegen François Lotin de Charny die Vicomté von Vaux erworben ${ }^{1}$. Obwohl der Finanzminister seinen Besitz bereits in den Jahren nach dem Erwerb erheblich vergrößert hatte, tätigte er ab 1654 weitere bedeutende Landkäufe. Ein letztes Teilstück erwarb er 1656 von Mme de Lionne, so dass er nunmehr über mehr als 400 ha zusammenhängenden Landes verfügte, welches ihm als Baugrund für eine neue Schlossanlage dienen konnte ${ }^{2}$.

Schon früh hatte Nicolas Fouquet mit Baumaßnahmen in Vaux-le-Vicomte begonnen, die sich bis 1655 jedoch auf den Garten beschränkten. Erst nach der Übernahme seines Amtes als Finanzminister begannen Planungen für eine über den Nutzgarten hinausgehende Anlage. Um 1655 legte man den kleinen Kanal, die Fontänen und die große Allee an. In den folgenden zwei Jahren war der aus der Umgebung von Vaux stammende Architekt Daniel Gittard (1625-1686) mit der Errichtung der Wasserfälle und der Wasserbecken beauftragt $^{3}$. Ballon schreibt Gittard zudem einen ersten Entwurf für den geplanten Schlossbau $\mathrm{zu}^{4}$. Pläne aus der Hand Gittards sind jedoch nicht überliefert. Seine Entwürfe für die Gartenanlage wie für den Schlossbau sollten über erste Realisierungsansätze nie hinauskommen, denn zwischen 1655 und 1656 beschloss Nicolas Fouquet, die Planungen für seine neue Schlossanlage in die Hände weit bekannterer und angesehenerer Künstler zu legen, die bereits im Dienst des Königs standen und wahrscheinlich schon alle in Saint-

1 Während des Prozesses behauptete Fouquet, er habe bereits seit 1640 in Vaux Arbeiten an der neuen Schlossanlage unternehmen lassen (FouQueT, Euvres, Bd.IX, S.124 und Bd.XVI, S. 90, 92), der Kaufvertrag belegt jedoch, dass Vaux erst im Jahre 1641 in seinen Besitz überging (AN MC ET/XXX/24).

2 Petitfils, Fouquet, S. 535-546, Annexe II: Estimation des dépenses engagées par Nicolas Fouquet pour l'acquisition et l'aménagement du domaine de Vaux-le-Vicomte.

3 AN, Fonds d'Ormesson, 156 MI 18, fol. 79.

${ }^{4}$ Ballon, Vaux-le-Vicomte, S.275. Die Bildunterschrift eines nach 1673 entstandenen Stiches von Adam Pérelle veranlasste auch andere Autoren, den Beginn der Planungen einer neuen Schlossanlage auf die Zeit vor 1656 zu legen: Dézallier D’Argenville, Voyage pittoresque, S.237; Goudemetz, Voyage, S.183. 
Mandé für ihn tätig gewesen waren: Louis Le Vau, Charles Le Brun und André Le Nôtre 5 .

Louis Le Vau (1612-1670), seit 1638 architecte du Roi und 1654 zum premier architecte du Roi ernannt, hatte sich durch die Errichtung zahlreicher bedeutender Bauwerke einen Namen gemacht, bevor er in die Dienste Nicolas Fouquets trat ${ }^{6}$. Seine Ausbildung hatte Le Vau an der Seite seines Vaters erhalten, der als Bauunternehmer und Maurermeister maßgeblich an der Bebauung der Île Saint-Louis beteiligt gewesen war. Im Jahre 1637 begann Louis Le Vau seine Arbeit als selbständiger Architekt ${ }^{7}$. Obwohl er die italienische Architektur niemals vor Ort studiert hatte, verfügte Le Vau über eine breite Kenntnis der römischen Baukunst, die sich in seinen Arbeiten wiederfindet. $\mathrm{Zu}$ verdanken hatte er sein Wissen wohl vor allem dem Studium der vielen Architekturtraktate und Entwurfszeichnungen, die er in seiner Bibliothek aufbewahrte ${ }^{8}$. Bis 1660 fanden sich die Bauherren Le Vaus vor allem im Kreis der Minister und Financiers: Für Mazarin und Servien plante der Architekt den Umbau ihrer Schlösser in Vincennes und Meudon, für Jean-Baptiste Lambert und Louis Hesselin ihre Pariser hôtels sowie die Neugestaltung ihrer Schlösser in der Provinz. Seine erste ex novo geplante Schlossanlage entwarf Le Vau um 1642 für den Finanzintendanten Jacques Bordier: »Le château de Raincy était une des demeures les plus somptueuses des environs de Paris, une des plus remarquables constructions de l'art classique français à ses débuts; il annonçait Vaux-le-Vicomte ${ }^{9}$. Für die Familie Fouquet arbeitete Le Vau seit den frühen fünfziger Jahren. Basile Fouquet nahm seine Dienste vor 1654 für den Umbau seines hôtel in der Rue du Temple in Anspruch. Für Nicolas Fouquet war Le Vau seit 1654 in Saint-Mandé tätig. La Fontaine zufolge entschied sich Fouquet auf Drängen des Financiers und Diplomaten Pierre Chanut für ein Engagement Louis Le Vaus. In einem Brief des Poeten an seinen Freund Maucroix vom 26. Oktober 1693 heißt es: »J'ai vu M. Le Brun et un nommé Getart, architecte, estimer si peu ce Le Vau-là qu'ils le censuraient en tout. M. Chanut avait conseillé Monsieur Fouquet de l'employer, parce qu'il servait gratuitement Monsieur Chanut « ${ }^{10}$.

Charles Le Brun (1619-1690) ist der einzige der drei von Fouquet für den Bau von Vaux-le-Vicomte engagierten Künstler, dessen Können durch eine

\footnotetext{
${ }^{5}$ Gittard stand in der Folge weiterhin in Fouquets Diensten und realisierte in seinem Auftrag die Baumaßnahmen auf der 1658 erworbenen Insel Belle-Île.

${ }^{6}$ La Fontaine, Euvres complètes II, S. 729.

${ }^{7}$ Insgesamt wird ihm die Planung für 120 einfache Häuser, 47 hôtels und 12 Schlösser zugesprochen (FelKaY, »Le Vau«, in: DGS, S. 869).

${ }^{8}$ Das 1670 erstellte Inventar der Bibliothek findet sich im Anhang (Appendix D) von BALlon, Louis Le Vau, S. 149-176. Von den 176 aufgeführten Titeln sind allein 55 aus dem Gebiet der Architektur.

9 Pillement, Environs de Paris, S.139. Le Raincy wurde zwischen 1815 und 1819 zerstört.

${ }^{10}$ Brief La Fontaines an Maucroix vom 26. Oktober 1693, in: La Fontaine, Euvres complètes II, S. 729.
} 
Italienreise geschult worden war. Er stand seit 1638 in den Diensten Ludwigs XIII. und wurde fünf Jahre später zum peintre et valet de la Chambre $d u$ Roi ernannt. Neben der Arbeit für den König erhielt er zahlreiche Aufträge aus den Kreisen der Staatsbeamten und schmückte mit seinen Malereien die Decken vieler Pariser hôtels - niemals jedoch einen ganzen Bau. Zu seinen bekanntesten Förderern gehörte der Kanzler Séguier, der ihm zwischen 1642 und 1645 den Italienaufenthalt ermöglicht hatte. Seit dem Tod seines Lehrers Simon Vouet ${ }^{11}$ und von Eustache Le Sueur ${ }^{12}$ galt er als der bedeutendste Innenraumdekorateur Frankreichs. Von Bordier hatte er zwischen 1645 und 1648 den Auftrag für die Ausführung einzelner Deckengemälde in Le Raincy erhalten. Zehn Jahre später, kurz vor dem Beginn seiner Arbeit in Vaux-le-Vicomte, führte er im Hôtel Lambert die Deckengemälde der galerie d'Hercule aus.

Seit 1655 gehörte auch Fouquet zu Le Bruns Auftraggebern. Ab 1658 fand der Maler in Vaux als maître d'œuvre ein Tätigkeitsfeld, das alle seine bisherigen Arbeiten an Umfang übertraf. Der sowohl mit der gesamten Innendekoration als auch mit der skulpturalen Ausgestaltung des Gartens beauftragte Le Brun begann seine Arbeiten an dem Schloss erst nach der Fertigstellung des Rohbaus und der Verlegung von Fußböden und Täfelungen ${ }^{13}$. Neben den Dekorationsarbeiten war er zuständig für die Überwachung der Produktion der Tapisseriemanufaktur in Maincy sowie für die Organisation der Empfänge und Feste ${ }^{14}$. Zu den wichtigsten Arbeiten Le Bruns in Vaux gehört jedoch der Entwurf und die Ausführung der Deckenmalereien.

Der für die Gartenanlage von Vaux zuständige André Le Nôtre (1613-1700) entstammte einer erfolgreichen Familie von Gartenplanern - bereits sein Großvater Pierre Le Nôtre arbeitete für die königliche Familie in den Tuilerien - und perfektionierte seine Ausbildung als Gärtner durch einen Aufenthalt im Atelier des Malers Simon Vouet, wo er die Bekanntschaft Le Bruns machte. Daneben studierte er, wahrscheinlich unter der Aufsicht François Mansarts, die Grundlagen der Architektur, bevor er im Jahre 1637 jardinier en chef des Tuileries wurde. Im Dezember 1643 erhielt er das Amt des dessinateur des plans et parterres de tous les jardins de S.M. und wurde 1658 zum contrôleur général des bâtiments et jardins du Roi ernannt. Le Nôtre steht für das Aufkommen eines neuen Gartentyps in Frankreich, der den jardin italien

11 LÉPIcIÉ, Vies, S. 6: »Il [Pierre Séguier] le mit âgé d'onze ans sous la discipline de Vouet, le plus fameux des Peintres du temps«. Vouet starb im Jahre 1648.

12 Le Sueur starb im Jahre 1655.

13 Ein zwischen Fouquet und Le Brun abgeschlossener Vertrag ist nicht erhalten. Zahlreiche erhaltene Rechnungen (unter anderem: CoRdey, Vaux-le-Vicomte, Dokument V, S. 206-208; Dokument X, S.228) belegen jedoch, dass Le Brun für die gesamte Innendekoration in Vaux-le-Vicomte verantwortlich gewesen ist.

${ }^{14}$ Nach Pérouse de Montclos wurde der Umfang der dekorativen Arbeit Le Bruns in Vaux lange überschätzt. Man schrieb ihm mehr Zeichnungen zu, als er tatsächlich angefertigt hat. Da eine Liste aller an Vaux' Innendekoration beteiligten Künstler nicht überliefert ist, ist eine genaue Zuordnung der einzelnen Gemälde nur schwer möglich (PÉRousE DE Montclos, Vaux-le-Vicomte, S.131-134). 
als vorherrschenden Typ ablöste und als jardin à la française bezeichnet wird ${ }^{15}$. Da nur sehr wenige Gesamtgartenpläne aus der ersten Hälfte des 17. Jahrhunderts überliefert sind ${ }^{16}$, ist unklar, inwieweit Le Nôtre in der Gestaltung der von ihm geplanten Gärten innovativ war oder inwieweit er dem Trend seiner Zeit folgte ${ }^{17}$. Seine Gartenbaukunst wird beschrieben als ein Nebeneinander von symmetrischen Achsen und Gartenabschnitten sowie einer phantasievollen Detailgestaltung, die in Wasser-, Licht- und Grünanlagen, in ihrer Farbgestaltung von den Jahreszeiten abhängig, zum Ausdruck kommt ${ }^{18}$.

Trotz seiner zahlreichen Titel und Ämter sind keine Gesamtentwürfe Le Nôtres bekannt, die vor dem Park von Vaux entstanden sind ${ }^{19}$. Der Plan der Anlage von Vaux gilt zugleich als der erste in Gänze erhaltene Plan eines französischen Landschaftsgartens.

Der genaue Zeitpunkt des Beginns der Arbeit des Künstlertrios in Vaux-leVicomte lässt sich nicht eindeutig festlegen, da weder Verträge, die zwischen Fouquet und den drei leitenden Künstlern abgeschlossen worden sind, noch jene, die der Bauherr mit den jeweiligen Bauunternehmern unterzeichnet hat, überliefert sind. Ein im Laufe des Prozesses in Vaux sichergestellter Koffer barg 321 Briefe Fouquets, seiner commis oder agents »sur le fait des bâtiments et décorations de Vaux «20; die Originale sind mit hoher Wahrscheinlichkeit zerstört worden, und der procès-verbal des commissaires analysiert lediglich neun der im Koffer enthaltenen Schriftstücke. Im Archiv von Vaux werden jedoch verschiedene Zahlungsbelege aufbewahrt, die das Engagement zahlreicher Künstler und Handwerker in Vaux ab dem Jahr 1656 belegen ${ }^{21}$.

15 Der französische Garten unterscheidet sich vom italienischen Garten in der Hauptsache durch seine enorme Größe und die symmetrische wie geometrische Anlage, die von einer Mittelachse bestimmt wird.

${ }^{16}$ Ein Grund für das Fehlen von Gesamtplänen ist sicherlich die Tatsache, dass der Garten lange Zeit ein Nebenprodukt der Arbeit durch die Architekten war. Soviel man weiß, ist Vaux das erste Schlossbauprojekt, bei dem für die Anlage des Parks eigens ein Gartenarchitekt eingestellt wurde.

17 Gegen die Annahme, dass die Invention des französischen Landschaftsgartens Le Nôtre zugesprochen werden kann, spricht die Vielzahl gartentheoretischer Schriften der ersten Hälfte des 17. Jahrhunderts von Jacques Boyceau und André und Claude I Mollet, alle Kollegen des Vaters von André Le Nôtre, die diesen also direkt beeinflusst haben könnten. In ihren Werken empfehlen die Autoren »(de) varier les différentes parties du jardin et les proportionner les unes aux autres tout en les séparant par de grandes allées«. Für die Detailausgestaltung schlagen sie die Aufnahme italienischer Gestaltungselemente (wie Grotten, Wasseranlagen und -spiele samt hydraulischer Anlagen sowie Statuen) vor. 18 Vgl. Hoog, »Le Nôtre«, in: DGS, S. 856.

19 Le Nôtre hat keine Mémoiren und kein Traité hinterlassen. Bekannt sind jedoch seine Arbeiten für das französische Königshaus, vor allem der Entwurf des jardin de la Reine in Fontainebleau zwischen 1645 und 1646.

${ }^{20}$ Grésy, Documents, S.2.

${ }^{21}$ Ein Großteil dieser Verträge wurde 1924 von Jean Cordey im Anhang seiner Monographie zu Vaux-le-Vicomte veröffentlicht: Quittance délivrée par Michel Villedo et Antoine Bergeron à Fouquet pour la somme de 3200 Livres qui leur restait due en raison des travaux de maçonnerie et de charpenterie qu'ils ont exécutés à Vaux-le-Vicomte, Paris, 
Louis Le Vau begann vermutlich noch im Jahr 1655 mit den Entwürfen für das Schloss. Es ist anzunehmen, dass sich seine Planungen mit ersten, noch nach Plänen Gittards durchgeführten Baumaßnahmen überschnitten. Der Aussage des Bauunternehmers Michel Villedo aus dem Jahr 1666 zufolge wurden die Arbeiten am aufgehenden Mauerwerk ab August 1656 auf den bereits gelegten Fundamenten unternommen ${ }^{22}$. Diese dürften, wie sich bei der Beschreibung der Planungsgenese durch Le Vau zeigen wird, noch von Gittard angelegt worden sein 23 . Unklar bleibt, ob Louis Fouquet die Pläne Gittards oder bereits jene Le Vaus im Sinn hatte, als er seinem Bruder am 16. August 1655 eine Überarbeitung der Entwürfe in Rom vorschlug: »Si vous vouliez envoyer les plans de vos maisons et de vos jardins pour les faire un peu contreroller ici par les habilles, peut-estre ne seroit-ce pas chose inutile « ${ }^{24}$. Der Finanzminister nahm das Angebot seines Bruders anscheinend nicht an, da in den folgenden Briefen des Abbé aus Rom keine Rede mehr davon ist ${ }^{25}$. Das Ende der Entwurfsphase für Vaux-le-Vicomte durch Louis Le Vau ist durch mehrere Bildquellen dokumentiert. Zwei Grundrisse (Erdgeschoss und

25 février 1661; Déclarations de Villedo et de Bergeron relatives à leurs travaux exécutés à Vaux-le-Vicomte; Mémoires des travaux de menuiserie exécutés à Vaux-le-Vicomte par Jacques Prou; Mémoire des travaux de serrurerie exécutés à Vaux-le-Vicome par Louis Hanicle; Mémoire des travaux de ferronerie exécutés à Vaux-le-Vicomte par Claude Venard; Mémoire et quittance relatifs aux travaux de sculpture exécutés à Vaux-le-Vicomte par Michel Anguier; Mémoires et devis concernant les travaux de sculpture exécutés à Vaux-le-Vicomte par Mathieu Lespagnandel; Devis et Mémoires des travaux de dorure exécutés à Vaux-le-Vicomte par Paul Goujon de la Baronnière; Copies des quittances délivrées par divers artistes à Le Brun pour le paiement de travaux exécutés à Vaux-le-Vicomte; Engagement du couvreur Alexandre Girard d'entretenir toutes les toitures de Vaux-le-Vicomte pendant six ans, Paris, 23 mars 1661.

22 Déclarations de Villedo et de Bergeron relatives à leurs travaux exécutés à Vaux-le-Vicomte (AN O1 1964), abgedruckt in: Cordey, Vaux-le-Vicomte, S.199-201. Auf Seite 199 heißt es: »Le dit sieur Villedot [...] a dit qu'en l'année 1656, il entreprit les bastimens de la motte du chasteau au-dessus des fondations «.

${ }^{23}$ Die während des gesamten Baus gezeigte Eile lässt vermuten, dass die Fundamente von diesem gegen 1655/1656 gelegt wurden, da eine große zeitliche Lücke dem Charakter des gesamten Bauvorhabens nicht entsprechen würde.

${ }^{24}$ Louis Fouquet in einem Brief an seinen Bruder vom 16. August 1655, in: Fouquet, Lettres, S. 291.

25 Möglich wäre zum einen, dass Louis Fouquet Gittards Entwürfe ansprach, die Nicolas Fouquet jedoch längst nicht mehr realisiert sehen wollte, und dass der Finanzminister aus diesem Grund nicht auf das Angebot seines Bruders einging. Zum anderen wäre denkbar, dass Le Vau zu diesem Zeitpunkt bereits mit den Planungen betraut war - diese jedoch noch nicht an die Öffentlichkeit gelangen sollten. In dem Brief Louis' wird von den Häusern Fouquets in der Mehrzahl gesprochen. Es bleibt unklar, von welchen Bauprojekten Fouquets der Abbé spricht: Meint Louis die Planungen für Vaux-le-Vicomte? Oder sind weitere Umbauten in Saint-Mandé geplant? Vielleicht handelt es sich auch um Entwürfe für ein Pariser hôtel? Louis' Briefen entnehmen wir, dass Fouquet, der sich aus Rom »toutes les estampes d'architecture, fontaines et palais « (Brief Louis Fouquets an seinen Bruder vom 2. August 1655, in: ibid., S.290) und ein mémoire zu dem Thema senden ließ, den Italienaufenthalt seines Bruders auch dafür nutzte, sich über die römische Architektur zu unterrichten. 
Kellergeschoss) und zwei aquarellierte Aufrisse von Vaux, die heute im Schloss selbst aufbewahrt werden, geben auf der Rückseite bekannt, dass Auftraggeber und Architekt am 2. August 1656 durch ihre Unterschrift ihr Übereinkommen über die Gestaltung des Baus besiegeln ${ }^{26}$.

Die Arbeiten in Vaux wurden eiligst vorangetrieben. 1657 verzeichnen die von Grésy in Maincy eingesehenen Dokumente erstmalig ortsfremde Arbeiter $^{27}$. Der Rohbau des Schlosses war im September des Jahres fertiggestellt, und es wurde mit dem Einbau von Marmor- und Parkettböden begonnen. Die Nebengebäude sind wohl um das Frühjahr 1658 vollendet worden, die Kuppelkrönung erfolgte im August desselben Jahres, die Entfernung des Bauschutts schließlich im März $1660^{28}$.

Die Arbeiten in den Räumen des Schlosses wurden um das Jahr 1658 begonnen. Le Brun zog im September 1658 mit seiner Familie in das bei Vauxle-Vicomte gelegene Maincy und richtete sich ein Atelier im Westflügel des Obergeschosses ein ${ }^{29}$, um vor Ort die Arbeiten ausführen und überwachen zu können ${ }^{30}$.

${ }^{26}$ Der beigefügte schriftliche Zusatz »ne varietur « macht deutlich, dass das Schloss in der dargestellten Form erbaut werden sollte. Dieser Zusatz kann zudem als Beleg dafür dienen, dass es bereits frühere Pläne Le Vaus für den Schlossbau gegeben hat. Ein möglicher erster Entwurf ist auf Stichen Jean Marots überliefert, die allerdings erst 1670 veröffentlicht wurden und vielleicht erst kurz zuvor angefertigt worden waren. Diese Vermutung findet Bestätigung durch den von Villedo seiner »Déclaration « beigefügten Satz: »Et en faisant laquelle construction [Villedo und Bergeron sprechen von den im Jahr 1656 durchgeführten Arbeiten an den bastimens de la motte du chasteau au-dessus des fondations] s'estant trouvé de grandes augmentations et changemens au dit dessin «(CORDEY, Vaux-le-Vicomte, S.199).

27 GrésY, Documents, S. 4.

28 CoRdey, Vaux-le-Vicomte, S. 41; Grésy, Documents, S. 3.

${ }^{29}$ Le Brun dürfte mehrere Räume im Schloss zur Verfügung gehabt haben, was aus der Beschreibung der Inventaristen (Inventaire de Vaux, in: Bonnaffé, Foucquet, S. 90f.) hervorgeht. Es handelt sich hierbei um das Appartement, das sich über der Chambre carrée im Nordwesten des ersten Obergeschosses befand. In Le Bruns Räumen befanden sich 1661 Gemälde, Statuen und Büsten, was auf die Nutzung dieser Räume als Atelier schlieBen lässt. Neben Le Brun bezogen auch Le Vau und Le Nôtre Räume im Schloss. Nach der Beschreibung der Inventaristen müssten sich die Zimmer des Gartenarchitekten ebenfalls im ersten Obergeschoss befunden haben, und zwar am äußersten Ende des Westflügels (ibid., S. 88). Dagegen lässt sich Le Vaus Atelier aus der Beschreibung der Inventaristen (ibid., S.94) nicht genau lokalisieren.

${ }^{30}$ Neben Le Brun nennt Grésy in seinem Aufsatz zu den Künstlern in Vaux-le-Vicomte den Pariser M. Beaudrain und Philippe Lallement als an den Dekorationsarbeiten im Schloss partizipierende Maler. Über die Biographie Beaudrains gibt Grésy keine Auskünfte. Philippe Lallement stammte aus Reims und wurde am 11. Juni 1672 in die Académie aufgenommen. Als Landschaftsmaler war er an der Ausgestaltung zahlreicher hôtels particuliers, wie des Hôtel Lambert oder des Palais Mazarin, beteiligt. Er starb am 22. März 1716 im Alter von achtzig Jahren (GRÉsy, Documents, S.10). Grésy nennt außerdem die Namen folgender Skulpteure, die nach Entwürfen Le Bruns in Vaux gearbeitet haben: Michel Magnan, Nicolas Legendre, maître sculpteur, und den Bretonen Nicolas Lemort, der als sculpteur de vocation für die skulpturale Gestaltung der Schlossfassade und des Stuckdekors angestellt wurde (ibid., S.11). Die Papiere d'Ormessons nennen zudem die Skulpteure Blanchard, Lespagnandel und Poissard (AN, Fonds d'Ormesson,156 MI 18, fol. 84). 
$\mathrm{Zu}$ welchem Zeitpunkt Le Nôtre mit der Planung der Gartenanlage begann, ist nicht überliefert. Dem 1730 publizierten und seinem Neffen Claude Desgots zugeschriebenen »Abrégé de la vie d'André Le Nôtre« zufolge war der Gartenarchitekt »près de quarante ans lorsque M. Foucquet lui donna occasion de se faire connaître par les magnifiques jardins de Vaux-le-Vicomte « ${ }^{31}$. Der am 12. März 1613 geborene André Le Nôtre müsste demnach ab spätestens 1653 in Vaux tätig gewesen sein. Da ein erst kürzlich entdeckter Plan der Gartenanlage von Saint-Mandé jedoch mit größter Wahrscheinlichkeit auf eine Planung durch Le Nôtre hinweist, ist es naheliegender, dass der Gartenarchitekt zwar um 1653, vielleicht Anfang 1654, in die Dienste Fouquets trat, zunächst aber den Garten von Saint-Mandé gestaltete und erst um 1656 mit der Planung des Gartens von Vaux-le-Vicomte begann. Zuvor waren auf dem Gelände bereits alle Spuren früherer Gebäude beseitigt, das Gelände von Hügeln, Tälern und Flussläufen »gereinigt« worden. Vor dem Schloss waren Teile des Parterres angelegt, die von Le Nôtre nach 1656 jedoch in ihrer Gestaltung eine erhebliche Veränderung erfuhren ${ }^{32}$.

\subsection{Die Bauaufgabe}

Mit dem Bau von Vaux-le-Vicomte reagierte der Finanzminister auf ein verändertes politisches Klima, in dem seine Stellung und sein weiterer Aufstieg stets gefährdet waren. Bereits zwei Jahre nachdem er von Mazarin mit dem Amt des Finanzministers für seine treue Haltung gegenüber der Krone während der Fronde belohnt worden war, schien er in der Gunst des Premierministers gesunken zu sein. Im September 1655 berichtete Nicolas in einem Brief an seinen Bruder Basile erstmalig von Unstimmigkeiten zwischen ihm und Mazarin: »Il me semble par une lettre de Son Éminence qu'elle ne soit pas satisfaite de mes soins pour l'argent et que j'ai promis quelque chose à quoi j'ai manqué «33. Tatsächlich hatte sich der Premierminister unzufrieden über die Führung der Staatsfinanzen und besonders seiner persönlichen Geldwünsche gezeigt. Sein Missmut wurde genährt von den Intrigen Colberts, der in Fouquet seinen größten politischen Widersacher sah. Fouquet erkannte die Gefahr, die sich hinter Mazarins missmutigen Äußerungen verbarg.

Mit einem innovativen Schlossbau versuchte der Finanzminister nun, sich einem neuen politischen Förderer zuzuwenden. Hatte Nicolas Fouquet mit Saint-Mandé nur wenige Jahre zuvor ein Anwesen in direkter Nachbarschaft zu Mazarin erworben, das ihm die stete Nähe zu dem Premierminister sicher-

31 Zitiert nach: Pérouse de Montclos, Vaux-le-Vicomte, S.101, Anmerkung 4. Der Text von Desgots wurde 1730 von P. N. Desmolets im neunten Band seiner »Continuation des mémoires, de littérature et d'histoire « veröffentlicht.

32 AN, Fonds d'Ormesson, MF 156 MI 18, fol. 79f.

${ }^{33}$ Lettre de Foucquet, Archives des Affaires étrangères, France, Bd.LXXXIX, zitiert nach: CoviLle, Mazarin et Fouquet, S. 77. 
te und sich in seiner baulichen Erscheinung dem nahegelegenen Vincennes unterwarf, so reagierte er ab 1656 architektonisch auf eine neue Art und Weise auf eine veränderte politische Situation: im Südosten von Paris, auf halbem Weg nach Fontainebleau, ließ er einen prachtvollen Schlossneubau nebst moderner Gartenanlage entstehen, der nicht mehr die Nähe zu dem Premierminister, sondern zu dem häufig in Fontainebleau weilenden Ludwig XIV. suchte. Dies drückte sich nicht nur in der geographischen Nähe zur königlichen Residenz aus. Auch die Ikonographie und die Konzeption der neuen Anlage formulierten die Verbindung zwischen dem Schlossherrn und seinem König. Damit nicht genug: Nicolas Fouquet sorgte dafür, dass die Öffentlichkeit noch vor ihrer Fertigstellung ihr Augenmerk auf Vaux-le-Vicomte richtete. In Stichen machte er die Schönheiten der Anlage publik ${ }^{34}$. Zugleich ließ er mit Hilfe des Kunsttheoretikers Félibien, des Dichters La Fontaine und der Romancière Scudéry die von ihm intendierte Interpretation vor allem der Deckenmalereien der Innenräume von Vaux-le-Vicomte verkünden ${ }^{35}$. Mit dieser engen thematischen und zeitlichen Verbindung von Architektur, bildender Kunst und verschiedensten literarischen Gattungen wusste Fouquet seine mit Vaux intendierte Botschaft an den König und den Hofstaat zu verbreiten und schuf zugleich mit Hilfe der Künste eine neue Art der Propaganda.

Auf den ersten Blick jedoch ist Vaux-le-Vicomte durchaus kein ungewöhnlicher Bau. Die Architektur des neuen Schlosses lehnte sich an die baulichen Traditionen seiner Zeit an. Die architektonischen Vorläufer finden sich vor allem unter den ministeriellen Neubauten des 17. Jahrhunderts. Die beeindruckendsten Bauprojekte vor Vaux-le-Vicomte wurden im Namen der beiden Premierminister durchgeführt. Richelieu ließ nicht nur das heutige Palais Royal errichten und seine Schlösser in Rueil, Limours, Bois-le-Vicomte und Champigny erneuern, in Richelieu plante er gleich eine ganze Stadt, die mit der neu gestalteten Schlossanlage in einem architektonischen Wechselspiel

${ }^{34}$ Der graveur Israël Silvestre (1621-1691) fertigte wahrscheinlich vor 1659 zwölf Stiche von Vaux-le-Vicomte an, auf denen das Schloss selbst sowie die wichtigsten Details des Gartens dargestellt waren (siehe auch: S.126, Anm.108).

${ }_{35}$ Wann die drei Autoren den Auftrag erhielten, bleibt ungewiss. Es wird jedoch angenommen, dass dies um das Jahr 1659 geschah (siehe S. 162ff.). André Félibien, der kunsttheoretische Avantgardist seiner Zeit, machte Vaux-le-Vicomte zunächst zum Mittelpunkt seines Malereitraktates »De l'origine de la peinture et des plus excellens peintres de l'Antiquité«, welches 1660 in Paris erschien. Diesem folgten zwei in Briefform verfasste Schriften, die in ausführlicher Weise auf die Räumlichkeiten des Schlosses eingehen. Im Jahr 1661 beschrieb er schließlich auch noch das große Einweihungsfest zu Ehren des Königs, welches Gegenstand des vierten Kapitels sein wird. Jean de La Fontaine hatte von Fouquet den Auftrag zu einer Ekphrasis zu Vaux-le-Vicomte erhalten. Der »Songe de Vaux « blieb wegen der Verhaftung Fouquets unvollendet. Bis 1661 waren neun Fragmente fertiggestellt, in denen das Anwesen poetisch verklärt wird. Das Werk enthält daher nur wenige Angaben zum tatsächlichen Aussehen des Anwesens. Madeleine de Scudéry liefert im 1660 erschienenen zehnten Band ihres Romanzyklus »Clélie« eine Beschreibung des Vorhofes, der Räume und des Gartens von Valterre (alias Vaux-le-Vicomte), dem Schloss Cléonimes (Fouquet). 


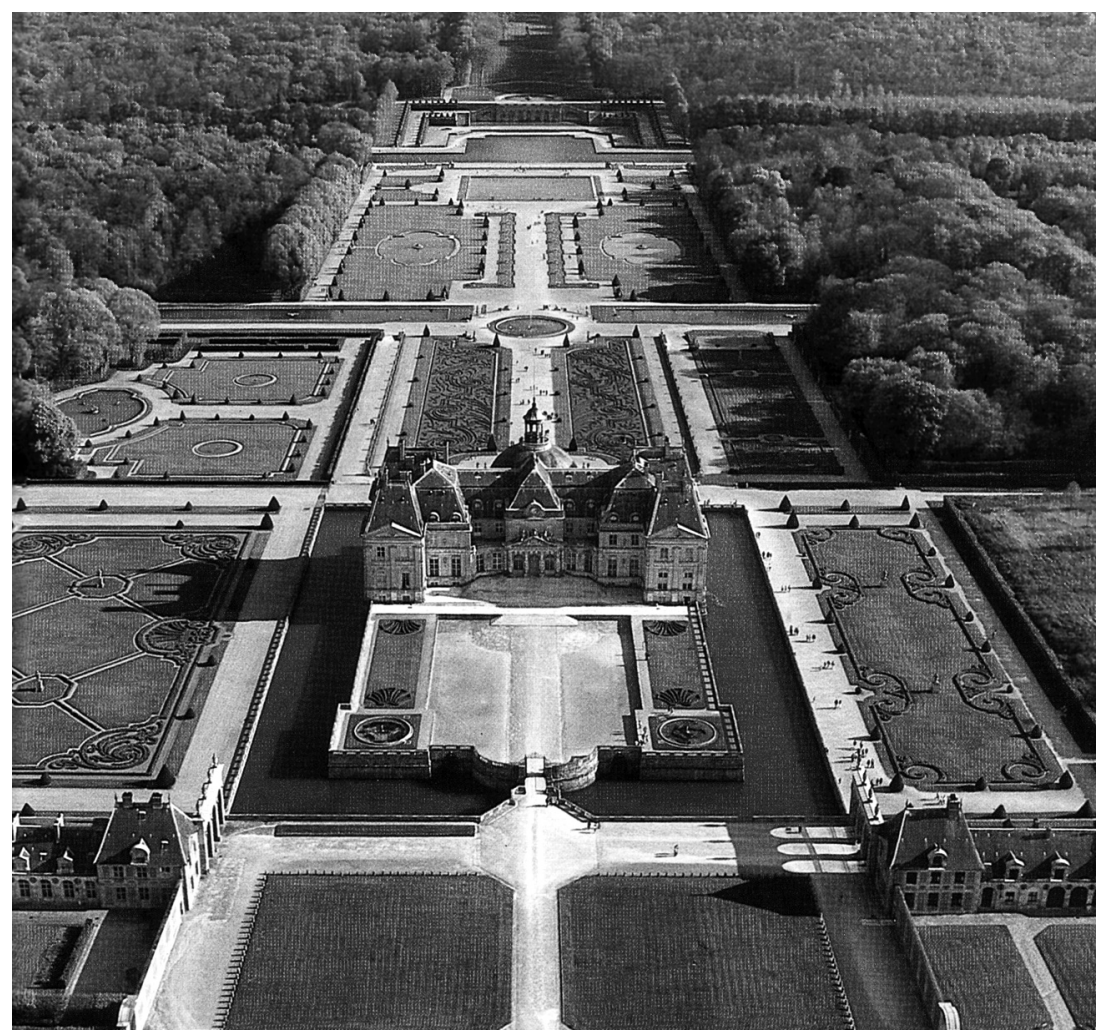

Abb. 2: Vaux-le-Vicomte, Luftaufnahme.

stand. Mazarin reagierte mit seinen architektonischen Projekten etwas verhaltener. Wenngleich er keinen eigenen Schlossbau errichten ließ, wusste er das königliche Schloss von Vincennes, in dem er residierte, herrschaftlich umzugestalten und verewigte sich postum mit dem Collège des Quatre-Nations, das in seiner barocken Gestalt des im klassizistischen Paris verstorbenen Italieners gedachte und seinen diplomatischen Fähigkeiten in der Funktion des Gebäudes - unter anderem war ein Kolleg für die Erziehung junger Männer

Abb.3: Plan der Anlage von Vaux-le-Vicomte: 1. Eingangsgitter mit Hermen - 2. Wirtschaftsgebäude - 3. Schloss - 4. Broderieparterre - 5. Parterre de la Couronnne - 6. Blumenparterre - 7. Rundbassin-8. Grille d'eau - 9. Eingangsgitter zum Gemüsegarten-10. Kleine Kanäle - 11. Rasenparterre (dazwischen befand sich die allée d'eau) - 12. Grand carré d'eau oder miroir d'eau - 13. Confessionnal - 14. Große Terrassen mit Alleen - 15. Große Kaskade - 16. Grand Canal-17. Rundbassin des Kanals - 18. Grotte - 19. Grande Gerbe 20. Herkulesstatue. 


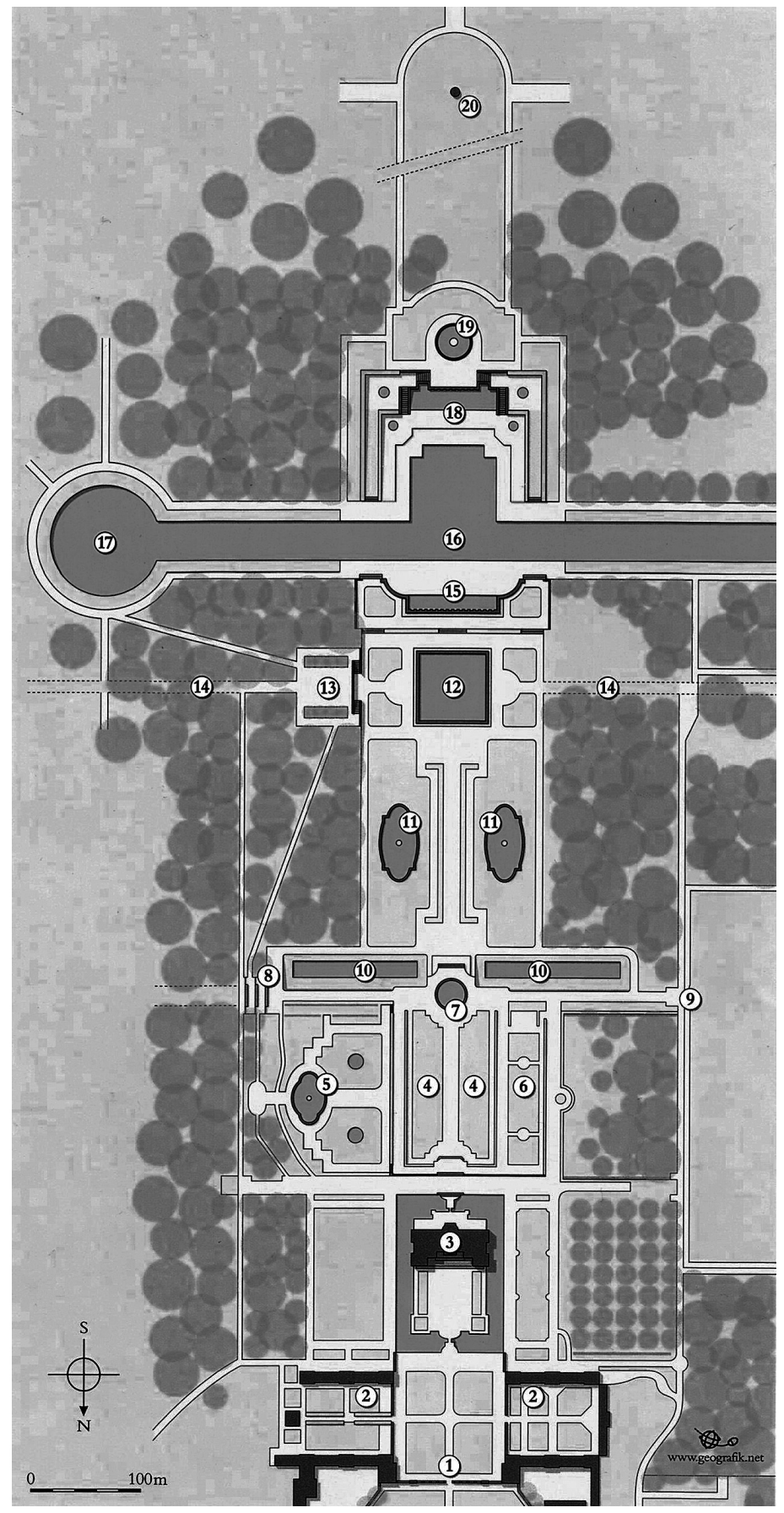




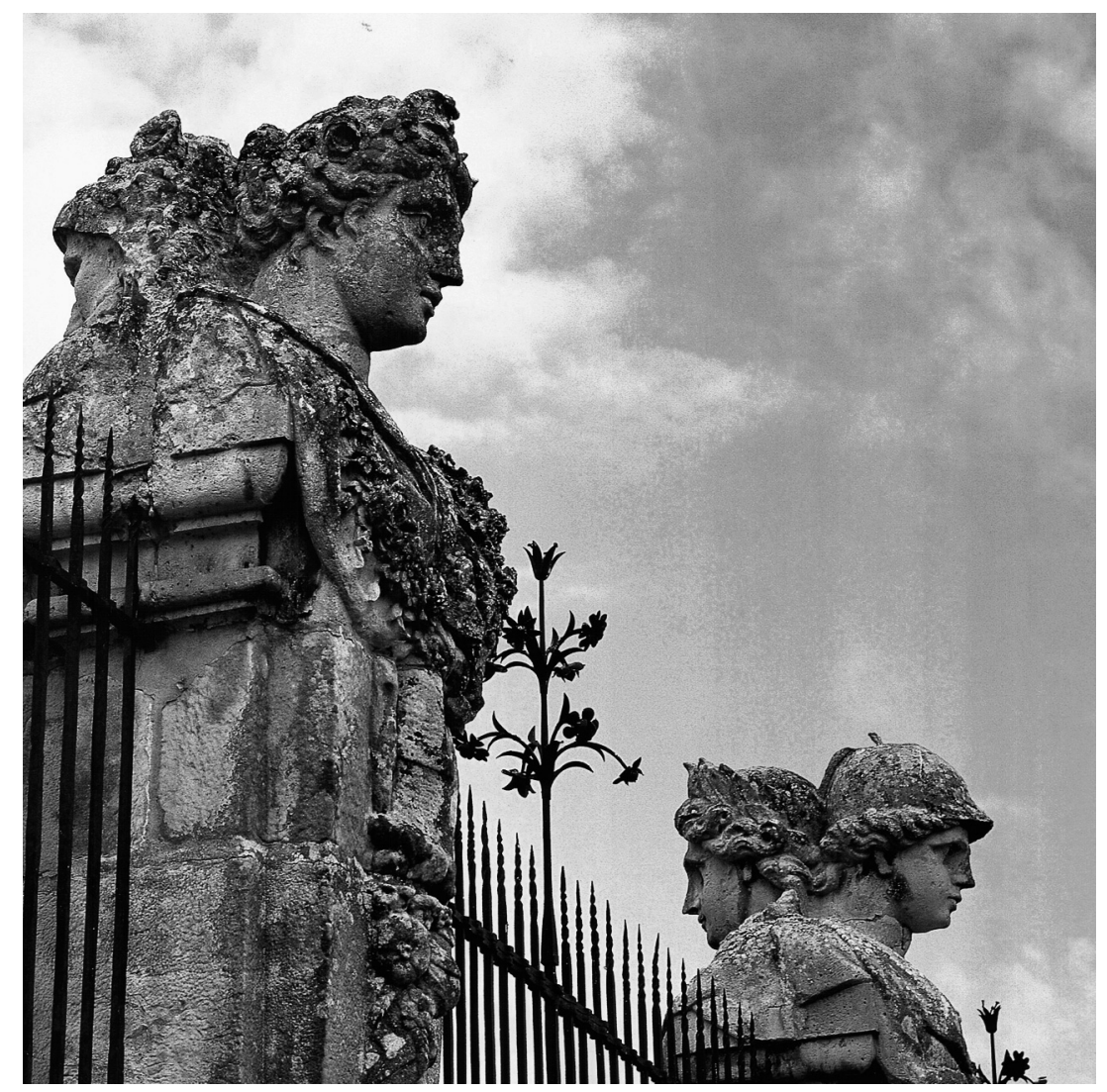

Abb. 4: Hermengitter.

aus den unter Mazarin annektierten Gebieten Frankreichs darin untergebracht - ein politisches Denkmal setzte ${ }^{36}$.

Auch die Finanzelite war Fouquet mit gutem Beispiel vorangegangen und hatte sich im Pariser Umland aufwendige Schlossanlagen errichten lassen. Um 1630 hatte der surintendant des Finances Antoine Coiffier de Ruzé, Marquis d'Effiat, in Chilly das alte Schloss abreißen und unter Le Mercier eine neue Anlage entstehen lassen, die von Vouet und Perrier mit Wandmalereien ausgeschmückt wurde. Kurz nach seiner Ernennung zum président à mortier au parlement de Paris ließ René de Longueil (surintendant des Finances von 1650-1651) nach Entwürfen von François Mansart die neue Schlossanlage Maisons errichten. Louis Le Vau entwarf etwa zur gleichen Zeit für den Finanzintendanten Jacques Bordier das Schloss Le Raincy, das in seiner

36 Ballon, Louis Le Vau, S. 14f. 
Architektur als direkter Vorläufer Vaux-le-Vicomtes gelten kann ${ }^{37}$. Abel Servien, Amtskollege Fouquets, engagierte den Architekten anschließend für den Umbau seines Schlosses Meudon. In den drei letztgenannten Fällen entstammten die Bauherren der robe, und ihre Schlossbauten waren baulicher Ausdruck ihres gesellschaftlichen Aufstiegs.

Von seinen ministeriellen Vorgängerbauten hebt sich das neue Schloss Nicolas Fouquets vor allem in einer Hinsicht ab: Wie sich in dem perfekt aufeinander abgestimmten Zusammenspiel von Architektur, künstlerischer Ausgestaltung und Gartenplanung zeigt, arbeitete das Künstlertrio von Vaux-leVicomte eng zusammen, so dass hier ein in allen seinen Teilen aufeinander bezogenes Gesamtkunstwerk entstand ${ }^{38}$.

Die Anlage von Vaux-le-Vicomte besteht aus drei Bereichen, die untereinander in einer engen Verbindung stehen. Es handelt sich um Räume, denen Bauherr und Architekt in der Gesamtanlage eine bestimmte Funktion zugewiesen haben. Der erste Raum umfasst die Vorhöfe und die Fassade des Schlosses, der zweite Raum die Innenarchitektur und Ausstattung und der dritte Raum die sich hinter dem Schloss erstreckende Gartenanlage.

\subsection{Der erste Raum: Vorhof und Fassade}

Die Schlossanlage bleibt dem von Melun über die Allee kommenden Besucher bis zur Ankunft verborgen. Zunächst erblickt er ein Hermengitter, das die Anlage von der Straße trennt. Die doppelseitigen Hermen erlauben einen ersten Einblick in das ikonographische Programm von Vaux-le-Vicomte.

Unter den eindeutig identifizierbaren Götterdarstellungen finden sich der alle Aufgaben spielend bewältigende Herkules und der Sonnengott Apollon, denen wir auf den Deckengemälden des Schlosses erneut begegnen werden. Ihnen folgen weitere Göttergrößen: Minerva, die Göttin der Wissenschaften, sowie Ceres, Göttin des Landbaus und der Früchte, können eindeutig bestimmt werden. Unsicher ist die Zuordnung der übrigen Figuren, die Saturn, Juno, Jupiter, Merkur, Venus und Flora darstellen könnten ${ }^{39}$. Wenngleich die Wahl dieser Gottheiten für die Ausschmückung einer Schlossanlage des 17. Jahrhunderts nicht ungewöhnlich war, so ist sie doch nicht zufällig. Die Hermen kennzeichnen Vaux noch vor dem Betreten der Anlage als einen besonderen, von göttlichen Kräften gesegneten Ort. Die Götter haben sich in Vaux eingefunden, um über das neue Schloss zu wachen und hier ihre Kräfte

37 Siehe auch: Berger, Raincy, S. 42-44 sowie Brattig, Vaux-le-Vicomte, S.162-164, $182 \mathrm{f}$.

38 Hinsichtlich des architektonischen Entwurfs von Vaux-le-Vicomte gab es von kunsthistorischer Seite immer wieder kritische Stimmen. Sie hierzu: FigEac, Châteaux, S.36f.

39 Vor dem Anwesen stehend finden sich folgende Figuren (von links nach rechts): Herkules, Apollon, unbestimmte Herme, ein Faun, Saturn (?), unbestimmte Herme, Juno (?), Merkur (?). Auf der Schlossinnenseite können folgende Figuren identifiziert werden (ebenfalls von links nach rechts): Juno (?), Jupiter (?), unbestimmte Herme, Flora (?), Ceres, ein Faun, Minerva, Venus (?) (zitiert nach: BratTig, Vaux-le-Vicomte, S. 243). 
Abb. 5 a-d: Triumphbögen an den vier Seiten der cour des Bornes.
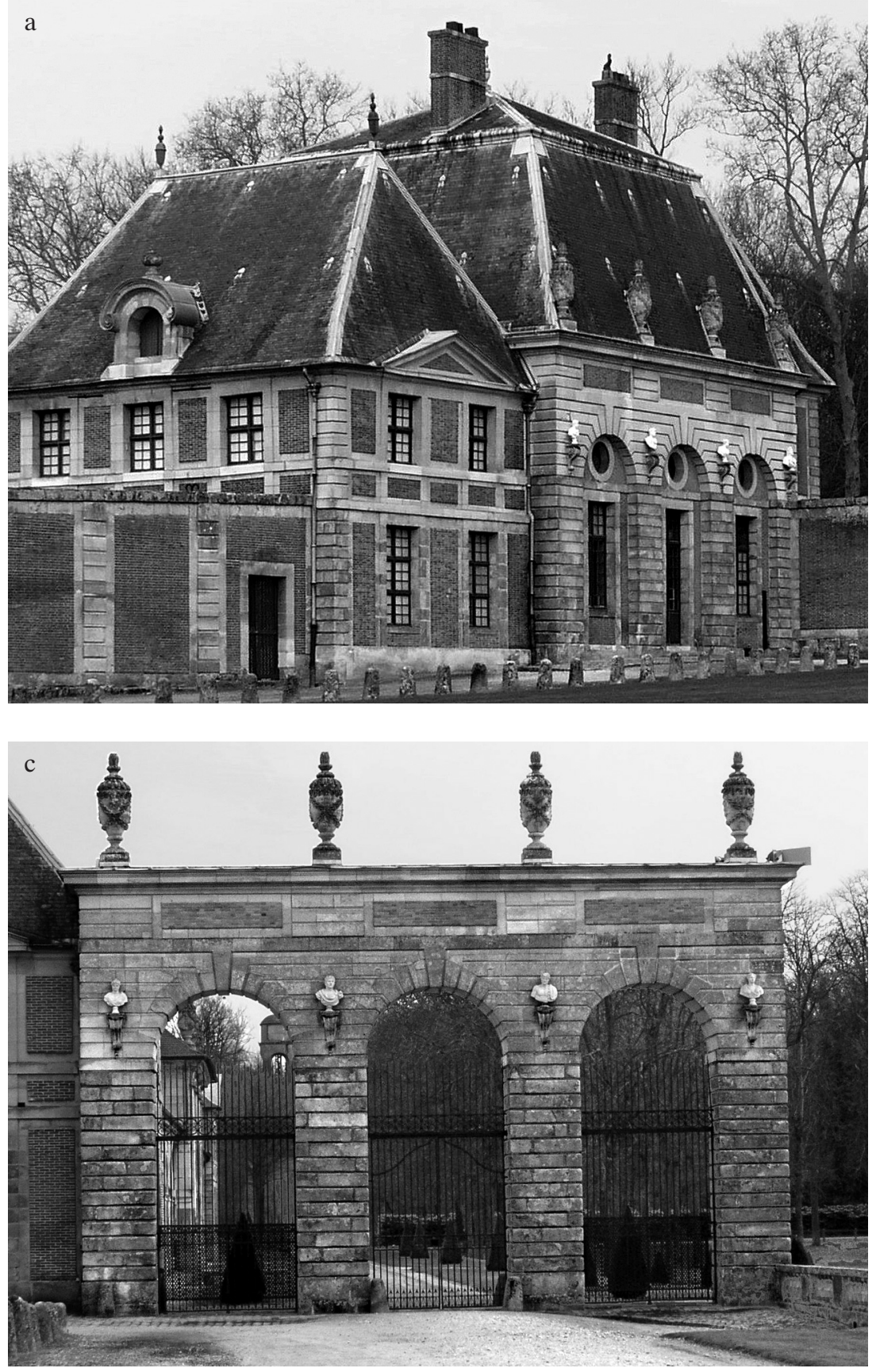

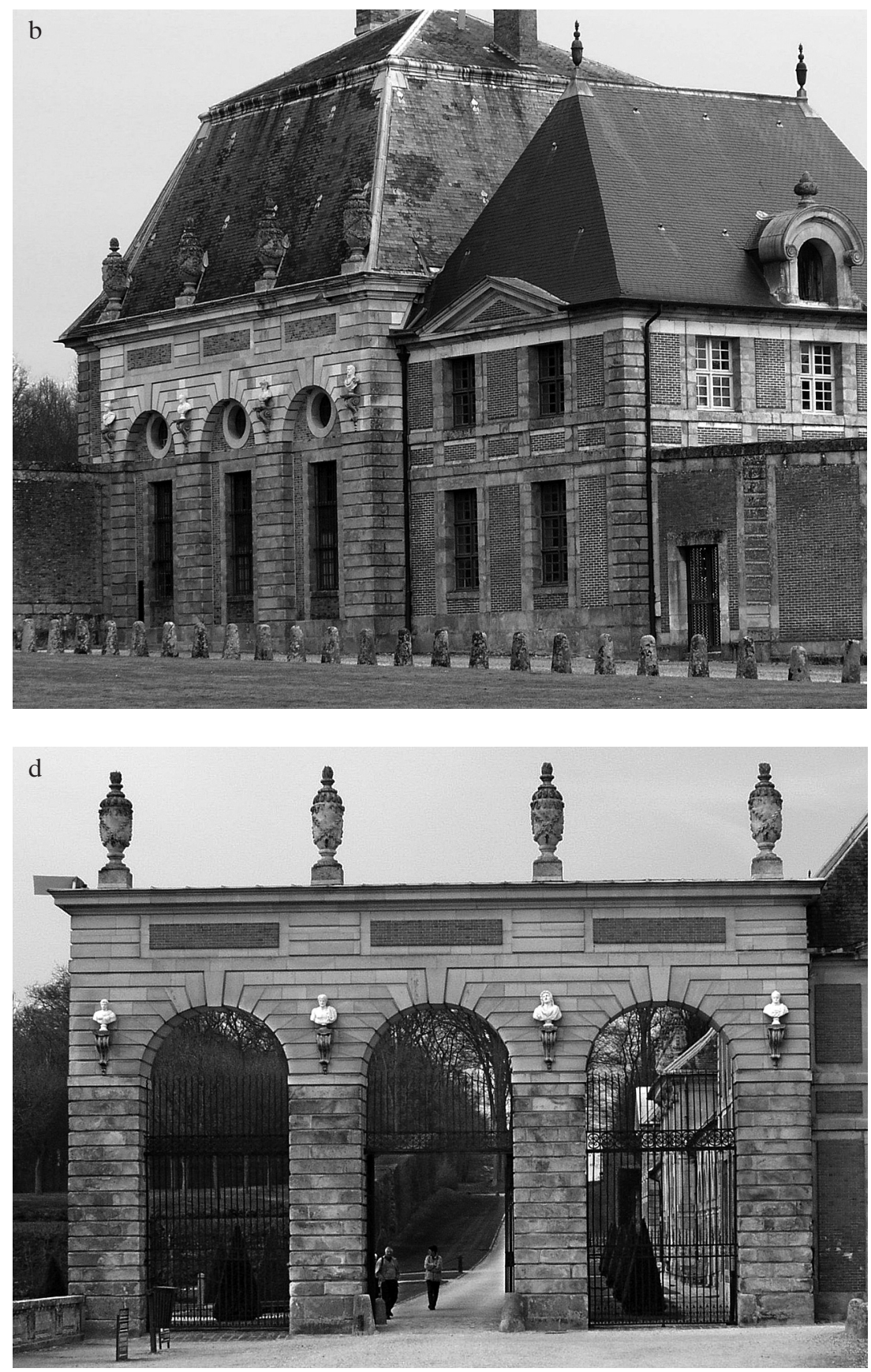
zu entfalten. Vaux steht damit unter ihrem Schutz und wird zum Sitz der göttlichen Herrschaft ${ }^{40}$.

Im Westen und Osten des ersten Vorhofs, der cour des Bornes, erheben sich die Neben- und Wirtschaftsgebäude aus Backstein. Auf den ersten Blick scheinen sie nur als bauliches Füllwerk zu dienen, das die gesamte Anlage breiter und herrschaftlicher erscheinen und den aus hellem Stein erschaffenen Schlossbau visuell hervortreten lässt. Sie sind jedoch weit mehr. Am jeweils südlichen und nördlichen Ende der den Vorhof beidseitig begrenzenden Wirtschaftsgebäude finden sich Triumphbögen, die den Vorplatz architektonisch erhöhen (Abb. 5 a-d).

Die nördlichen, an den Eingang grenzenden Triumphbögen sind den seitlichen Pavillons vorgeblendet, die beiden zum Schloss hin gelegenen Bögen stehen frei und dienen als Durchgang in den Garten. Die dreigliedrigen Bögen sind schlicht gehalten. Ihren rustizierten Baukörper aus Haustein zieren im oberen Drittel vier Büsten antiker Herrscher und drei Backsteintafeln über den jeweiligen Toröffnungen. Den Abschluss bilden vier Flammenvasen. Die Triumphbögen sollten den königlichen Einzug in das Schloss flankieren, an dessen Eingangsportal das Triumphbogenthema erneut aufgegriffen wird. Im Bau selbst kehrt es in den beiden dem Vorhof zugewandten Räumen, dem Esszimmer und der Chambre carrée, wieder ${ }^{41}$. Bereits im alten Rom war es üblich, dass Privatpersonen die von ihnen errichteten Triumph- oder Erinnerungsbögen dem Herrscher widmeten ${ }^{42}$. Louis Le Vau hatte schon in Vincennes Entwürfe für einen Triumphbogen vorgelegt ${ }^{43}$. Die Idee, einen solchen auch in Vaux zu Ehren des Königs zu planen, mag dem Architekten zu Beginn der Bauphase gekommen sein, denn auf den Stichen Silvestres sind die Bögen bereits zu erkennen.

Am südlichen Ende des Vorhofes erhebt sich das aus Haustein gefertigte Schloss, welches von einem Wassergraben umgeben ist und von Treppen erhöht wird:

Quand on est dans cette auant cour, on voit deuant soy la face du Palais, qui est basty sur vne montagne d'Architecture, s'il faut ainsi dire, car le perron qui occupe toute la largeur de la seconde cour, a quatre repos, \& a plus de vingt marches d'éleuation. De sorte que cela donne vne grande Majesté au bastiment ${ }^{44}$.

Mit dieser Erhebung erreichte Louis Le Vau die visuelle Dominanz des Schlosses über den Vorhof und die vorgelagerten Wirtschaftsgebäude, die bereits von der Straße aus erkennbar ist. So wird noch vor dem Betreten der

40 Als solcher wird er auch von La Fontaine im »Songe de Vaux« beschrieben: siehe Kapitel 3.3.

41 Siehe S.121.

42 Sturgeis, Dictionary, Bd. II, S. 856.

43 Ballon, Louis Le Vau, S.25f.

44 Scudéry, Clélie, Bd.X, S.1100. Der Wassergraben ist ein Element aus der Festungsarchitektur und wird von Le Vau zu rein dekorativen Zwecken beziehungsweise des visuellen Effektes willen benutzt. 


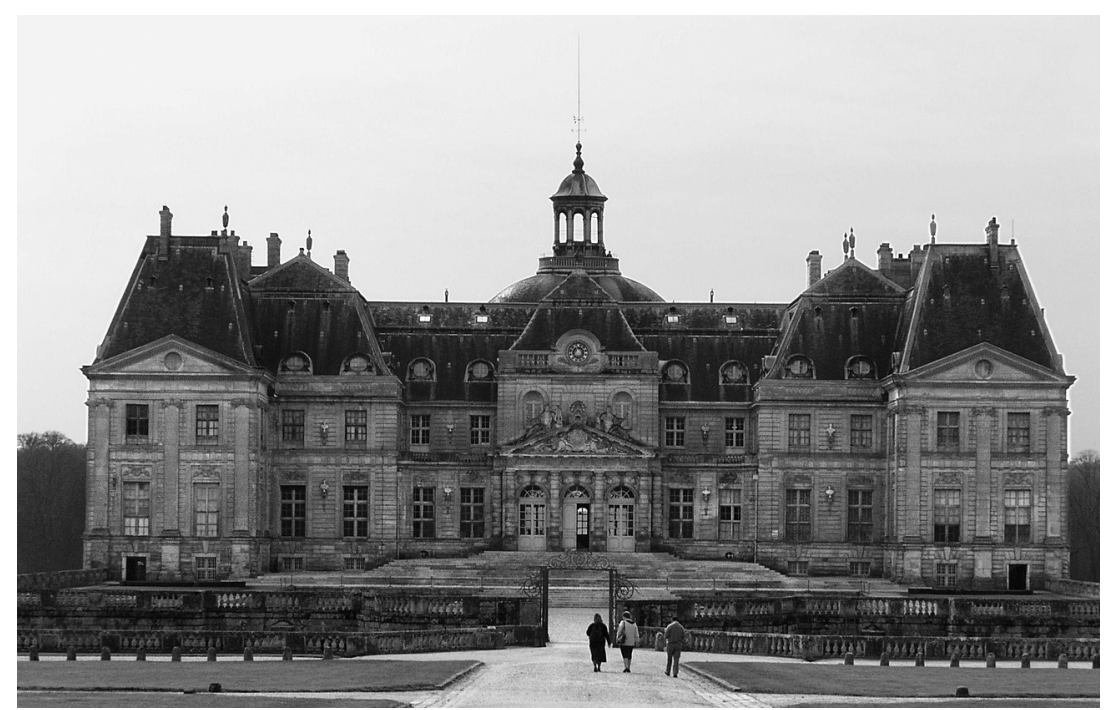

Abb. 6: Hoffassade des Schlosses von Vaux-le-Vicomte.

Anlage eine Regel preisgegeben, die die gesamte Domäne bestimmt: Alles ist in Vaux-le-Vicomte auf das Schloss hin ausgerichtet, das die für Fouquet wichtige Botschaft enthält.

Im zweiten Vorhof, der cour d'honneur, ersetzte Le Vau die diesen üblicherweise einrahmenden Seitenflügel durch Terrassen, die zur cour des Bornes hin jeweils mit einem runden Wasserbecken mit Springbrunnen abschließen und dem Überfluss an Wasser des hinter dem Schloss liegenden Gartens vorgreifen. Die Eingangsseite wölbt sich konkav und lädt damit in das Innere des Baus ein. Die großen lichten Türöffnungen sowohl zur Hof- als auch zur Gartenseite hin erlauben dem vor dem Schloss stehenden Besucher zugleich einen Durchblick bis in den Garten. Die Gartenseite hingegen hat eine konvexe Wölbung und verweist so architektonisch auf die Grünanlage und ihre Weite. Damit spiegelt der Grundriss des Schlosses (Abb.13) die Ausrichtung der Architektur von Vaux-le-Vicomte wider und schafft zugleich eine geschickte Verbindung der drei die Anlage bestimmenden Räume, des Vorhofs, des Schlossinneren und des Gartens.

An der Fassade des Schlosses wird mit der Darstellung des Löwen erstmalig direkt auf die Person des Königs verwiesen. Der Löwe tritt gemeinsam mit dem Eichhorn auf. Über den drei Fenstern der kurzen Flügel befinden sich im Erdgeschoss Reliefs mit einem von zwei Löwen gehaltenen eichenbekränzten Medaillon, in dem sich ein aufsteigendes Eichhorn befindet (Abb. 7).

Die Löwen schauen von dem Medaillon weg und scheinen mit ihren aus den Mäulern hängenden Zungen die von außen kommenden Bedrohungen 


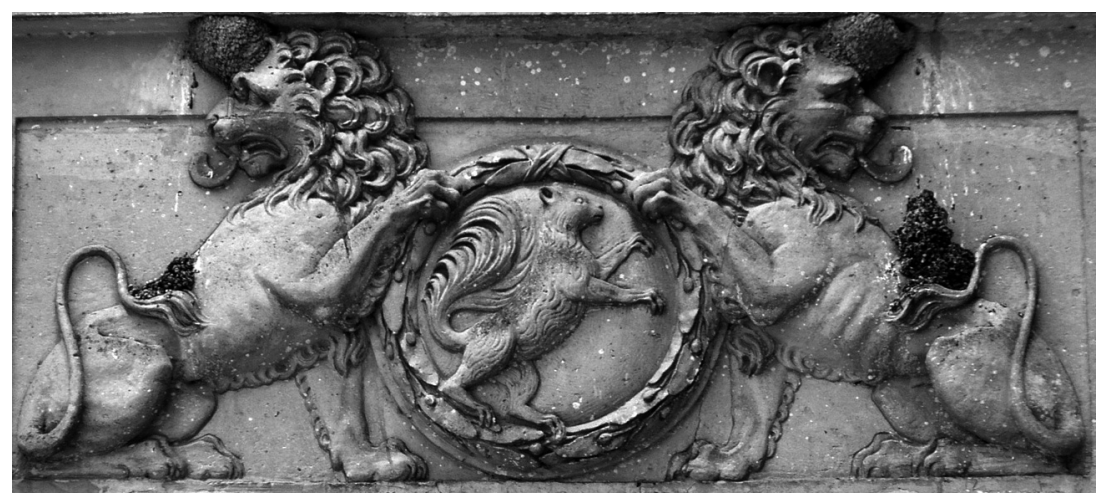

Abb. 7: Löwenrelief mit Eichhorn. Detail der Hoffassade von Vaux-le-Vicomte.

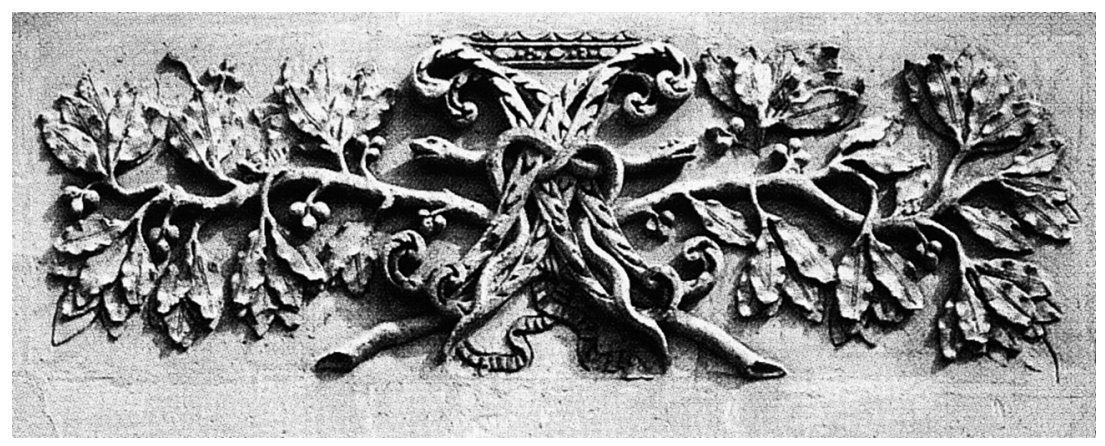

Abb. 8: Initialen Fouquets. Detail der Hoffassade von Vaux-le-Vicomte.

abwehren zu wollen. Mit der gemeinsamen Darstellung dieser beiden Tiere könnte ein Bündnis angedeutet sein, das der Hausherr Fouquet mit dem Bau der Anlage zu schaffen hoffte. Es ist nicht das letzte Mal, dass Löwe und Eichhorn in der Ikonographie von Vaux gemeinsam auftreten.

Die übrige Fassade wird von Anspielungen auf den Finanzminister dominiert. Über den Fenstern des Erdgeschosses am mittleren Baukörper finden sich die eichenumrankten Initialen Fouquets mit zwei Schlangen als Zeichen der Vorsicht und des folgerichtigen Denkens ${ }^{45}$.

45 RIPA, Iconologie, $1^{\text {re }}$ partie, S. 103: »Pour le regard du Serpent, il nous enseigne deux choses; La première, Que la Prudence est necessaire à cette profession, Comme à toutes les autres, veu que le plus grand effort de l'humaine industrie, est de sçavoir discerner le vray d'avecque le faux, \& d'operer selon cette distinction, avec une proportion conforme à la verité qu'on a reconnuë. La seconde, Que la Logique est prise pour une matière venimeuse \& inaccessible, par ceux qui n'ont pas l'esprit assez fort pour la concevoir; bien que toutesfois elle leur apprenne le contraire, \& qu'elle destruise ceux qui par une temerité trop grande s'opposent à sa doctrine«. 

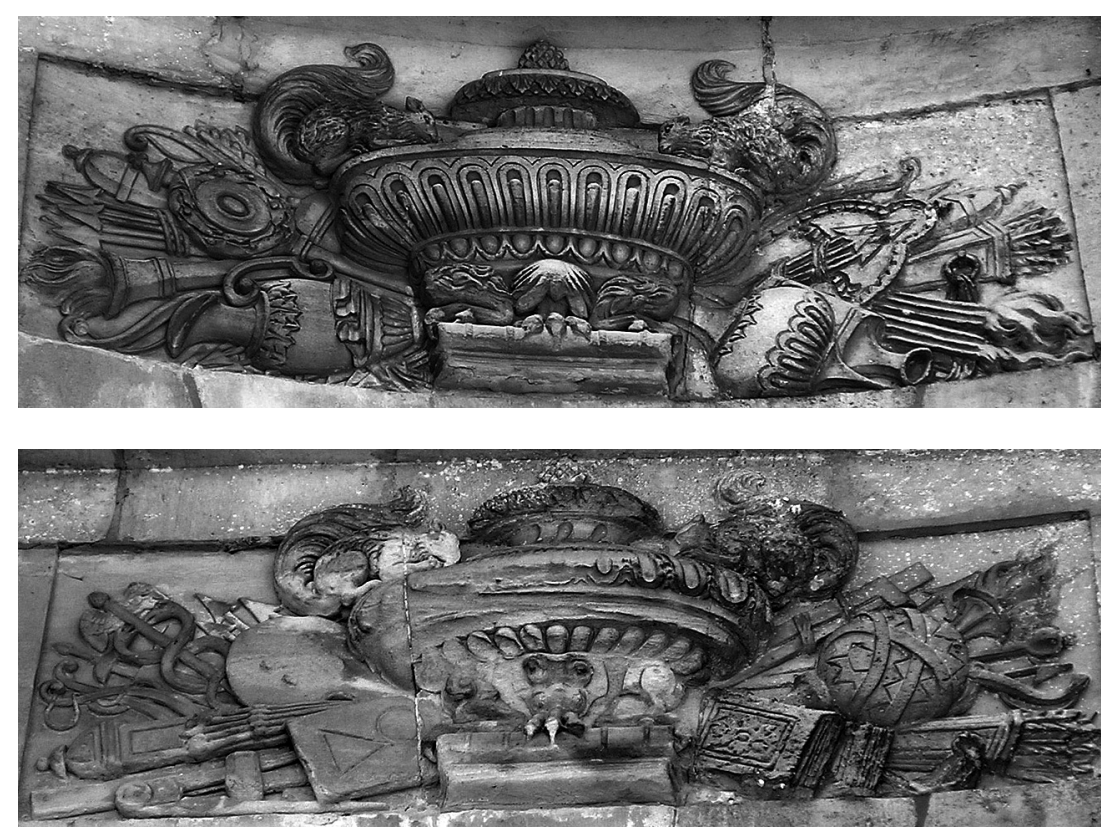

Abb.9 a-b: Brunnendarstellungen. Detail der Hoffassade von Vaux-le-Vicomte.

$\mathrm{Zu}$ beiden Seiten des Eingangsportals sind über den Fenstern des Erdgeschosses je zwei Brunnendarstellungen angebracht.

Auf dem Beckenrand sitzt beidseitig ein trinkendes Eichhorn. Die vier Reliefs unterscheiden sich in den den Hintergrund bestimmenden Attributen, die die Künste, Musik, Wissenschaften und die Jagd darstellen und diese durch die Präsenz von Fouquets Wappentier in Bezug zu dem Hausherrn setzen. Auch im Eingangsportal ist Fouquet omnipräsent. Im Fries des Gebälks wechseln sich zwischen den Triglyphen aufsteigende Eichhörnchen im Metopenrelief mit den Initialen des Finanzministers ab.

Das Tympanon über dem Eingang der Hofseite (Abb.12) zeigte wahrscheinlich bis zum Kauf von Vaux durch die Praslins im Jahre 1764 in seiner Mitte das bekrönte Wappen Fouquets, welches zu beiden Seiten von auf Löwen reitenden und diese sowohl bezähmenden als auch karessierenden Putten gehalten wurde. Der ikonologischen Lehre Cesare Ripas zufolge bedeutet das Abstützen einer Figur auf einem Löwen Großzügigkeit (linke Hand) oder Staatsraison (rechte Hand) ${ }^{46}$.

Mit dem Wappentier und Monogramm Nicolas Fouquets wird das Schloss als Bau des Finanzministers gekennzeichnet. Seinem gesellschaftlichen Aufstieg und Status setzte er mit dem Skulpturenschmuck der Fassade für die

${ }^{46}$ Ibid., $1^{\text {re }}$ partie, S. 79f. (générosité), $2^{\mathrm{e}}$ partie, S.167f. (raison d'État). 


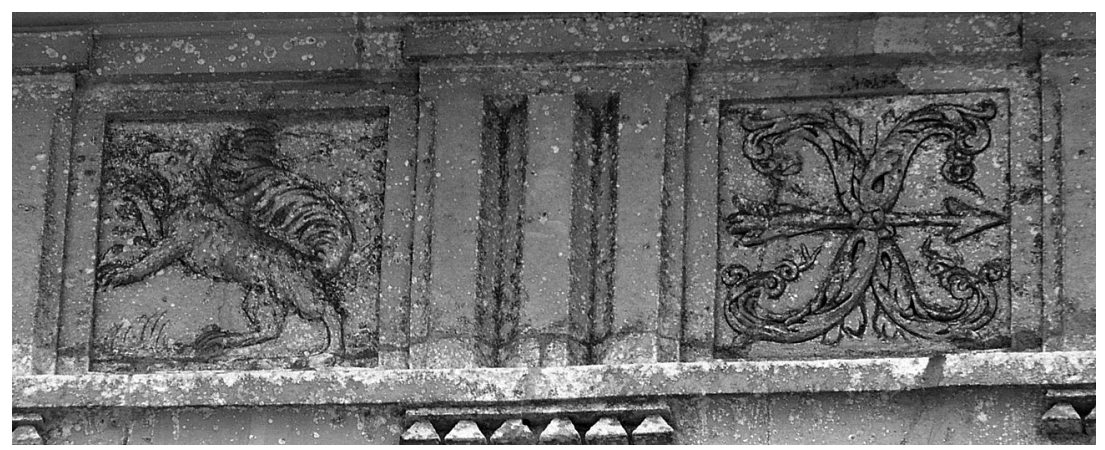

Abb.10: Detail Eingangsportal. Hoffassade von Vaux-le-Vicomte.

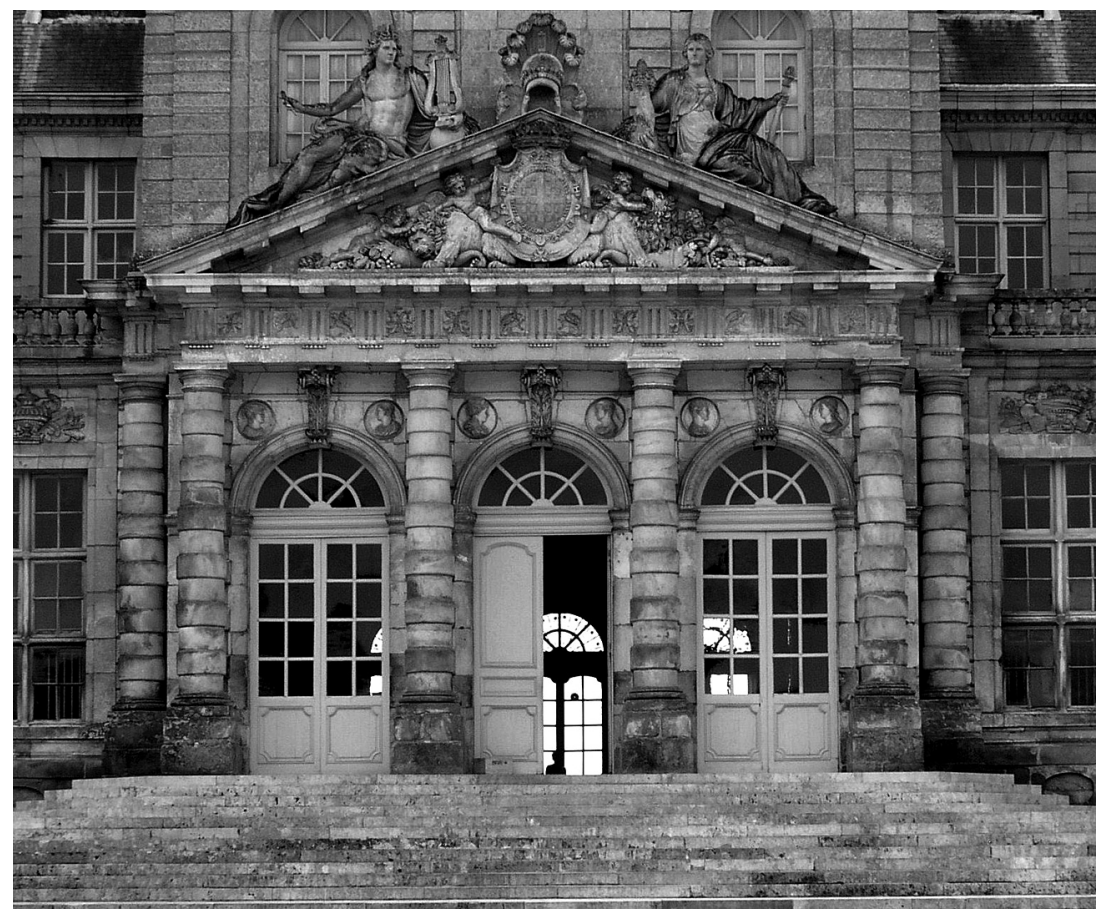

Abb.11: Eingangsportal. Hoffassade von Vaux-le-Vicomte.

Ewigkeit ein Denkmal. Durch die Fouquet repräsentierende Emblematik wird die Fassade zum Propagandamittel des Finanzministers. Auch in einem Text der Vaux beschreibenden und verherrlichenden Autoren findet sich eine Anspielung auf die Eichhhornsymbolik des Schlosses. In dem zehnten Band des Romanzyklus »Clélie«, der streckenweise in Valterre (Vaux-le-Vicomte) spielt, erzählt Mlle de Scudéry die Fabel, wie die Fouquets zu ihrem Wappen 
kamen. Auch die Scudéry bringt das écureuil in Verbindung mit dem König: »Le Roy [...] voulut, que Cleorante [Vorfahre Fouquets] \& ses successeurs portassent pour armes un Escureuil «47. Das Wappentier wird somit als Würdigung des Königs deklariert, der auf diesem Wege die Nähe der Familie zum Herrscher manifestiert. Die Anekdote um das Eichhorn, mit der Mlle de Scudéry die Beschreibung des Schlosses beginnt, hebt die Bedeutung des Wappentiers für die Ikonographie der ganzen Anlage hervor ${ }^{48}$.

Auch die bereits durch die Herrscherbüsten der Triumphbögen des Vorhofs enthaltene direkte Anspielung auf die römische Antike wiederholt sich in der Fassade der Hofseite. Zwischen den rustizierten Säulen des Eingangsportals sind über den drei Türöffnungen je zwei Medaillons mit Köpfen antiker Persönlichkeiten angebracht ${ }^{49}$. Sie wiederholen sich in den Mauerflächen zwischen den Fenstern im Erdgeschoss sowie im ersten Obergeschoss, wo sich von Konsolen getragene Büsten antiker Herrscher finden. Sie sind für die Ikonographie eines Schlosses nicht ungewöhnlich, sondern gehörten im Grand Siècle zum Kanon des skulpturalen Fassadenschmucks ${ }^{50}$. Mit den Antikendarstellungen reiht sich Fouquet nicht nur in die architektonische Tradition seiner Zeit und seines Standes ein, er beansprucht zugleich die antiken Herrschertugenden und Weisheiten zur Glorifizierung seines neuen Besitzes. Das Eingangsportal nimmt zudem durch seine Gestalt das Triumphbogenthema selbst wieder auf.

Ebenso wird die mit den Hermen am Eingangsgitter eingeführte Götterthematik im Eingangsportal erneut aufgegriffen. Auf dem Fronton, der knapp über die Höhe des Erdgeschosses hinausreicht, sitzt zur Linken Apollon mit seiner Lyra und zur Rechten Rea mit einem Füllhorn und einer Fackel. Der mit seinem Instrument dargestellte Apoll Musagetes gilt als Gott der Künste und Wissenschaften und Anführer der Musen ${ }^{51}$. Er ist ein Vorbote der bildlich in den Deckengemälden von Charles Le Brun dargestellten und literarisch im »Songe de Vaux« von Jean de La Fontaine besungenen Allgegenwart der Musen an der Seite Apollons in Vaux-le-Vicomte:

Apollon a juré de ne plus faire de vers que quand Oronte et Sylvie [M. et Mme Fouquet] le souhaiteront. Il gouvernera leurs troupeaux; il sera contrôleur de leurs bâtiments; il conduira la main de nos peintres, de nos statuaires, de nos sculpteurs; il t'inspirera toimême, si tu écris pour plaire au héros ou à la héroïne, et non autrement ${ }^{52}$.

47 Scudéry, Clélie, Bd.X, S. 1098f.

48 Ibid., S. 1095.

49 Von den sechs Darstellungen lassen sich drei aufgrund einer Aufschrift identifizieren. Es handelt sich um Hadrian, Marius und Augustus. Die Bildnisse zweier Frauen und eines Knaben können nicht näher bestimmt werden.

${ }^{50}$ In nahezu allen Fassaden des 17. Jahrhunderts finden sich Statuen, Büsten und Medaillons antiker Herrscher und Gelehrter, zum Beispiel: Richelieu oder Vincennes.

51 Die Verbindung der Musen mit dem Sonnengott wird schon von Homer in der »Ilias« (I 601-604) beschrieben. Hier unterhalten die Musen die feiernden Götter mit ihrem Gesang und werden von Apollon auf der Lyra begleitet. Nicolas Poussin verbildlichte dieses Thema um 1625 in »Der Parnass « (Madrid, Prado).

52 La Fontaine, Euvres complètes I, Bd. VIII, S. 277. 


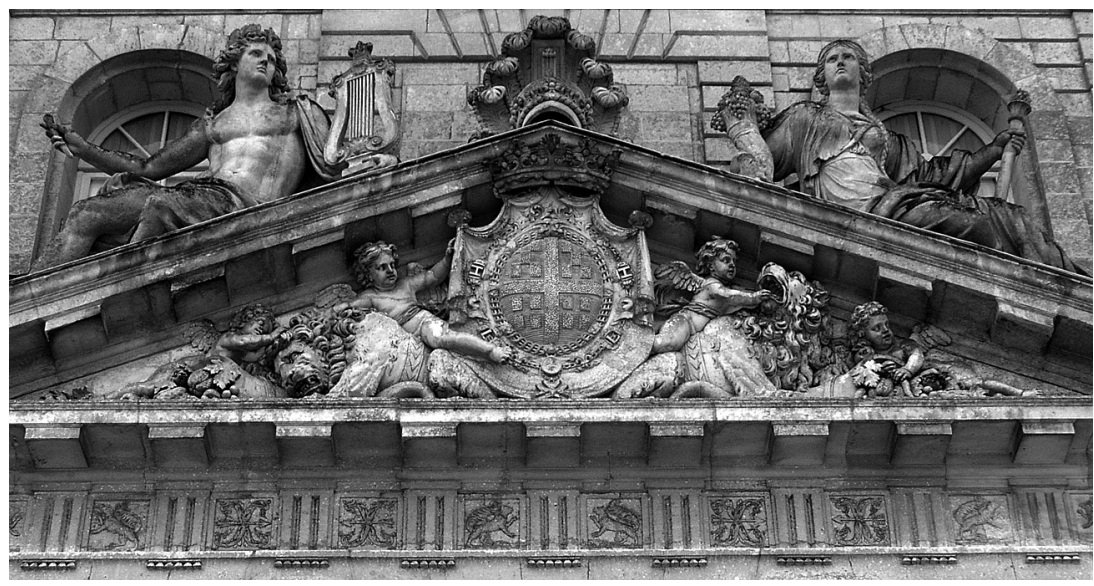

Abb.12: Tympanon des Eingangsportals. Hoffassade von Vaux-le-Vicomte.

Rea, Erdengöttin und Mutter aller Götter, steht stellvertretend für die ganze Gottheit am Eingang zum Schloss. Darüber hinaus ist sie Vertreterin und Botin des Goldenen Zeitalters, in dem sie mit ihrem Bruder und Gemahl noch immer lebt. Ihre Attribute - das Füllhorn und die Fackel - sind Symbole für ein Leben in Glück und Frieden ${ }^{53}$.

Der Fassadenschmuck wurde in seiner Fülle erst möglich gemacht durch die Entscheidung, statt des im Plan vom 2. August 1656 vorgesehenen Backsteins für den Bau des Schlosses Haustein zu verwenden. Es ist nicht auszuschließen, dass der politische Druck seitens Mazarins und Colberts die Entscheidung Fouquets, das ikonographische Programm von Vaux zu intensivieren und zu propagandistischen Zwecken zu verwenden, bestärkt hatte. Der skulpturale Schmuck verweist auf den Bauherrn und nimmt Themen der Innenraumgestaltung und des Gartens vorweg ${ }^{54}$. Die politische Bedeutung von

${ }^{53}$ RIPA, Iconologie, $1^{\text {re }}$ partie, S. 138f. (paix), $2^{\mathrm{e}}$ partie, S. 63 (bonne fortune).

54 Die Fassadengestaltung der Hofseite nimmt einige, wenngleich nicht alle Elemente der Gartenseite vorweg. Diese soll hier nicht im Einzelnen besprochen werden. Das Eichhorn dominiert auch im Süden und in gleicher Weise die Fassade. Die Gartenseite unterscheidet sich in einem Detail von jener des Hofes: Anstatt des Brunnenmotivs finden sich über den Fenstern des sich zur Gartenseite hin nach außen wölbenden Baukörpers zu beiden Seiten je zwei Reliefdarstellungen einer Engelsfigur, deren Beine durch Eichenblattranken ersetzt wurden. An ihren ausgestreckten Armen halten die Engel Palmenzweige, Eichenlaub, Kronen beziehungsweise eine Taube. Auf den sich rankenden Beinen sitzen zu beiden Seiten aufblickende oder laubnagende Eichhörnchen. Im Tympanon der Gartenseite zeigt sich die Allegorie des Ruhmes. Sie hält zwei Schilder, die einstmals das Wappen von Fouquet und seiner Frau trugen. Die Säulen des Erdgeschosses finden über dem Gebälk ihren Abschluss in vier weiblichen Figuren, die vor den Pilastern des ersten Obergeschosses stehen. Es handelt sich um die Allegorien der Tugenden. 
Vaux-le-Vicomte wird durch das Zusammenspiel von Löwe und Eichhorn symbolisiert. Diese politische Dimension des Ortes wird durch den Rückgriff auf die Antike in den römischen Herrschermedaillons zusätzlich unterstrichen. Die Brunnenreliefs und Apollon markieren Vaux darüber hinaus als einen Ort der Musen und der Künste und - im Hinblick auf die Aufenthalte des Königs - zugleich als einen alltagsabgewandten Ort, an dem der Herrscher sich fern der Regierungsgeschäfte zerstreuen konnte. Die göttliche Dimension in Gestalt von Rea und Apollon kennzeichnet die Erhabenheit Vaux-le-Vicomtes in Abgrenzung zum ordinären Leben außerhalb seiner Mauern. Die Nähe zu den Göttern ist allein eines Königs würdig - und dieser sollte sich so oft wie möglich in Vaux-le-Vicomte aufhalten.

Der erste Raum von Vaux ist primär auf den Empfang des Königs ausgerichtet. Die Triumphbögen begleiten seinen Weg zum Schloss, dessen konkave Wölbung den königlichen Gast in sein Inneres weist. Der Fassadenschmuck nimmt im Eingangsportal, durch das der König in das Schlossinnere schreitet, nicht nur die Triumphbogenthematik erneut auf, es bereitet zudem auf die Botschaft der Anlage vor. Fouquet ist präsent, dies jedoch offensichtlich in Abhängigkeit von und im Zusammenspiel mit dem König.

\subsection{Der zweite Raum: das Schloss und seine Innendekoration}

War der erste Raum von Vaux dem Empfang des Königs gewidmet, so sollte der zweite Raum, das Schlossinnere, dem jungen Monarchen als Ort der Ruhe und der Divertissements, zugleich aber der politischen Belehrung dienen. In den Deckengemälden der Prunkappartements verbirgt sich die Botschaft, die Fouquet von seinem König erkannt und anerkannt sehen wollte, bevor dieser sich den ihm bereiteten Vergnügungen hingab und - im besten Falle und als Anerkennung der Dienste und Fähigkeiten des Hausherrn - ein häufiger Gast in Vaux-le-Vicomte wurde.

Die Innenräume des Schlosses waren ganz auf die Bedürfnisse eines Königs ausgerichtet, der sich an der Seite seines Finanz- (und zukünftigen Premier-) ministers einrichten sollte. Bereits von außen weist die rustizierte Fassade auf eine Besonderheit der architektonischen Disposition Vaux' hin: Das erste Obergeschoss ist von geringerer Höhe als das Erdgeschoss, die Beletage von außen erkennbar im Parterre gelegen.

Durch die Verlegung der Prachträume ins Erdgeschoss konnte auf eine aufwendige Treppenanlage verzichtet werden. In dem so gewonnenen Raum wurde ein ovaler Salon eingerichtet, der dem in das Schloss eintretenden Besucher einen freien Blick auf den Garten ermöglicht und von einer Kuppel gekrönt wird. Zu beiden Seiten des Salons schließen sich auf der Gartenseite die aus antichambre, chambre und cabinet bestehenden Prunkappartements an. Le Vau hat hier die erst seit 1650 verwendete Form des appartement double aufgenommen, eine Verdoppelung der einfachen Raumreihe, die den direkten Zugang zu den Zimmern ermöglichte. Im Westen findet sich das 


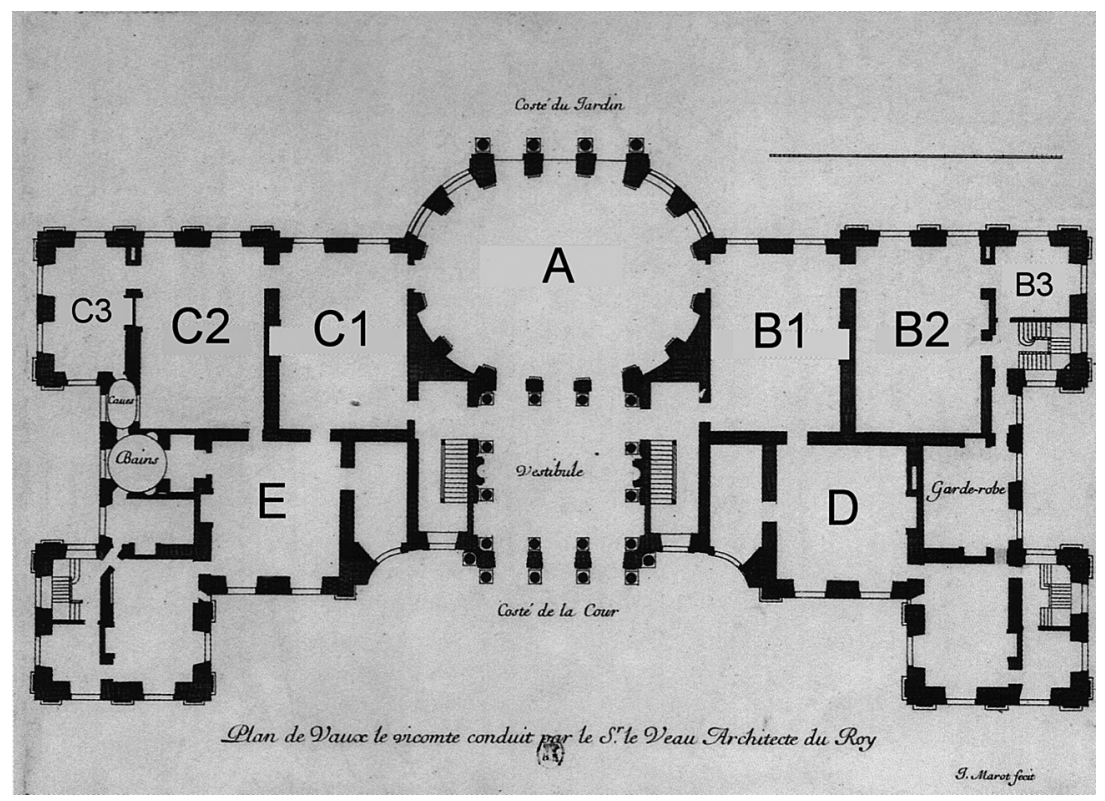

Abb.13: Grundriss von Vaux-le-Vicomte (Erdgeschoss): »Plan de Vaux le vicomte conduit par le Sieur le Veau Architecte du Roy"(J. Marot, o.J.), Paris, Bibliothèque nationale de France: $A$. Salon - B. Appartement de Fouquet - B1. Salon d'Hercule - B2. Chambre des Muses - B3. Cabinet des Jeux $-C$. Appartement du Roi $-C 1$. Antichambre $-C 2$. Chambre $-C 3$. Cabinet $-D$. Chambre carrée $-E$. Salle à manger.

Appartement des Hausherrn, an das sich auf der Hofseite die Chambre carrée anschließt, im Osten das appartement du Roi, hinter dem sich auf der Nordseite das Esszimmer befindet. Die unter Fouquet vorgesehene Aufteilung des ersten Obergeschosses bleibt für den Westflügel, in dem zu Bauzeiten das Atelier Le Bruns untergebracht war ${ }^{55}$, ungewiss. Im Ostflügel befanden sich auf der Gartenseite - über dem appartement du Roi - die Zimmer der Hausherrin Marie-Madeleine de Castille und auf der Hofseite das private Appartement Nicolas Fouquets. Durch die Verlagerung dieser Räume ins erste Obergeschoss und den direkten Zugang der Repräsentations- und Festräume im Erdgeschoss wird die Hauptaufgabe des Baus als Ort der Muße und des plaisir unterstrichen. Eine solche Raumaufteilung gab es in Frankreich bisher nicht. Sie charakterisiert das Schloss als ein auf Bequemlichkeit ausgerichtetes Gebäude, das dem König jede Art von Annehmlichkeiten bieten sollte.

Bis heute besitzt Vaux-le-Vicomte die für seine Zeit umfangreichste und einheitlichste Innendekoration in Frankreich, wenngleich sie nie vollendet

55 Inventaire de Vaux (1661), BN ms.fr.7620, fol.106r-152r, in Auszügen abgedruckt in: Bonnaffé, Fouquet, S.77-96. 
wurde $^{56}$. Nach der Verhaftung Fouquets im September 1661 brach Le Brun die Arbeiten im Schloss ab, um sich anderen, vor allem königlichen Projekten zuzuwenden. Ein Großteil der Repräsentationsräume im Erdgeschoss war jedoch - bis auf das Deckengemälde des Salons und die Zentralgemälde der antichambre und des cabinet des appartement du Roi - zur Vollendung gekommen, die Räume im ersten Obergeschoss hingegen nur in Teilen ${ }^{57}$. Der Zustand der Dekorationsarbeiten zum Zeitpunkt der Verhaftung Fouquets macht deutlich, dass zunächst die Fertigstellung des Appartements von Nicolas Fouquet im Vordergrund des bauherrlichen Interesses gestanden hatte. Für seine weitere Karriere war die visuelle Botschaft dieser Deckengemälde, in denen die Vorzüge des Finanzministers gepriesen wurden, von großer Bedeutung. Es kann daher nicht verwundern, dass ihre Ausführung Priorität hatte. Eine derart penetrante Darstellung des Hausherrn in der Ikonographie seiner Räumlichkeiten war in Frankreich eine Neuheit. Sie in dem Prunkappartement des Königs anzubringen, wäre unmöglich gewesen. Hier konnten allein der König und seine Tugenden Thema der Malereien sein.

Die Gestaltung der Decken in Vaux-le-Vicomte unterwarf Le Brun einem hierarchisch angeordneten Bildsystem. Das Hauptgemälde findet sich im Zentrum der Decke. Es ist umgeben von einer Reihe kleinformatiger Darstellungen, die das Generalthema ergänzen, so dass eine Vielzahl aufeinander bezogener Episoden der Geschichte des Helden zu sehen sind, ein Prinzip, das Madeleine de Scudéry wie folgt beschreibt: »Ce Tableau, qui est celuy du milieu de cette chambre, est le principal dessein du Peintre, tous les autres qui l'environnent y conuiennent \& en dependent $\ll^{58}$. Zur Abgrenzung des Hauptgemäldes von den ihm untergeordneten Deckendarstellungen unterschied Le Brun in der Darstellungsform und -technik ${ }^{59}$. Abgebildet sind allegorische Gestalten der klassischen Mythologie. Hin und wieder auftauchende Wappen und Devisen verweisen auf zeitgenössische Personen. Die der Deckendarstellung des westlichen Prunkappartements zugefügten Eichhörnchen und

56 Die Innendekoration gilt zudem als die am besten erhaltene ihrer Zeit. Dem allgemeinen Schicksal der meisten Innendekorationen, die den jeweils herrschenden Moden zum Opfer fielen, entging Vaux dank der Fürsorge der nachfolgenden Besitzer. Zu Restaurationsarbeiten in Vaux-le-Vicomte siehe: BratTig, Vaux-le-Vicomte, S. 57-61, 231-234 (Anhang: Restaurationsarbeiten im Überblick).

57 Im Obergeschoss kamen nur die Dekoration des Schlafzimmers Fouquets und diejenige des Appartements seiner Frau zur Ausführung, von der nur noch ein Teil des cabinet erhalten ist.

58 SCUdÉrY, Clélie, Bd.X, S.1118. Siehe auch: KIRCHNER, Held, S. 236-239.

${ }^{59}$ Le Brun verwendete in Vaux-le-Vicomte zwei Gestaltungsprinzipien: die quadratura und die quadro riportato. Der Unterschied zwischen beiden Prinzipien liegt in der Anwendung der Perspektive. Bei der quadratura soll die Illusion hervorgerufen werden, die gemalte Darstellung, und nicht der reale Baukörper, würde den oberen Raumabschluss bilden. Das Prinzip der quadro riportato soll die Illusion eines von der Wand an die Decke versetzten Gemäldes oder Reliefs erwecken. Auf die Position des Betrachters wird bei dieser Versetzung keine Rücksicht genommen; siehe hierzu auch: SütTERLIN, Le Brun, S.10f. 
Spruchbänder mit der Devise »Quo non ascendet? « geben dem wissenden Betrachter den Hausherrn selbst zu erkennen ${ }^{60}$. Er ist der Held der himmlischen Ereignisse, die Le Brun in seinen Gemälden darstellt ${ }^{61}$. Der Sieg über Bedrohungen und menschliche Laster verherrlicht seine Tugenden und seine Persönlichkeit. Die Malerei wird zu einem Instrument der Propaganda, welches Le Brun mit der Idee der Verknüpfung von allegorischen und mythologischen Sujets einerseits und persönlichen Attributen andererseits erstmals in dieser umfassenden Form in Frankreich einsetzte ${ }^{62}$. Seine italienischen Vorbilder, die der Künstler in den vierziger Jahren persönlich studiert hatte, waren vor allem die Arbeiten Pietro da Cortonas (1596-1669), wie das Deckenfresko »Ruhm der Barberini « im römischen Palazzo Barberini ${ }^{63}$. Erstmals auf französischen Boden übertragen wurde das neue Gestaltungsprinzip zwischen 1654 und 1657 in den Räumen Annas von Österreich im Louvre, wo Romanelli die Taten der Königin verherrlichte. Auch Charles Le Brun hatte dem Königshaus vor Vaux-le-Vicomte bereits Entwürfe für konzeptuell ähnliche Deckengemälde geliefert ${ }^{64}$. Bis 1658 war die neue Darstellungsform in Frankreich also ausschließlich für das Königshaus angewendet worden. In Vaux-leVicomte wurde das Prinzip der »aktualisierenden Allegorisierung ${ }^{65}$ erstmals aus dem höfischen Rahmen herausgehoben, in den es nach dem Sturz des Finanzministers mit der Ausmalung Versailles wieder eingefügt werden sollte, und überdies auf ein ganzes Schloss und, schließt man die Skulpturen des Gartens mit ein, auf die gesamte Schlossanlage übertragen. Für Vaux-leVicomte wählte Fouquet nicht nur ein neues und propagandistisch besonders geeignetes Gestaltungsprinzip, er übernahm zugleich ein königliches Darstellungsmittel, das Vaux als Ort des Hofes auszeichnete: Hier sollte sich der junge König bevorzugt aufhalten.

Vier zeitgenössische Quellen beschreiben die Deckengestaltungen der Räume im Erdgeschoss. André Félibien beschränkt sich in seinen zwei Briefen über Vaux-le-Vicomte auf das appartement Fouquets. Der erste Brief

${ }^{60}$ FÉLIBIEN, Relations, Troisième relation, S. 43: »Car pour faire voir ce qu'il y a de grand dans la Personne pour qui il travaille, il a creu ne pouvoir trouver un moyen plus avantageux que d'employer dans tous ses Ouvrages le sens mysterieux de cette devise: QUO NON ASCENDET? que l'on a si heureusement rencontrée sur les armes du Maistre de ce Palais «.

61 Ibid., S. 44: »En effet comme les grandes qualitez de ce grand Ministre le rendent differend des autres hommes, il falloit trouver des moyens qui en representent l'éminence de son Esprit \& de ses vertus, fissent voir sa veritable Image sous des figures proportionnées à ce qu'il y a de plus excellent en luy«.

62 Germer, Félibien, S.145. Germer hat hierfür den Begriff der »aktualisierenden Allegorisierung des überkommenen Bildrepertoires« gefunden (ibid.).

63 Kirchner, Held, S. 203-205.

64 Siehe Montagu, Ceiling Decorations, S. 401f. Es handelt sich um zwei für den Louvre konzipierte Projekte. Der erste Entwurf war für die Decke der chambre de conseil bestimmt gewesen (um 1653) und der zweite für die Kuppel des vor der Petite Galerie gelegenen Raumes (um 1660).

65 Germer, Félibien, S. 145. 
(»Seconde relation«) geht ausschließlich auf die chambre des Muses ein, der zweite (»Troisième relation«) beschreibt den salon d'Hercule sowie ein Porträt Le Bruns von Mme Fouquet. In Jean de La Fontaines »Songe de Vaux « findet sich eine kurze Beschreibung der Deckenmalereien der chambre des Muses. In Madeleine de Scudérys »Clélie« wird die Kuppeldarstellung des Salons sowie die Deckendekoration des salon d'Hercule und der chambre des Muses beschrieben. Die Texte der drei mit der literarischen Glorifizierung von Vaux-le-Vicomte beauftragten Autoren beschränken sich auf die Gemälde, in denen den Tugenden des Hausherrn gehuldigt wird (Deckengemälde des appartement Fouquets und des Salons). In ihren Beschreibungen finden sich auch Hinweise auf die Symbolik des Eichhörnchens sowie auf die Devise des Hausherrn. Claude Nivelon, der erste ausführliche Biograph Charles Le Bruns, beschreibt in seinem um 1690 fertiggestellten Manuskript die Salonkuppel und die Räume des appartement Fouquets (nicht nur antichambre und chambre, sondern auch cabinet) und erwähnt als Einziger auch die Ausgestaltung des appartement du Roi. Er stand, soweit man es den spärlichen Informationen zu seiner Biographie entnehmen kann ${ }^{66}$, nicht in Fouquets Diensten. In seinem Text fehlt jeglicher Hinweis auf eine Verbindung der Malerei mit dem Hausherrn. Seine Beschreibungen scheinen zudem nicht auf eigener Kenntnis der Deckengemälde zu beruhen. Am ausführlichsten beschreibt er die Deckengestaltung des Salons, die niemals zur Ausführung kam. Seine detaillierte Beschreibung lässt jedoch vermuten, dass ihm die Entwurfzeichnungen bekannt waren, er sie vielleicht sogar mit Le Brun besprochen hatte.

Die Deckengemälde nehmen die drei bereits in der Fassade eingeführten Themenbereiche wieder auf. Durch den Ort ihrer Handlung, die ausnahmslos im Himmel spielt, und den Handlungsträger wird auf den göttlichen Aspekt der Ikonologie verwiesen. Die in der chambre des appartement von Fouquet dargestellten Musen kennzeichnen Vaux als einen zweiten Parnass. Die Gemälde mit den darauf abgebildeten Tugenden des Hausherrn verkünden die politische Botschaft von Vaux.

Die Ikonographie der Salonkuppel sollte das Zentrum der bildnerischen Propaganda für den Hausherrn werden. Wenngleich das aufwendige Deckengemälde vor 1661 nicht mehr ausgeführt werden konnte, lassen die überkommene Entwurfszeichnung von Le Brun und ein erhaltener Stich von Gérard Audran den wesentlichen Inhalt der Darstellung erahnen und die Botschaft des Gemäldes erkennen. Bereits im Salon von Saint-Mandé hatte Charles Le Brun die Decke mit einem ähnlichen Thema ausgestaltet ${ }^{67}$.

${ }^{66}$ Pericolo erläutert in der Einleitung zu der von ihm herausgegebenen kritischen Ausgabe der Handschrift Claude Nivelons die Dürftigkeit der biographischen Informationen zu Nivelon (Nivelon, Le Brun, S.17-27). Da dieser erst 1667 Mitarbeiter Le Bruns wurde, ist zu vermuten, dass Nivelon nicht in Fouquets Diensten stand.

67 Guillet de Saint-George, Mémoires, Bd.I, S. 440: »On y voit le plafond d'un salon, où $\mathrm{M}$. Le Brun a représenté le Soleil levant avec tous les accompagnements convenables du sujet $\ll$. 


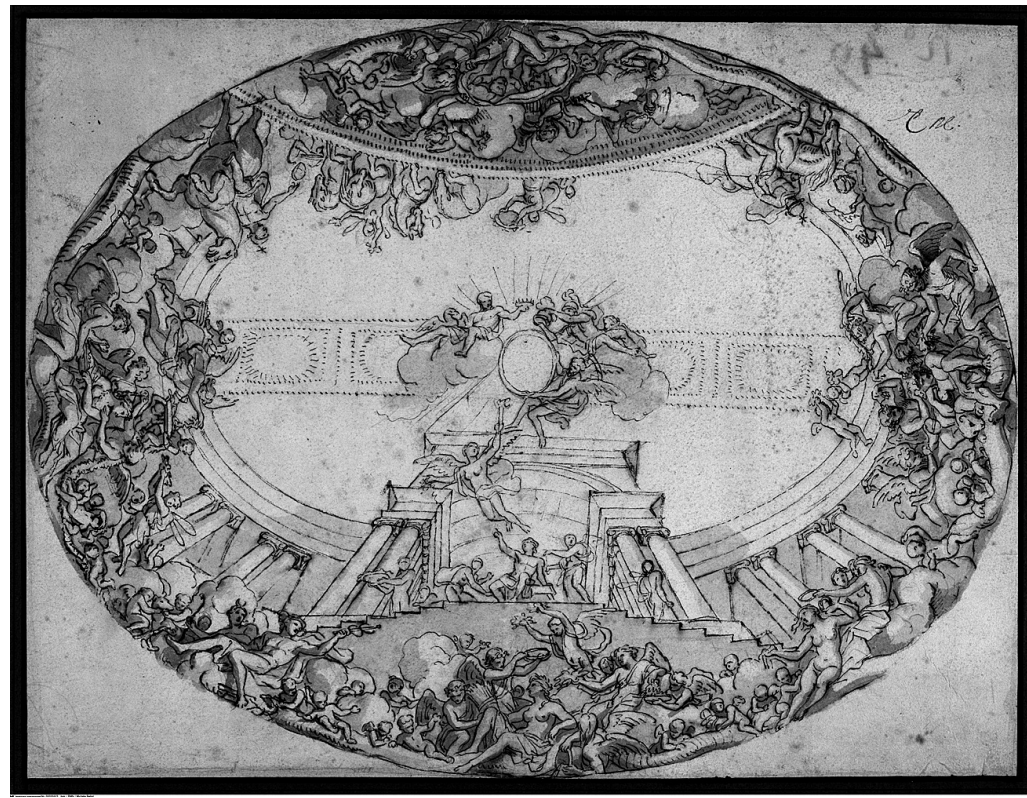

Abb. 14: Erste Entwurfszeichnung für die Salonkuppel (Charles Le Brun, um 1660). Paris, musée du Louvre.

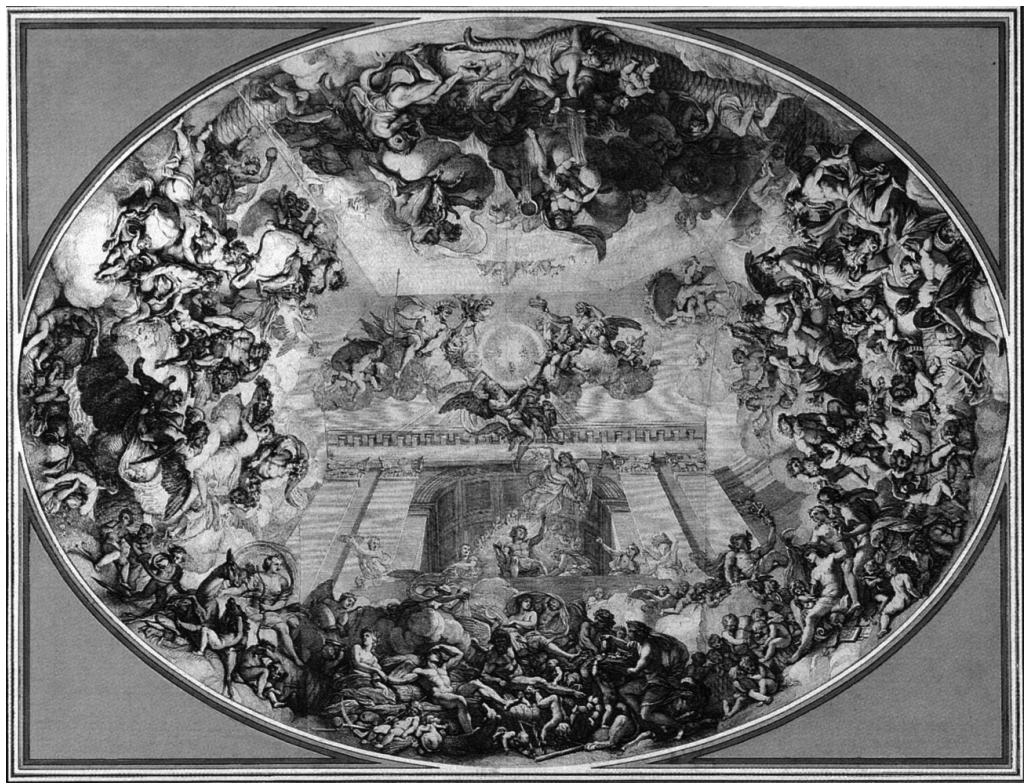

Abb.15: Stich zu einem zweiten Entwurf Charles Le Bruns für die Salonkuppel (Gérard Audran, um 1660). Vaux-le-Vicomte. 
Für das Zentrum der Darstellung war ein Wappenschild vorgesehen, das ein Eichhorn zeigt ${ }^{68}$. Als Thema der Kuppelgestaltung nennt Madeleine de Scudéry die Aufnahme eines neuen Sterns in den Götterhimmel ${ }^{69}$. Der neue Stern wird durch eben den Wappenschild symbolisiert, der von Saturn emporgehoben und in die Sphäre ewigen Ruhms entrückt wird. Jupiter bekränzt den Neuankömmling mit einer goldenen Krone als Zeichen der Autorität, Mars überreicht ihm seine Stärke, symbolisiert durch einen Löwen und einen Helm $^{70}$. Merkur, Venus und andere Gottheiten betrachten die Szene mit Wohlwollen. Doch damit nicht genug. Nicht nur durch sein Wappenschild wird Fouquet in diesem Gemälde dargestellt. Nicht nur die Eigenschaften des Göttertrios Saturn, Jupiter und Mars werden ihm zugeordnet. Mlle de Scudéry geht noch einen Schritt weiter, indem sie Fouquet mit Apollon vergleicht und die dem Sonnengott zugeschriebenen Eigenschaften Vernunft und Intelligenz auf den Schlossherrn überträgt: »I'ay à vous dire que le Soleil represente Cleonime [Fouquet], qui selon l'estenduë de ses grands employs; fait tout, luit par tout, fait du bien à tout, \& trauaille continuellement pour l'vtilité \& l'embelissement de l'Vnivers «"11. Doch scheint diese doppelte Präsenz des Hausherrn in der Interpretation der Romanautorin überzogen. Sie passt zudem nicht wirklich in die übrige Ikonographie des Schlosses, die immer auch einen Bezug zum König aufweist, als dessen treuer Diener sich Fouquet sieht. Es scheint daher wahrscheinlicher, dass der Sonnengott für den König selbst steht, der die Aufnahme Fouquets in den Götterhimmel anordnet. Dies ist umso wahrscheinlicher, da Ludwig XIV. sich seit jungen Jahren mit dem Gott der Musen verglich und seine Ballettkostüme ihn als Apollon zeigten.

Der Aufstieg Fouquets in den Götterhimmel und seine Glorifizierung sind nicht zeitlich begrenzt. Die das Zentrum umgebenden vier Figurengruppen werden von den allegorischen Darstellungen der Jahreszeiten angeführt. Umringt werden diese von Personifikationen der Monate und Winde, die der jeweiligen Jahreszeit angehören, und von den Verkörperungen von Wochen, Tagen und Stunden. Doch erst die Darstellung der Schlange am Kuppelfuß, auf der die Zeitallegorien sitzen, versinnbildlicht in Gänze den Gedanken des Jahresablaufs: Die sich in den eigenen Schwanz beißende Schlange symbolisiert die ewige Wiederkehr des Jahres. Die dargestellte Handlung wird durch sie ein Akt für die Ewigkeit. Nicolas Fouquet wird zum ewigen Helden.

68 Auf dem Stich von Audran wurde das Wappentier Fouquets durch eine Lilie ersetzt. Aus der Beschreibung Madeleine de Scudérys wissen wir aber, dass es ursprünglich ein Eichhorn trug (ScudéRY, Clélie, Bd.X, S.1107). Kirchner vermutet, dass Le Brun das Projekt nach der Verhaftung Fouquets an einem anderen Ort verwirklicht sehen wollte: »Le Brun war ungemein an dem Projekt gelegen. Nach der Verhaftung von Fouquet bemühte er sich, wenn auch ohne Erfolg, das Projekt im Louvre zu realisieren. Diskutiert wurde der zwischen der Petite und der Grande Galerie gelegene Salon carré« (KIrCHNER, Held, S. 244).

69 Scudéry, Clélie, Bd.X, S.1106f.

70 Ibid., S.1107. Siehe auch: Montagu, Ceiling Decorations, S. 405.

71 Scudéry, Clélie, Bd.X, S.1112. 


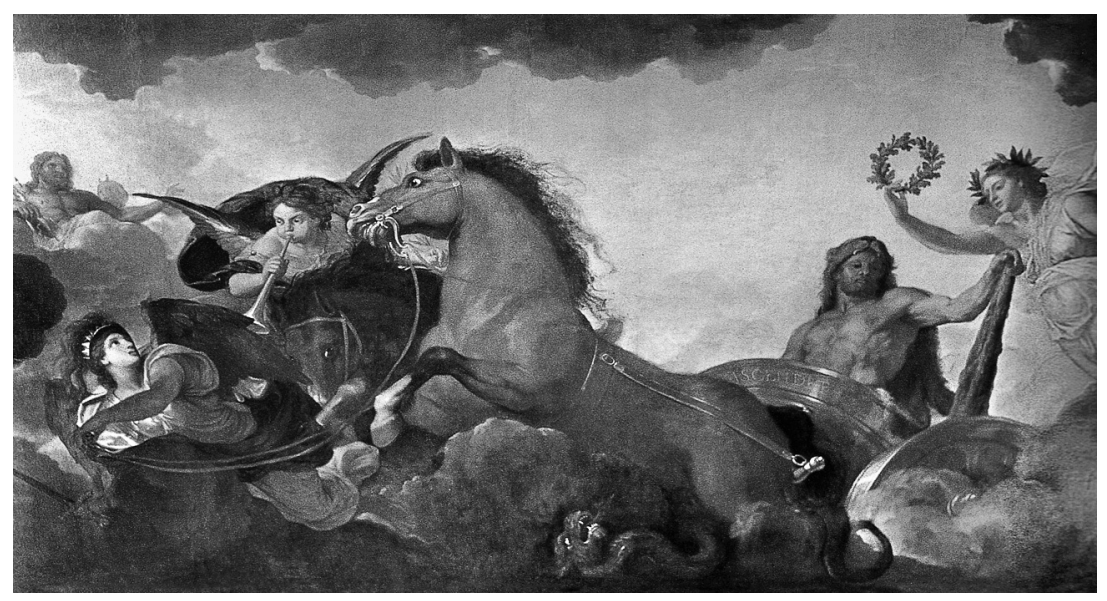

Abb.16: Zentrales Deckengemälde des salon d'Hercule. »Die Apotheose des Herkules« (Charles Le Brun).

Im Prunkappartement des Finanzministers finden sich die Gründe für die im Salon dargestellte Aufnahme Fouquets in den Götterhimmel ${ }^{72}$. Es schließt im Westen an den ovalen Salon an und besteht aus der antichambre (salon d'Hercule), der chambre (chambre des Muses) und dem cabinet (cabinet des Jeux).

Das Zentralbild der Decke des salon d'Hercule zeigt den auf einem goldenen Wagen stehenden Herkules, der zum Himmel auffährt, wo ihn Jupiter und andere Götter erwarten (Abb.16) ${ }^{73}$. Seine linke Hand hat er auf seine Keule gestützt. Hinter ihm erhebt sich die Allegorie des Ruhmes, die ihn mit einem Lorbeerkranz bekränzt. Der von Herkules geführte Wagen überfährt auf seinem Weg in den Himmel eine sich windende Schlange. Den Grund für die Apotheose des Herkules zeigt die linke Hälfte des Bildes, auf der die beiden Rosse des Heros, die die stärksten menschlichen Leidenschaften Liebe und Hass symbolisieren, von der Allegorie der Vernunft in Gestalt der Minerva gelenkt werden: »Le Peintre a judicieusement disposé la Raison à la teste de ces deux chevaux, afin qu'elle puisse observer tous leurs mouvemens \& leur servir comme d'une lumiere pour les éclairer parmy les nuages qui les environnent ${ }^{74}$. Der Aufstieg des Herkules wird von Fama durch einen Trompetenstoß bekanntgegeben. Die das zentrale Deckenbild rahmenden Gemälde zeigen die vier Temperamente als Ursachen der menschlichen Leiden-

72 Sowohl antichambre als auch chambre besitzen von ihrer ursprünglichen Wanddekoration nur noch die Vertäfelung, die Decken sind in diesen Räumen wie auch im cabinet in ihrer originalen Gestaltung erhalten.

73 Scudéry, Clélie, Bd.X, S.1114.

74 FÉlibien, Relations, Troisième relation, S. 44. 
Abb. 17: Zentrales Deckengemälde der chambre des Muses. »Triumph der Fidelitas"(Charles Le Brun).

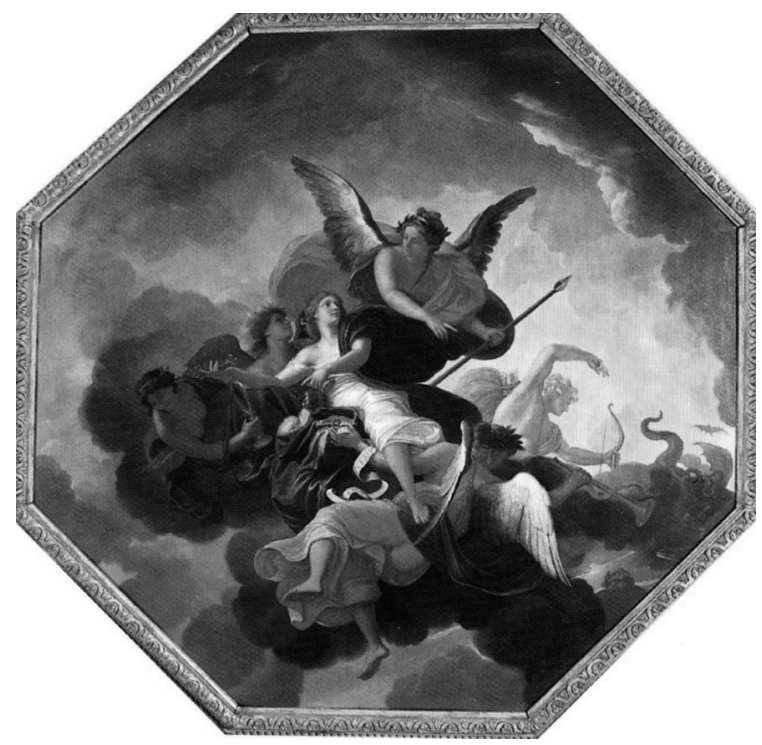

schaften. Ihre Darstellung erhöht die im Zentrum dargestellte Unterwerfung von Hass und Liebe durch Herkules zusätzlich. Wie es zu ihrer Bezwingung kommen konnte, wird in den Ecken der Kehle thematisiert, wo einige Taten des Herkules dargestellt sind ${ }^{75}$.

Der die menschlichen Leidenschaften bezwingende Herkules verdankt seine Stärke nicht in erster Linie seiner physischen Kraft, sondern der Vernunft (die auch die zwei Rösser lenkt) sowie seiner Weisheit, auf die er sich symbolisch in Gestalt der Keule stützt. Seiner Geistesstärke gelingt jedoch nicht allein die Bezwingung der Leidenschaften. Ihr verdankt der Held auch seinen Aufstieg in die himmlische Sphäre. Seine Fahrt in den Himmel kann selbst durch das Laster (die vom Wagen überrollte Schlange) nicht aufgehalten werden. Herkules bezwingt seine Affekte mit Hilfe der Vernunft. Die Darstellung formuliert damit eine wichtige Herrschertugend: »Nous sommes incapables de gouverner les autres, si nous n'obëissons nous-mesmes à la raison « ${ }^{76}$.

Das Dargestellte kann wegen der auf dem oberen Wagenrand angebrachten Devise »Quo non ascendet? « mit dem Finanzminister in Verbindung gebracht werden. Félibien nennt als Thema des Zentralbildes die Verherrlichung des Geistes und der Tugend Fouquets, dargestellt in der Apotheose des Herkules: »Car le peintre, voulant faire voir son véritable héros victorieux de ses passions, il le représente sous la figure d'Hercule montant au ciel «77.

75 Siehe Anhang 1, S. 201.

76 FÉlibien, Relations, Troisième relation, S. 46; siehe auch: KirCHnER, Held, S. 238.

77 FÉlibien, Relations, Troisième relation, S. 44. 
Fouquet wird damit in der Dekoration der antichambre als tugendhafter Mann dargestellt, der - dank seiner Vernunft - Macht und Reichtum besitzt. Seine Vernunft verleiht ihm Geistesstärke und Überlegenheit, die im Zentralbild als gegenwärtiger und zugleich immerwährender Idealzustand verherrlicht werden.

Die Decke der chambre des Muses (Abb.17) zeigt in ihrer Mitte die von einer Figurengruppe emporgetragene, in Weiß gekleidete und mit ihren Attributen, dem Hund und dem Siegel, versehene Allegorie der Treue. Als Verkörperung der Vernunft geht Minerva der Treue voran und macht sie auf deren Wirkung, die Vertreibung der Feinde im Hintergrund durch Apollon, aufmerksam. Das Auftreten der Treue wird außerdem durch die ihr den Spiegel vorhaltende Figur der Prudentia als weise dargestellt. Emporgehoben wird die Treue von der beflügelten Geschichtsmuse Clio, welche ein um den linken Arm gewundenes Band mit der Devise des Hausherrn trägt, das den Aufstieg der Treue in direkten Zusammenhang mit Fouquet bringt. In der anderen Hand hält sie eine Trompete, die helfen soll, die Handlung kundzutun: »Cette Muse aide à la Fidelité pour l'éleuer au Ciel, \& tient une trompette pour publier qu'il n'y a rien où la fidelité de Cleonime [Fouquet] ne puisse atteindre $\ll^{78}$.

Die Verherrlichung von Fouquets Treue wird sowohl von Félibien als auch von Scudéry als Thema des Zentralbildes genannt ${ }^{79}$. Cordey vermutet, dass die Darstellung zeithistorische Züge besitzt und auf die treue Haltung Fouquets gegenüber der französischen Regierung während der Fronde anspielt ${ }^{80}$. Diese Annahme wird von den zeitgenössischen Autoren nicht bestätigt. Félibien zufolge steht Apollon jedoch für die geistige Gewandheit Fouquets, die eine indirekte Anspielung auf seine - den für die Krone glücklichen Ausgang der Fronde befördernde - Begabungen sein könnte ${ }^{81}$. Die Anwesenheit der Geschichtsmuse Clio soll jedoch nicht allein auf historische Begebenheiten bezogen werden. Für Félibien symbolisiert Clio die Kenntnis der Künste und Wissenschaften im Allgemeinen, die zum Aufstieg in den Himmel führen ${ }^{82}$.

Im Bereich der Kehle befinden sich, paarweise in den Ecken sitzend, die übrigen Musen. Im Gegensatz zu Clio besitzen sie keine Flügel, »da sie sich als Hüterinnen des Hauses nicht vom Schloss entfernen dürfen, um stets den-

\footnotetext{
78 Scudéry, Clélie, Bd.X, S. 1118.

79 Ibid., S.1116: »Mais enfin puis que vous le voulez, continua-t'il, ie vous diray que le fameux Meleandre [Le Brun] songeant touiours à la gloire de son Heros, a representé au haut de cette chambre la Fidelité, que son puissant genie esleve dans les Cieux«. Siehe auch: FÉLIBIEN, relations, Seconde relation, S.35.

80 Cordey, Vaux-le-Vicomte, S. 66.

81 Félibien, Relations, Seconde relation, S.36: „Cet Apollon qui chasse les Monstres ennemis de sa vertu, \& dissipe par la force de ses rayons tous les nuages qui l'environnent, represente assez bien la vivacité \& les lumières de l'Esprit de cet Homme illustre, qui penetre dans les choses les plus cachées, \& sçait discerner la vérité d'avec le mensonge«.

82 Ibid.: »Par la Muse Clio, le Peintre veut faire voir que la connoissance que ce Ministre à des Arts \& des Sciences, sert à pousser sa reputation jusques dans le Ciel«.
} 


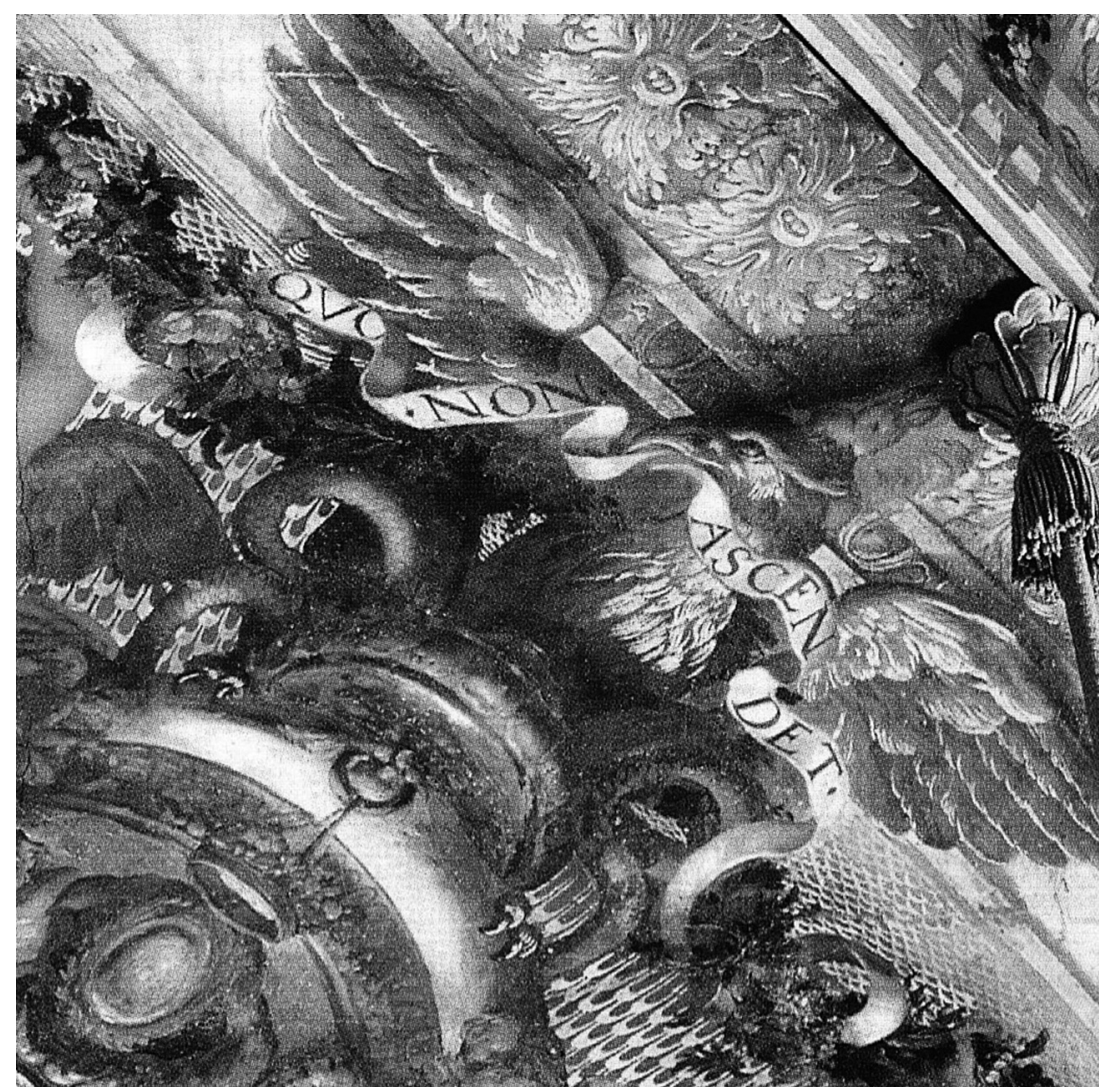

Abb. 18: Detail der Kehle, chambre des Muses.

jenigen zu preisen, der ihnen Unterkunft gewähre $«^{83}$. Die Gemälde über der Fensterwand und dem Alkoven zeigen die vergangene Bestrafung, die den Sirenen und Pieriden für ihre frevelhafte Herausforderung der Musen widerfuhr. Der Sieg der Musen ist in der auf den Medaillons der anderen beiden Kehlenseiten dargestellten Verkörperung der Viktoria und der Figur der Minerva, die hier als Beschützerin der Künste und Wissenschaften auftritt, verewigt. Die Kehle ist eine von Kunst und Wissenschaft beherrschte Zone. Dies wird von den Eckreliefs zwischen den Musenpaaren noch unterstrichen. Sie zeigen Symbole für die satyrische, die bukolische, die heroische und die lyrische Dichtkunst, die jeweils durch das sie rahmende Musenpaar repräsentiert werden. Die Treue Fouquets soll als eine Voraussetzung für die Entfaltung der Künste interpretiert werden. Zeigt die Zentraldarstellung das Ideal der

83 Kirchner, Held, S. 235. Siehe auch: Scudéry, Clélie, Bd.X, S. 1124 und FéLIBIEn, Relations, Seconde relation, S. 37. 
ewigen Treue Fouquets, so propagieren die Darstellungen der Kehle die reiche Kunstentfaltung als gegenwärtige Realität und Resultat der Treue. Die Musen verherrlichen Fouquet als den führenden Mäzen. Fouquet kann in diesem Sinne mit Apollon als Beschützer der Musen verglichen werden, auch wenn der Gott im Zentralbild nur eine Nebenrolle spielt. Die in den Ecken der Kehle zu findenden Eichhörnchen, die auf dem Kopf eines Adlers sitzen, der in seinem Schnabel das Devisenband Fouquets hält (Abb.18), stellen neben dem im zentralen Deckengemälde zu findenden Devisenband einen direkten Bezug des Raumthemas zu Fouquet her. So kann auch die Bestrafung der Konkurrentinnen der Musen auf Fouquets Stellung als Mäzen hinweisen: Wer sich mit ihm misst, den ereilt das Schicksal der Sirenen und Pieriden.

Doch die chambre des Muses dient nicht allein der Verherrlichung Fouquets. Sie kennzeichnet darüber hinaus - und natürlich als Folge der Taten des Hausherrn - Vaux-le-Vicomte als neuen Sitz der Musen, der in La Fontaines »Songe de Vaux« thematisiert wird:

Quoi? je vous trouve ici, mes divines maitresses!

De vos monts écartés vous cesses d'être hôtesses!

Quel charme ont eu pour vous les lambris que je vois?

Vous aimiez, disoit-on, le silence des bois?

[...] Oronte [Fouquet], dit Ariste, occupe leurs esprits:

Tantôt dans les forêts, tantôt sous les lambris,

Elles font résonner sa gloire et son mérite.

Voyez comme pour luy Melpomène médite ${ }^{84}$.

Das cabinet bildet den Abschluss des appartement von Nicolas Fouquet. Das Zentralbild (Abb.19) zeigt die Personifikation des Schlafes, die auf den Charakter des Raumes als Ort der Ruhe verweist. Die spielenden Putten könnten andeuten, dass das cabinet für alle Arten der Spielfreuden gedacht war, die sich im Hause Fouquets allgemeiner Beliebtheit erfreuten ${ }^{85}$.

Auffällig und in der Literatur mehrmals diskutiert ist das Motiv des vor einer Schlange fliehenden Eichhorns in der Deckenwölbung des cabinet (Abb. 20) ${ }^{86}$.

Hinter der Schlange, die meist als Natter, das Wappentier Colberts, interpretiert wird, blickt ein Löwe, Symbol der königlichen Macht, auf die Verfolgungsszene. Die Wappentiere Fouquets und Colberts im cabinet des Jeux wurden bislang als Hinweis auf deren Feindschaft interpretiert, die sich seit Mitte der fünfziger Jahre verschärfte und von der sich der Finanzminister bedroht fühlte ${ }^{87}$. Die Darstellung könnte demnach Ausdruck der Hoffnung

84 La Fontaine, Euvres complètes I, Bd. VIII, S. 278.

85 Auch in den Rechnungen wird das Cabinet als »cabinet à jouer « aufgeführt (CORDEY, Vaux-le-Vicomte, Dokument V, S. 208). Zum Spielgenuss bei den Fouquets: siehe Kapitel 2.3 .

${ }^{86}$ Fournier-Sarlovèze, Vaux-le-Vicomte, S.406; Chatelain, Foucquet, S.395 (allgemein); Cordey, Vaux-le-Vicomte, S.70; Demoriane, Le Brun, S. 89.

${ }^{87}$ Einzig Peyre und Sütterlin bezweifeln die Annahme, dass Fouquet in seinem Schloss auf seine Bedrohung durch Colbert verweisen wollte. Peyre vertritt die Meinung, dass 
Abb.19: Zentrales Deckengemälde des cabinet des Jeux. "Allegorie des Schlafes « (Charles Le Brun).
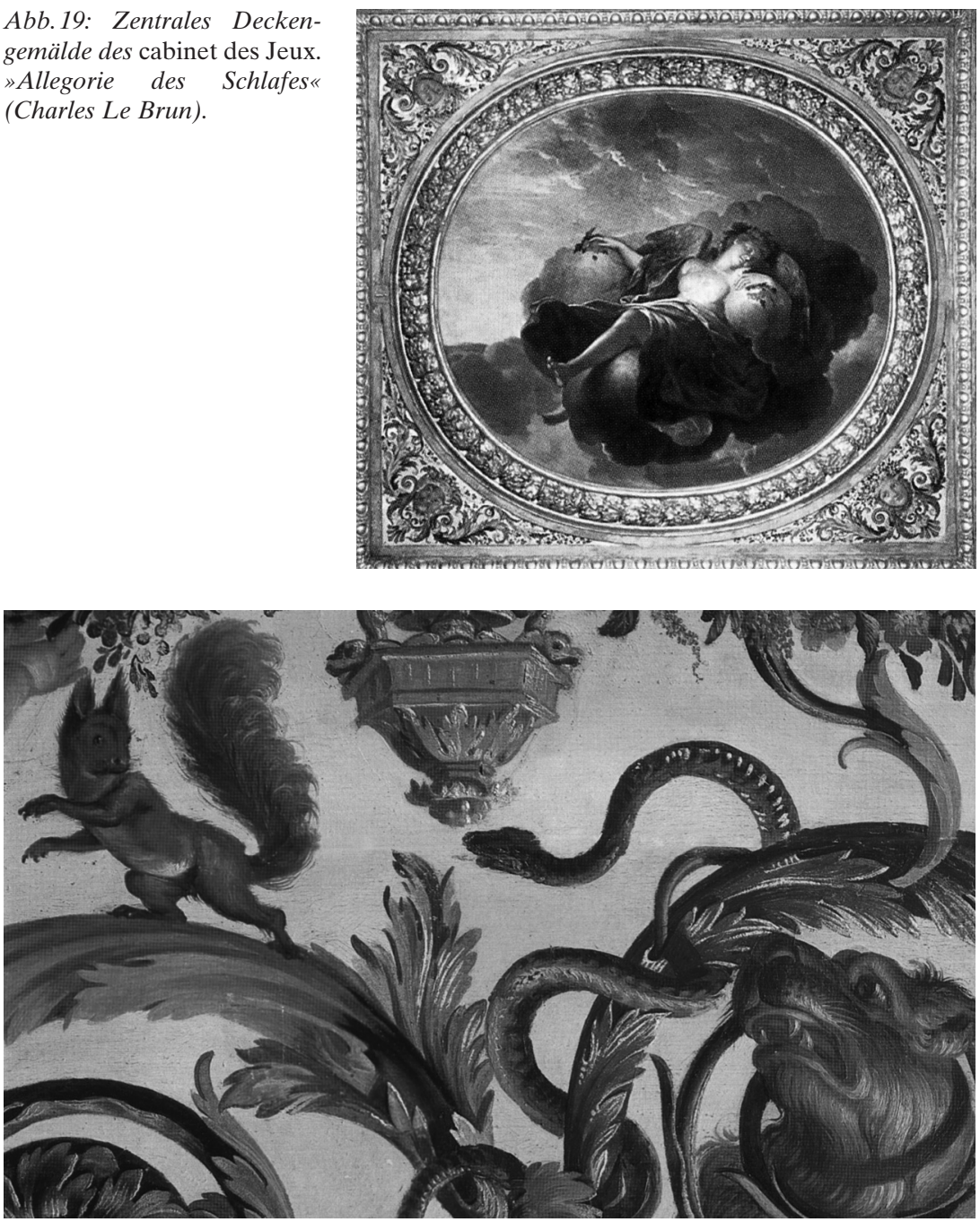

Abb.20: Detail der Deckenbemalung, cabinet des Jeux.

Colbert zum Zeitpunkt der Entstehung der Dekoration in Vaux-le-Vicomte längst nicht die Bedeutung hatte, die ihm durch eine solche Anspielung zuteil geworden wäre (PEYRE, Galeries célèbres, S.1052f.). Sütterlin weist darauf hin, dass das Eichhorn in dieser Haltung auch ohne Schlange im Schloss immer wieder erscheint, beispielsweise im Esszimmer oder in der chambre von Fouquet. Ihrer Meinung nach soll diese Haltung eher selbstbewusste Eleganz vermitteln, und dies auch im cabinet Fouquets, wo die Schlange nur zufällig das Eichhörnchen zu verfolgen scheint (SüTTERLIN, Le Brun, S. 79f.). Anders als in der salle à manger trifft das Eichhorn im cabinet aber auf die Schlange und den Löwen, eine Interaktion der drei Tiere ist wahrscheinlich. 
Fouquets sein, dass der König die Gefahr für das Eichhorn erkennen möge. Möglich ist jedoch auch eine Deutung, die in der Beschreibung Scudérys für den Salon zu finden ist: »ce serpent lumineux dont i'ay deja parlé, marque la prudence de ce Heros ${ }^{88}$. Das sich zur Schlange umblickende Eichhorn wäre demnach als Symbol für die Vorsicht Fouquets zu lesen. Die Präsenz des Löwen bezieht die Aktion auf die Staatsgeschäfte.

Die Deckengestaltung des königlichen Appartements blieb bis 1661 unvollendet $^{89}$. Da keine Entwurfszeichnungen aus dem Atelier Le Bruns überliefert sind, können für eine Analyse der Ikonographie dieses Appartements nur die Dekorationsfragmente als Quellenbasis dienen. Der Grund für den unvollendeten Zustand der Deckendekoration mag - neben der bereits vermuteten prioritären Ausgestaltung des Fouquetschen Appartements aus politischen Gründen - auch mit der Konzeption der Dekoration des königlichen Appartements selbst in Zusammenhang stehen. Der Überfluss an vergoldeten Stuckornamenten, die bis 1661 in den Räumen dieses Appartements angebracht wurden, ist ein Hinweis darauf, dass Le Brun für diesen Teil des Erdgeschosses eine wesentlich prunkvollere, dem König entsprechende Dekoration plante, die weit mehr Zeitaufwand erforderte als die Malereien der westlichen Räume ${ }^{90}$.

Eine »allegorisierende Aktualisierung « ist in den vor dem Sturz des Finanzministers bereits ausgeführten Deckenmalereien des appartement du Roi (Kehldarstellungen der antichambre, Deckenmalereien der chambre) nicht zu erkennen. Es ist aber davon auszugehen, dass hier - wie im benachbarten Appartement - der Bewohner Protagonist der Darstellungen sein sollte. Die bildlichen und skulpturalen Überreste müssen aus diesem Grund auf den König bezogen werden. Von den zeitgenössischen Autoren erwähnt einzig Nivelon auch die Arbeiten Le Bruns im appartement $d u$ Roi, aber nur am Rande und wenig ausführlich: »Le second appartement a été décoré, sur les dessins qu'il [Le Brun] en a donnés, de tous les ornements qui sont très riches ${ }{ }^{91}$.

\footnotetext{
88 ScUdÉRY, Clélie, Bd.X, S.1112f.

${ }^{89} \mathrm{Im}$ cabinet war bis 1661 lediglich ein Teil der Stuckdekoration angebracht. Auf eine Interpretation wird daher an dieser Stelle verzichtet. Zum cabinet: siehe Anhang 1, S. 206.

90 Das Stuckdekor der chambre du Roi wurde ab 1659 von Nicolas Legendre (1619-1671) und François Girardon (1628-1715) ausgeführt. Guillet dE SAint-George, Mémoires, Bd. I, S. 411 schreibt in seinen Mémoiren: »M. Le Brun, qui en 1659 étant prêt à travailler au château de Vaux le Vicomte, [...] y emmena M. Legendre, et l'employa à tous les ornements de stuc qui sont aux plafonds des appartements de Vaux«. Am 17. September 1661 unterschrieb Legendre eine Quittung über 470lt, die ihm und Girardon von Le Brun für ihre Arbeiten in Vaux gezahlt wurden (Archives de Vaux-le-Vicomte, siehe Cordey, Vauxle-Vicomte, S.236). In der chambre du Roi kann den beiden Skulpteuren der Eckstuck eindeutig zugeordnet werden: zwei beflügelte Frauenfiguren, die die Konsole mit ihren Händen zu tragen scheinen. In ihrer Mitte ein Kind, das auf dem oktogonalen Rahmen eines Eckgemäldes sitzt. Zu Füßen der Frauen befinden sich zwei Löwen.

91 Nivelon, Le Brun, S. 259f.
} 


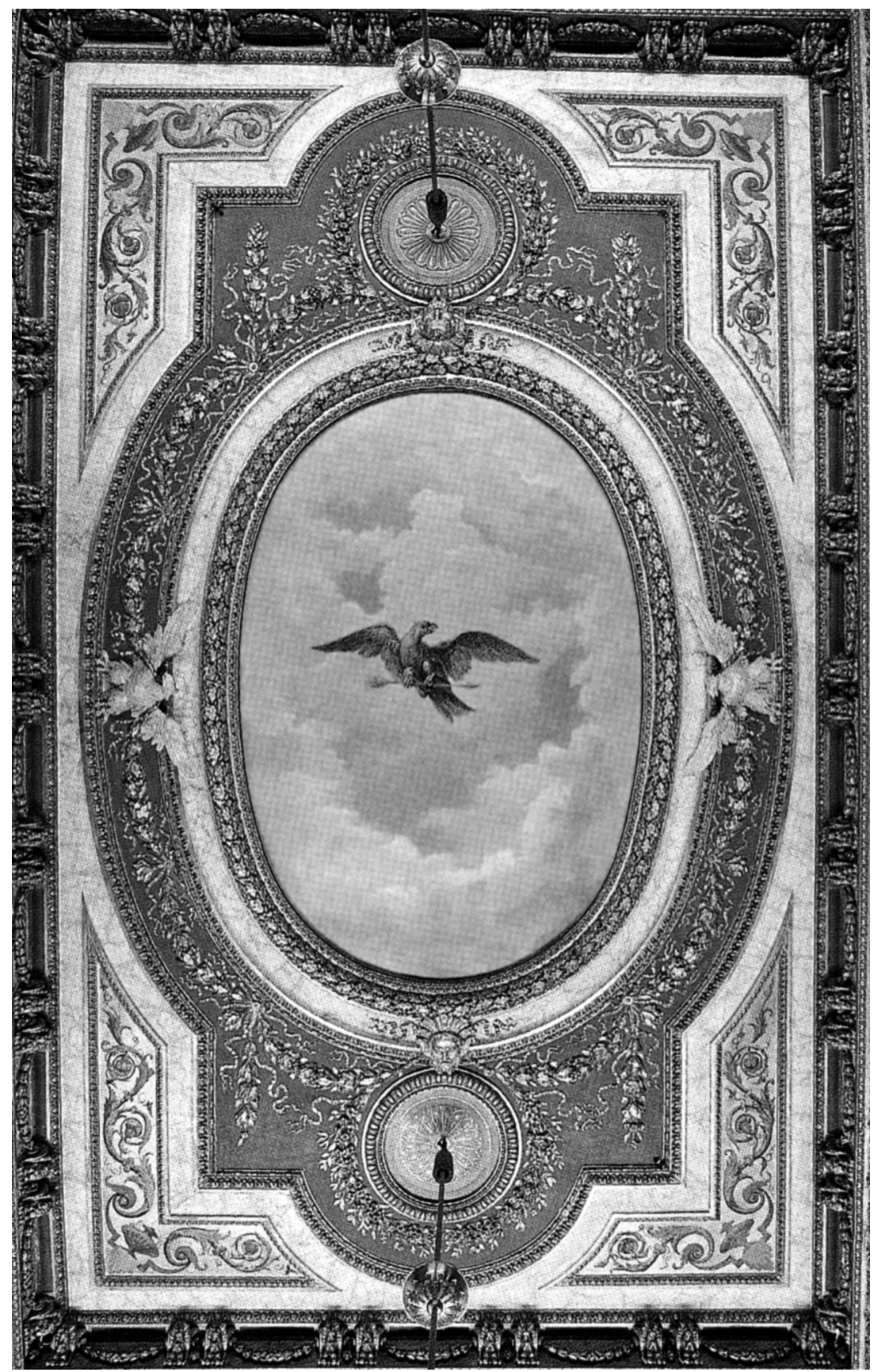

Abb.21: Zentrales Deckengemälde der antichambre du Roi. 


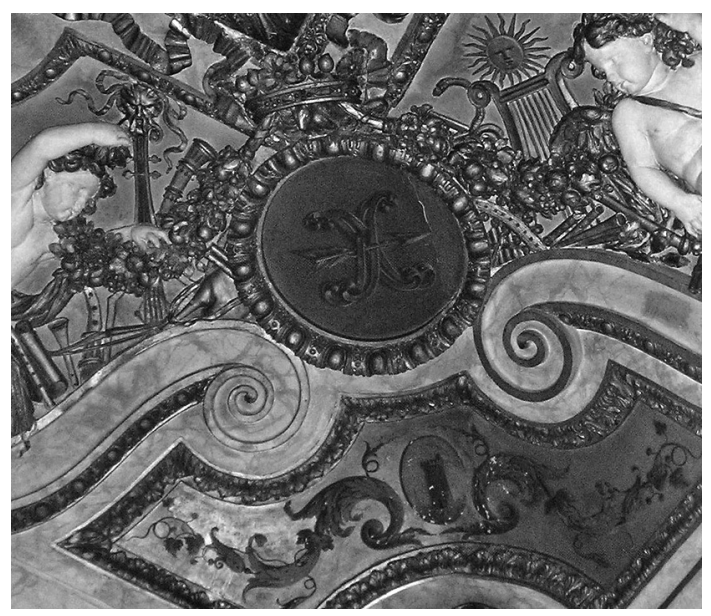

Abb.22: Detail der Kehlecken, antichambre du Roi.

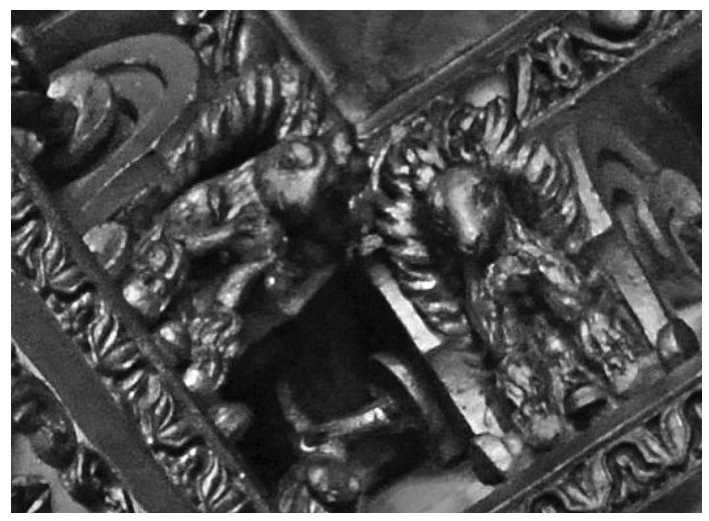

Abb.23: Konsolfries, antichambre du Roi.

In der antichambre ist ein klar bestimmbarer Inhalt wegen des Fehlens des originalen Zentralbildes sowie zeitgenössischer Beschreibungen nicht zu ermitteln ${ }^{92}$. Am Deckenspiegel finden sich in Form von Stuckadlern und einem Eichenkranz eindeutige Symbole der Macht (Abb.21). Die Putten der Kehlendarstellungen vermitteln den Eindruck von Verspieltheit und Gelöstheit. Sie unterstreichen den Charakter des Hauses als Rahmen für das königliche Divertissement. Das Gemälde der Nordseite zeigt einen Putto, der zusammen mit einem Adler mit den Blitzen des Jupiter davonfliegt. Auf der Südseite flieht ein weiterer Putto mit einer Weinranke vor einem Panther, Anspielungen auf Bacchus und auf die in Vaux zu erwartende ausgelassene Festlichkeit, der sich der König - losgelöst von den Staatsgeschäften - hingeben sollte.

92 Die heute im Zentrum zu sehende Darstellung eines in der Luft schwebenden Adlers wurde erst nach der Verhaftung des Schlossherrn eingefügt. 
An den Langseiten ist im Westen Diana nach der Jagd zu sehen, die auf die vom König favorisierte Zerstreuung anspielt. Zu ihr gehören die Enten und Pfauen in den Kehlenöffnungen. Die Adler (Jupiter) und Pfauen (Juno) in den übrigen Öffnungen könnten hingegen wieder auf das Thema Macht und Reichtum anspielen. Im Osten sind Mars und Venus zu sehen, die ein weiteres Mal darauf hinweisen, dass für den König in Vaux-le-Vicomte die Regierungsgeschäfte ruhen sollten: »Zusammen mit der Deutung des Deckenspiegels kann die gesamte Deckendekoration zum Ausdruck bringen, dass der französische König in Vaux-le-Vicomte die Rolle des politisch handelnden Souveräns ruhen lassen kann, während seine Autorität als Monarch dennoch unangefochten bestehen bleibt $\ll^{93}$.

Die Dekoration der antichambre bezieht sich auf den König, den sie als machtvollen Herrscher darstellt. Sie spielt zugleich auf den Charakter von Vaux-le-Vicomte an, wo der junge Herrscher fernab der Regierungsgeschäfte Raum für allerlei Vergnügungen finden sollte. Doch auch der Hausherr ist auf dieser Seite des Salons nicht vergessen. Seine Initialen finden sich in den Medaillons der Kehlecken zusammen mit dem Wappen seiner zweiten Frau Marie-Madeleine de Castille (Abb.22). Zudem stützt ein aus einer endlosen Reihe von Eichhörnchen geformter Konsolfries den Deckenspiegel (Abb.23): Fouquet ist die tragende Kraft des Königreichs.

Das zentrale Deckengemälde der auf die antichambre folgenden chambre (Abb.24) wurde bereits vor 1661 angefertigt. Es zeigt als Hauptmotiv die in Weiß gekleidete Figur der Wahrheit, die von der Zeit in Gestalt des Saturn, der die Sense bei sich trägt und dessen Sanduhr von einem Putto gehalten wird, emporgetragen wird.

In den Kehlenfeldern finden sich Götter, von denen Jupiter die Macht, Merkur die Wachsamkeit, Mars die Tapferkeit und Vertumnus den Reichtum symbolisieren $^{94}$. Sütterlin zufolge erhält das Dargestellte durch den Bezug auf die französische Monarchie einen tieferen Sinn: Die Zentraldarstellung könne als Allegorie des Goldenen Zeitalters verstanden werden, dessen Herrscher Saturn einen der wichtigsten Werte dieses Zeitalters, die Wahrheit, emporträgt. Die Götterfiguren der Lünetten könnten, diesem Interpretationsansatz folgend, die herausragenden Herrschertugenden Ludwigs XIV. verkörpern ${ }^{95}$. Die Wahrheit, die die Herrschaft des jungen Königs charakterisiert, könnte in Bezug auf die politische Situation Fouquets der Hoffnung des Finanzministers Ausdruck geben, keinen politischen Intrigen zu erliegen. Doch eine andere Interpretation wäre ebenso denkbar: Montagu nennt als Thema des Zentralbildes ebenfalls das neue Goldene Zeitalter, das mit der Regierungs-

93 SütTerlin, Le Brun, S. 47.

${ }^{94}$ Hinter Vertumnus greift ein Putto in den Rachen des Löwen, nach RIPA, Iconologie, $1^{\text {re }}$ partie, S.51f. ein Symbol für Großmut und Freigebigkeit.

95 SÜTterLin, Le Brun, S. 53. 


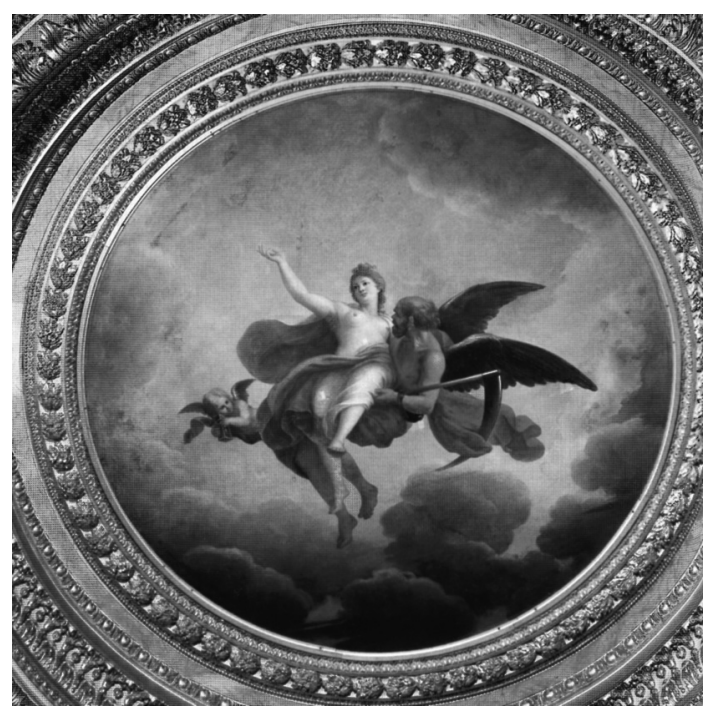

Abb.24: Zentrales Deckengemälde der chambre du Roi. »Triumph der Wahrheit« (Charles Le Brun).

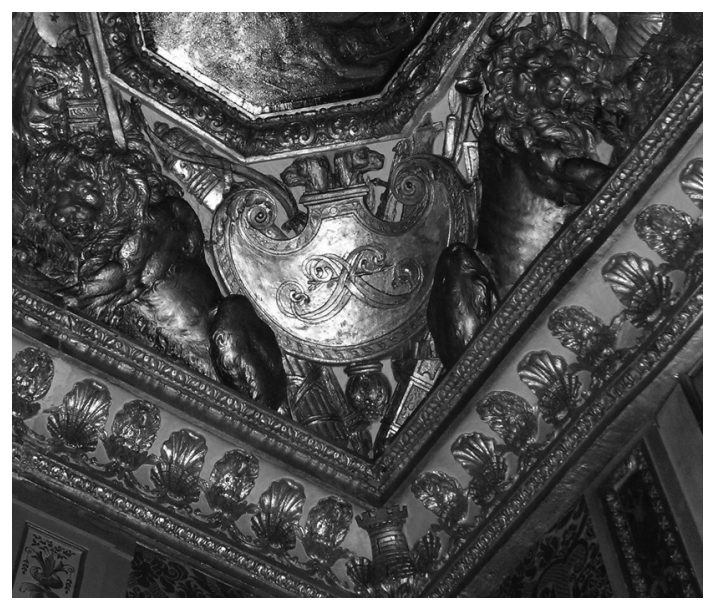

Abb.25: Kehlecke und Eichhörnchenkonsole, chambre du Roi.

übernahme durch Ludwig XIV. anbricht ${ }^{96}$. Sie sieht in der von Saturn emporgetragenen Figur jedoch nicht die Allegorie der Wahrheit, sondern Themis, die Göttin der Gerechtigkeit und der Ordnung. Die Götter der Kehle stellen ihrer Meinung nach die vorangegangenen Zeitalter dar. Jupiter steht für das Silberne, Merkur für das Eiserne, Mars für das Eherne und Vertumnus für das erste Goldene Zeitalter ${ }^{97}$. Die Vergoldung des Stuckdekors steht in Bezie-

96 Montagu, Ceiling Decorations, S. 405.

97 SÜTTERLIN, Le Brun, S.119, Anmerkung 154: »Diese Interpretation berücksichtigt allerdings nicht, in welchem Sinn Le Brun die beiden Gestaltungsprinzipien der Deckenmale- 
Abb.26: Wanddetail, salle à manger.

Abb.27: Zentrales Deckengemälde der salle à manger. »Einkehr des Friedens und des Überflusses« (Charles Le Brun).
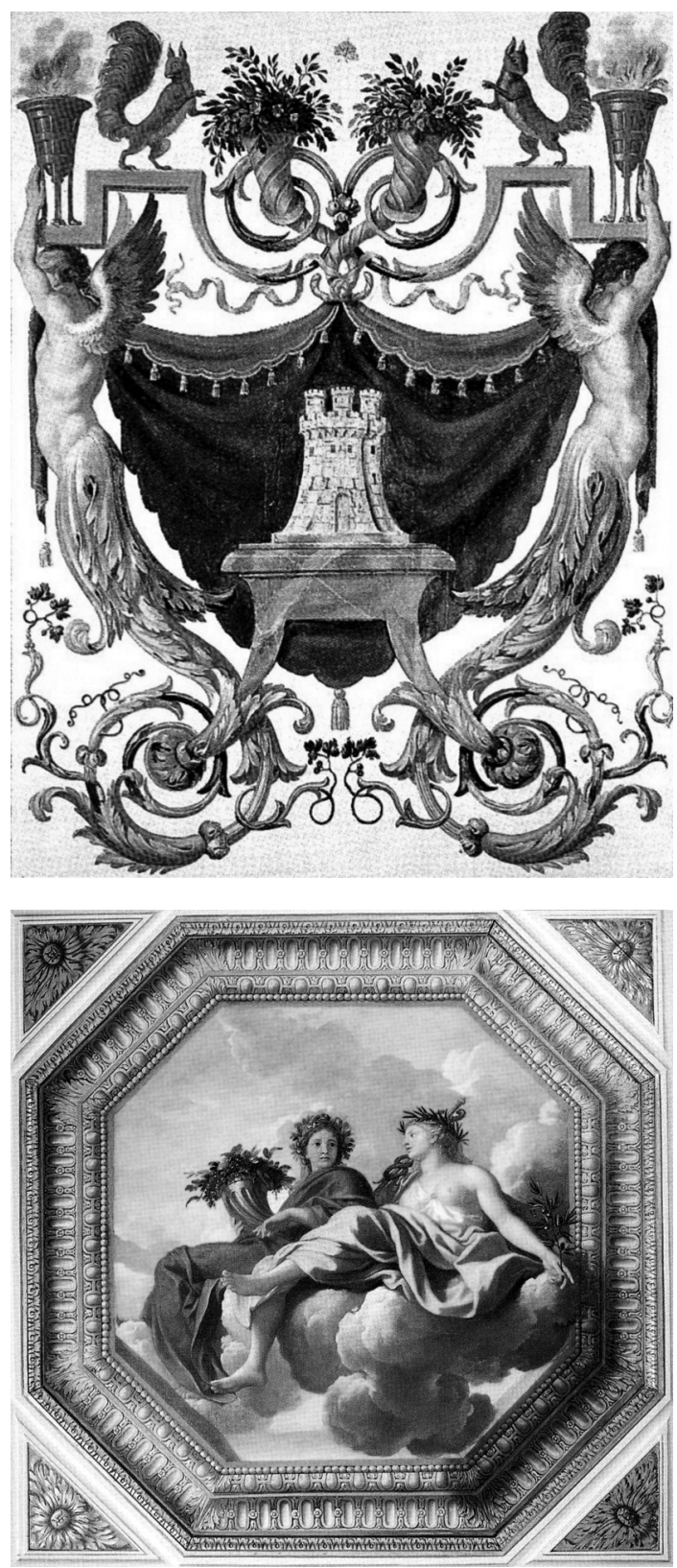

rei einsetzte. Bisher nahmen Darstellungen, die dem Prinzip der >quadratura < folgten, immer einen Bezug auf die Gegenwart Fouquets. Daher können die Götterdarstellungen nicht Montagus Interpretation entsprechen. Auch die Uminterpretation der Figur der Wahrheit als Themis macht eine Deutung unnötig kompliziert«. 
hung zu dem Thema der Decke. Der Hausherr ist auch in diesem Raum mit seinen Initialen und in Form unzähliger Eichhörnchen präsent, die sich in den Konsolen tummeln (Abb.25).

Im Norden grenzen zwei Räume an die Prunkappartements des Erdgeschosses ${ }^{98}$. Sie ergänzen die ikonographischen Programme der Zimmer, an die sie anschließen. Zugleich nehmen sie ein wichtiges Sujet des Vorhofes wieder auf und dienen damit als Verbindungsglied zwischen dem ersten und dem zweiten Raum von Vaux.

Nördlich des Fouquetschen Appartements im Erdgeschoss befindet sich die Grande Chambre carrée, die dem surintendant des Finances - wie man heute vermutet - als Arbeitszimmer diente ${ }^{99}$. Von der ursprünglichen Wandgestaltung ist nur der Paneelsockel erhalten, über dem bis zur Verhaftung Fouquets sechs Tapisserien mit der Geschichte der Iphigenie hingen. Die Deckengestaltung folgt ganz den Gestaltungsvorgaben der französischen Renaissance, die zur Zeit Fouquets eigentlich bereits aus der Mode gekommen war und so gar nicht zu der Modernität der übrigen Räumlichkeiten von Vaux passen mag. Sie trägt zur dunklen, schweren und altertümlichen Erscheinung des Raumes bei. Die braunen, mit einer feinen gold-blauen Musterung versehenen Balken der Decke sind in enger Abfolge hintereinander gestaffelt und liegen auf zwei Querbalken auf.

Die Dekoration der salle à manger, die im Norden an das appartement $d u$ $R o i$ anschließt, ist vollständig erhalten. Die Wände sind mit Holzpaneelen getäfelt, die mit Grotesken bemalt sind.

Die Deckengestaltung wird, wie bereits die Räume der Appartements, von einem Zentralgemälde dominiert, welches auch das Thema des Raumes vorgibt (Abb.27).

Dargestellt ist die Personifikation des Friedens, die die sich noch etwas zierende Figur des Überflusses mit sich führt (»Einkehr des Friedens und des Überflusses«). Das Bild symbolisiert den Beginn des ewigen Friedens und Reichtums, der auch in den übrigen Darstellungen des Raumes thematisiert wird (siehe Anhang 1). Die unmittelbare Nähe zum königlichen Appartement setzt das Thema in Bezug zu Frankreich und seinem Herrscher. Auch ein Verweis auf die kriegerischen Wirren der vergangenen Jahre (die Fronde und den Krieg mit Spanien) fehlt nicht ${ }^{100}$.

\footnotetext{
98 Es existieren keine zeitgenössischen Beschreibungen dieser beiden Zimmer.

99 Der wahre Zweck des Raumes ist nicht bekannt. SüTTERLIN, Le Brun, S. 61 vergleicht die strenge Raumgestaltung mit der salle des gardes in Fontainebleau und vermutet, dass der Raum der gelegentlichen Abwicklung von Staatsgeschäften diente, für die er eine Umgebung in angemessener Sachlichkeit geboten hätte.

100 Die sich an den Seiten des Zentralbildes gegenüberliegenden Reliefdarstellungen entsprechen sich farblich und können auch inhaltlich als Paar aufgefasst werden. Süd- und Nordseite, die zum einen Luna in ihrem Wagen mit den Tauschwestern zeigt und zum anderen Meerwesen in dem ihnen zugeordneten Element, wo die Sonne in Gestalt des Apollon nach antiker Vorstellung während der Nacht verbleibt (OvID, Met. IV, Z.197-200),
} 
Chambre carrée und Esszimmer ergänzen die Ikonographie der an sie grenzenden appartements. Das appartement du Roi soll den König dem Vergnügen zuführen, dem er in Vaux, fern von allen Staatsaufgaben, frönen kann. In unmittelbarer Nähe zum König thematisiert die salle à manger die Zeit des Friedens und des Überflusses, die nun nach Beendigung der Kriege, bei denen der Finanzminister eine entscheidende Rolle gespielt hat, anbrechen kann. Fouquets Appartement hingegen wird im Norden, wo kühles Licht dem nur mit einer Fensterfront versehenen Raum eine strenge Wirkung gibt, von einem Arbeitszimmer ergänzt, welches Fouquet zur Abwicklung von Staatsgeschäften diente. Die ihn für diese Aufgabe qualifizierenden Tugenden sind in der Ikonographie des salon d'Hercule und der chambre des Muses dargelegt.

Sowohl das Esszimmer als auch die Chambre carrée nehmen darüber hinaus ein Thema des ersten Raumes von Vaux, des Vorhofs, wieder auf. Im ersten Zimmer ruft die Gliederung des Essbereiches und des an diesen anschließenden Buffets (Abb.28) mit der durch einen Bogen betonten Mitte und niedrigeren Seiten mit Durchgängen den Eindruck eines römischen Triumphbogens hervor (am nächsten kommt der hier gewählten Gliederung der Konstantinbogen). Die Supraporten, die in ihrer Form den Medaillons des antiken Bauwerks entsprechen, verstärken diesen Eindruck.

In der Chambre carrée ist unter der Decke ein Fries angebracht, auf dem der Triumphzug Konstantins dargestellt ist (Abb.29) ${ }^{101}$. Er wird in beiden Seitenmitten von den Wappen Fouquets und seiner Frau unterbrochen.

Die Dekoration des Obergeschosses - die nur zu einem kleinen Teil bis 1661 vollendet war - kann bei einer Betrachtung der politischen Botschaft der Schlossikonographie vernachlässigt werden, da hier die privaten Räume des

stehen für die Nacht. Im Osten und Westen, die vom Grün dominiert werden, ist Apollon auf seinem Wagen zu sehen. Die östliche Darstellung zeigt ihn vom Betrachter wegfahrend, während er auf der westlichen zusammen mit Flora abgebildet wird. Bei einer auf das Zentralbild bezogenen Interpretation könnte die Nacht die Zeit vor dem Frieden, also den Krieg, versinnbildlichen. Die beiden anderen Darstellungen könnten für die unmittelbaren Folgen des Krieges stehen, wobei der davonfahrende Apoll auf die Zerstörung durch den Krieg, Flora und Apoll dagegen auf einen Neuanfang nach dem Krieg verweisen könnten. So wird durch die vier Reliefs in verkürzter Form auf Wirren und Folgen des Krieges hingewiesen, was die Dramatik fast aller Darstellungen sinnfällig unterstreicht. Die Thematik von Krieg und Frieden, die den Raum dominiert, wird in den Darstellungen über den Bögen, die Kriegsgeräte als Symbol für militärische Macht und Krieg sowie Früchte, Blumen und Schalen als Symbol für Frieden und Reichtum zeigen, ein weiteres Mal bildnerisch dargestellt (SüTterLIN, Le Brun, S.65f., siehe auch: Anhang 1, S.208f.).

101 Pérouse de Montclos, Vaux-le-Vicomte, S.168. Guillet de Saint-George, Mémoires, Bd. I, S. 20 beschreibt einen weiteren Entwurf zum gleichen Thema durch Le Brun: »Il avoit aussi préparé pour Vaux-le-Vicomte le dessin de l'Entrée triomphante de Constantin dans la ville de Rome, après la bataille que cet empereur gagna sur Maxence. [...] La bataille ni le triomphe n'ont pas été peints, mais M. Audran en a gravé les dessins«. 


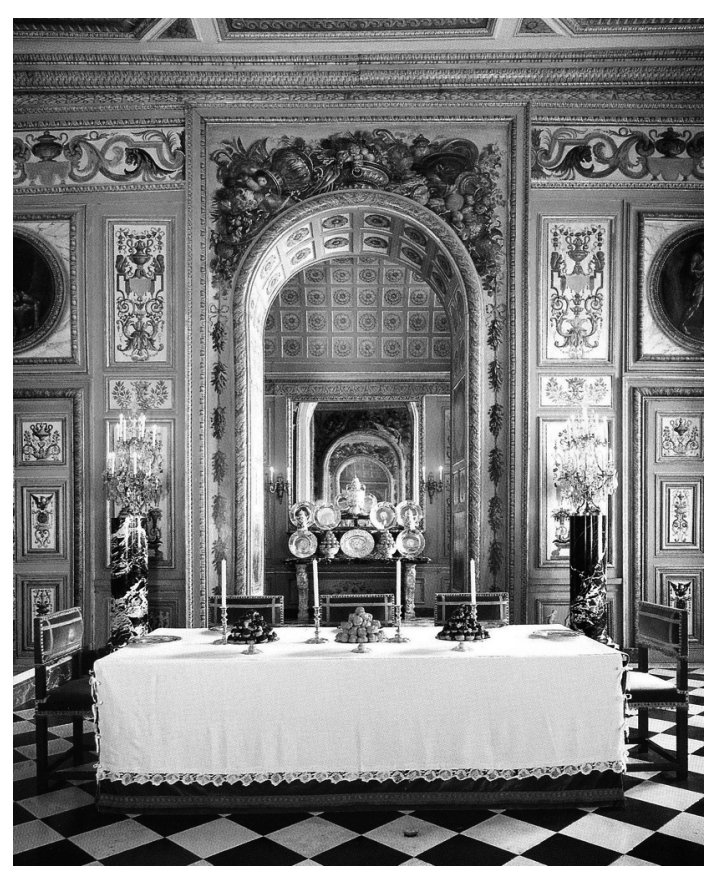

$A b b .28$ : salle à manger.

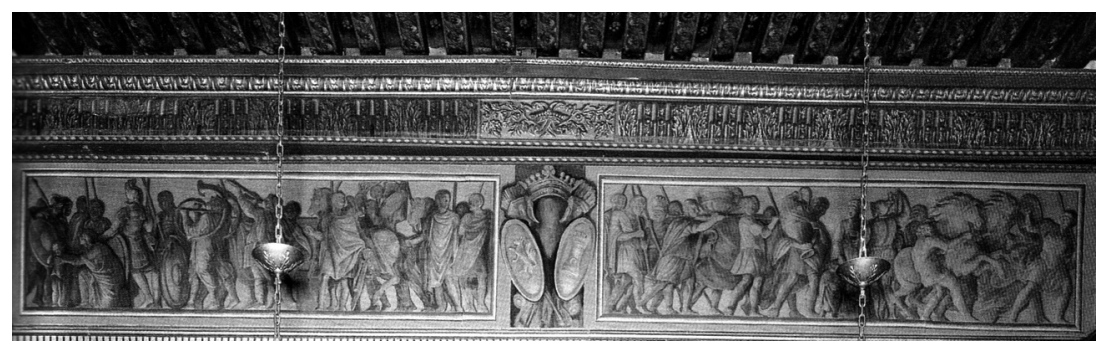

Abb.29: Fries, Chambre carrée.

Schlossherrn und seiner Familie untergebracht waren ${ }^{102}$. Aus diesem Grund sollen nur einige, für das Verständnis der Anlage wichtige Beobachtungen gemacht werden. Auffällig ist, dass sich die privaten Appartements sowohl Fouquets als auch seiner Frau auf der östlichen Seite des Schlosses (ersteres im Norden, das andere im Süden), also über dem appartement du Roi, befanden.

102 Es kommt hinzu, dass die Ausstattung der Räume zum Zeitpunkt des Sturzes von Fouquet noch nicht vollendet waren. Es existieren zudem keine zeitgenössischen Beschreibungen. Das appartement von Mme Fouquet wird im Inventar von 1661 als vergoldet, vertäfelt und bemalt beschrieben. Die chambre wie auch das cabinet besaßen zudem eine in dieser Zeit hochmoderne Spiegelverkleidung. Auf diese Räume wird im Folgenden nicht näher eingegangen. 


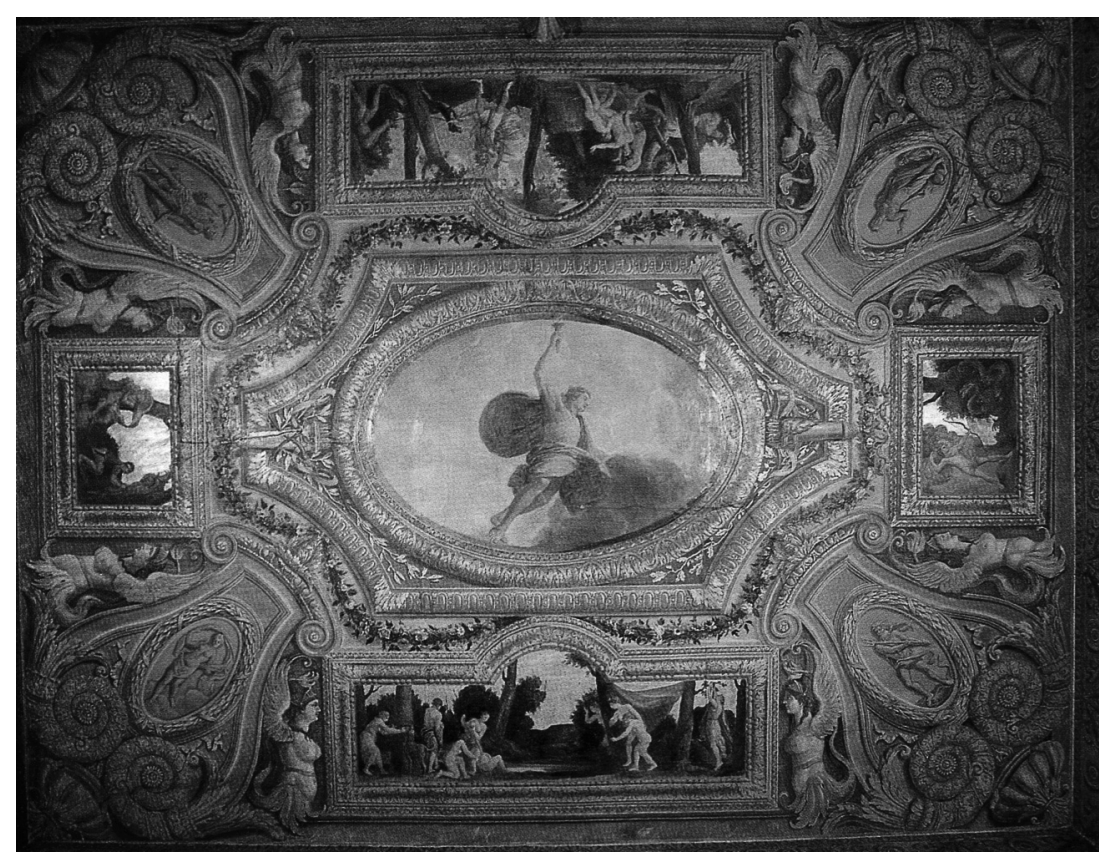

Abb.30: Zentrales Deckengemälde der chambre Fouquets »Apollo Helios«.

Ein Zugang zum königlichen Gast war mittels einer kleinen, zwischen den Appartements gelegenen Treppe vorgesehen. Die Nähe zum Monarchen sollte mit dieser architektonischen Disposition hergestellt werden ${ }^{103}$. Die Dekoration des privaten Appartements von Fouquet war 1661 bereits fortgeschritten. Sie wirkt weniger modern als die des Erdgeschosses. Auf persönliche Bezüge mittels Emblemen oder Devisen wurde gänzlich verzichtet. Interessant ist, dass im Schlafzimmer Fouquets die Apollon-Thematik wieder aufgenommen worden ist. Das große Deckenfeld zeigt den Sonnengott, der mit seiner Fackel den Raum erhellt.

Er wird an den Schmalseiten von Lorbeer eingefasst, der seine Taten erhöht. Seine Fackel lässt nicht nur den Raum, sondern auch die in den das Zentralbild einfassenden Medaillons dargestellten Götter erleuchten, welche die Elemente versinnbildlichen und damit die ewige Ordnung der Welt darstellen. Jupiter steht für das Feuer, Kybele für die Erde, Juno für die Luft und

103 Eine ähnliche Raumaufteilung findet sich auch in anderen Schlössern, die eine chambre oder ein appartement für den König eingerichtet haben. So verfügt das in Maisons für den Erbauer in einem Zwischengeschoss eingerichtete private appartement über einen direkten Zugang zur königlichen chambre. 
Neptun für das Wasser ${ }^{104}$. Da erst das Licht des Apollon diese Elemente sichtbar macht, wird der Sonnengott als allmächtiger Garant dieser Ordnung charakterisiert. Apollon steht demnach für die Erhellung der Welt und die Wahrung der Ordnung. Die Seitengemälde stellen die mit dieser Erhellung aufgedeckten Übel der Welt dar, die die Ordnung bedrohen und von Apollon bekämpft werden müssen. An den Schmalseiten sind die Häutung des Marsyas und die Tötung des Pythondrachen durch Apollon zu sehen, während die Langseiten Apollons Schwester Diana und die Verwandlung des Aktäon sowie die Entdeckung der Schwangerschaft Kallistos darstellen. Alle Gemälde zeigen das Aufdecken von Übeln, zumeist aber bereits deren Bestrafung, die zur Wahrung der Ordnung notwendig ist. Hierbei propagieren die beiden Bilder mit Apollon, dass Ordnung nur durch Vernunft garantiert ist, denn Apollon bestraft bzw. tötet in beiden Fällen unvernünftig Handelnde.

Es finden sich in dem Dargestellten keine Bezüge zu Fouquet. Da Apollon als Helios allgemein als Symbol des Königs galt, der sich seit den Ballettauftritten von 1651 und 1659 als Sonnenkönig mit diesem Gott verglich, muss man davon ausgehen, dass sich das Dargestellte allein auf die Allmächtigkeit des Königs bezieht. Die bereits im ovalen Salon dargestellte Apoll-Licht-Vernunft-Thematik findet sich also im privatesten Raum des Schlosses wieder. Diese Wiederaufnahme unterstreicht die unbedingte Loyalität Fouquets gegenüber dem jungen Herrscher.

Das Schlossinnere, den zweiten Raum der ganzen Anlage, nutzt der Finanzminister für die Darlegung seiner Vorzüge und Fähigkeiten. Seinem Prunkappartement kommt dabei die Aufgabe zu, seine Person selbst in Szene zu setzen, während dem König in dem ihm gewidmeten Appartement die Vorzüge einer Herrschaft vorgestellt werden, deren Hauptstütze Fouquet ist. Der Hausherr gibt sich im salon d'Hercule zunächst als tugendhafter Emporkömmling zu erkennen, der seinen Erfolg (die Zügelung der menschlichen Leidenschaften) seiner Vernunft (Minerva) und Weisheit (Keule) zu verdanken hat. Die anschließende chambre des Muses feiert das Ergebnis von Fouquets Treue, die von der Vernunft und der Vorsicht getragen wird. Nicolas Fouquet ist als treuer und vernünftiger Minister der Mann, den man in den Götterhimmel aufnehmen sollte (salon), um ihn an der Leitung der Welt teilhaben zu lassen. Lässt der König diese Wahrheit in seinem Reich regieren (chambre du Roi), so steht ihm ein goldenes Zeitalter in Frieden und Überfluss (salle à manger) bevor. Überall bleibt das Eichhorn präsent, welches als Konsolenfries (antichambre und chambre du Roi) und Dekorationselement der Wandvertäfelung (salle à manger, Abb.26) das kommende goldene Zeitalter stützt. Die Lobpreisung des französischen Königtums und der Macht Frankreichs treten hinter der starken Präsenz des Finanzministers in der Ikonographie der Innendekoration zurück. Diese Interpretation wird von der literarischen Propaganda Félibiens, La Fontaines und Scudérys untermauert.

104 Cordey, Vaux-le-Vicomte, S. 80. 
Die zeitgenössischen Schriften zu Vaux-le-Vicomte erwähnen den Herrscher nur am Rande. Für sie steht Fouquet im Mittelpunkt der Gemälde von Vaux. Einen stärkeren Bezug der Darstellungen zum König würde die Bildaussage jedoch nur unterstützen. Die Botschaft wäre umso schlüssiger. Im Salon würde der König in der Gestalt des Sonnengottes die Aufnahme Fouquets in den Götterhimmel anordnen (siehe S.107). Ein Aufstieg des Finanzministers wäre demnach auf den König selbst zurückzuführen.

Im salon d'Hercule könnte man den König (und nicht Fouquet) in der Person des Herkules vermuten, mit dem sich viele Herrscher gerne verglichen. In diesem Raum fährt Herkules auf einem Wagen in den Himmel auf, der die Devise des Finanzministers trägt. Der Wagen wäre dieser Interpretation zufolge ein Symbol für Nicolas Fouquet und seine Loyalität gegenüber der Krone. Er trägt den Herrscher und unterstützt ihn bei seinen Taten. In der chambre des Muses findet sich erneut die Figur des Apollon im zentralen Deckengemälde. Hier bleibt der Sonnengott jedoch im Hintergrund und spielt eine nebengeordnete Rolle. Er vertreibt die Feinde und Ungeheuer, die die Treue bedrohen. Nimmt man die Ikonographie des anschließenden cabinet voraus, so könnte man auch hier in der Figur des Apollon den König entdecken, der die Treue (Fouquet) beschützt und ihr den Weg für ihren Aufstieg frei macht. In Hinblick auf die Ambitionen des Finanzministers und die Ränke seiner Gegner würde eine solche Interpretation sich wunderbar in die Intentionen des Hausherrn fügen.

\subsection{Der dritte Raum: der Garten}

Im 17. Jahrhundert ist der Garten zum einen Ausdruck von Pracht und Reichtum und zum anderen ein Ort fern des Alltags, ein Ort der Verzauberung und der Abgeschiedenheit, bevölkert von Figuren der Mythologie und der Pastorale ${ }^{105}$.

Der Garten von Vaux-le-Vicomte vereint beides und erstaunt zudem durch seine exquisite Raffinesse. Erstmals erhielt hier ein Gartenarchitekt die Möglichkeit einer umfassenden Planung und Gestaltung, überliefert in dem heute in der Bibliothek des Institut de France verwahrten Plan von André Le Nôtre (Abb.31) ${ }^{106}$.

Neben dem Entwurf des Gartenarchitekten gibt es weitere zeitgenössische Quellen zur Gartenanlage: Ein nach einer Zeichnung Israël Silvestres angefertigter Gesamtplan ${ }^{107}$ sowie zwölf Stiche und drei Zeichnungen von Sil-

105 Krause, Maison de plaisance, S.7. Der lieu enchanté wird nach 1661 von Ludwig XIV. in seinen Festen inszeniert: Les Plaisirs de l'île enchantée (1664); Le Grand Divertissement royal de Versailles (1668); Les Divertissements de Versailles (1674).

106 Bibliothèque de l'Institut de France, ms. 1040, fol. 14.

107 Den Plan datiert Brix, Garten, S.167f. auf die Jahre 1657/58. Poulin, Silvestre, S. 23 (Anm.17) vermutet, dass es sich bei dem Plan um einen ersten Entwurf für den Garten von Vaux handelt. 


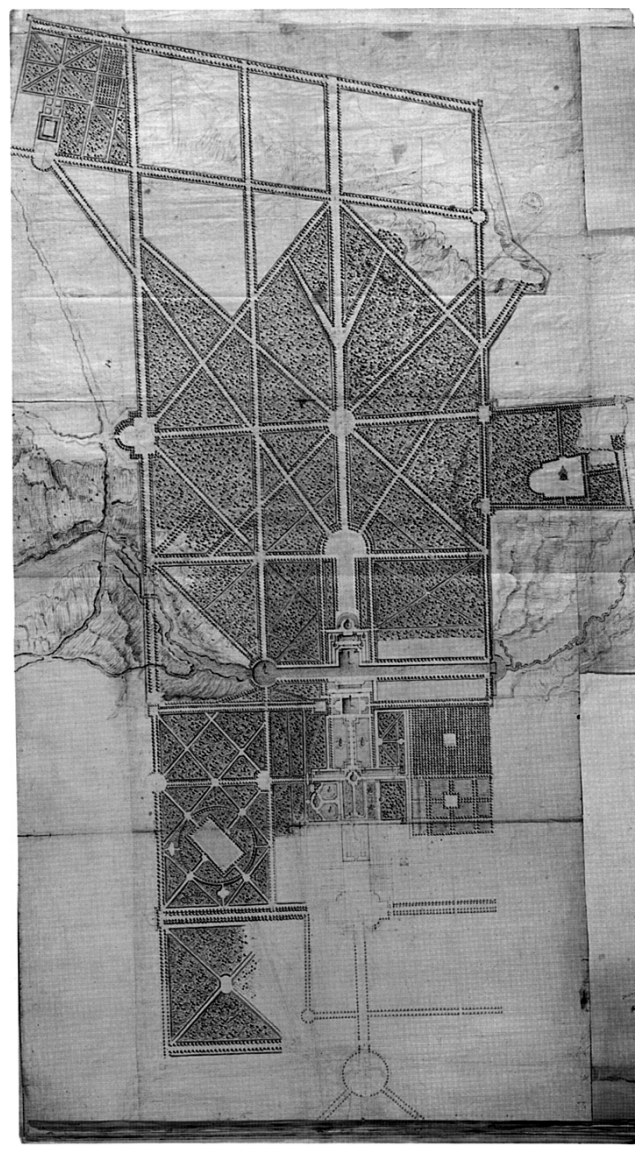

Abb.31: Plan der Gesamtanlage von Vaux-le-Vicomte (André Le Nôtre, um 1658). Paris, Institut de France.

vestre, die La Fontaine zufolge auf das Jahr 1659 zu datieren sind ${ }^{108}$. Des Weiteren sind zwei von Adam Pérelle nach Zeichnungen Silvestres angefertigte

108 Der »Songe de Vaux« von Jean de La Fontaine wurde erstmals 1671 vom Autor veröffentlicht. Im ersten Fragment heißt es: »C'étoit aussi cette maison magnifique, avec ses accompagnements et ses jardins, lesquels Silvestre m'avoient montrés, et que ma mémoire conservoit avec grand soin, comme étant les plus précieuses pièces de son trésor. Ce fut sur ce fondement que le Songe éleva son frêle édifice, et tâcha de me faire voir les choses en leur plus grande perfection « (LA Fontaine, Euvres complètes I, Bd. VIII, S. 246). Folgende Stiche sind von Silvestre überliefert: Veue de Vaux le Vicomte du coste de l'entrée; Veue et perspective du chasteau de Vaux, par le costé (côté cour); Veue du chasteau de Vaux par le coste (côté jardin); Veue et perspective du jardin de Vaux le Vicomte; Vue sur le parterre de la Couronne; Vue sur la fontaine de la Couronne; Vue à partir du parterre de la Couronne; Vue sur la grille d'eau; Vue à partir de la grille d'eau; Veue en perspective des cascades de Vaux; Veue et perspective de la grotte et dune partie du canal; Veue et perspective de Vaux le Vicomte du coste du iardin (BN Estampes, Va 420). Bei PérousE DE Montclos, Vaux-le-Vicomte, S. 108-112 finden sich zudem drei Zeichnungen Silvestres von Vaux: Vue et perspective du jardin de Vaux le Vicomte (Vue sur le jardin à partir du 
Stiche überliefert ${ }^{109}$. Eine literarische Beschreibung des Gartens findet sich sowohl im zehnten Band der »Clélie« von Madeleine de Scudéry als auch im »Songe de Vaux « von Jean de La Fontaine ${ }^{110}$. Im Archiv von Vaux finden sich zudem die »Mémoires des travaux de menuiserie«, in den Archives nationales die »Estimation des bustes de Vaux«, die beide Informationen zu den für den Garten gelieferten Statuen geben ${ }^{111}$.

Der heutige Garten von Vaux-le-Vicomte hat, dank einer umfassenden Restauration im ausgehenden 19. Jahrhundert, einen Großteil seiner Ursprünglichkeit zurückerhalten. Ein Vergleich mit dem Plan von Le Nôtre zeigt, dass die großen Grenzlinien erhalten geblieben sind und vorwiegend innerhalb der Parterrefelder Veränderungen vorgenommen wurden. Der tatsächliche $\mathrm{Zu}$ stand des Gartens zu Zeiten Fouquets lässt sich jedoch nicht rekonstruieren, da auch die überlieferten Quellen, wie zum Beispiel Le Nôtres Plan, nur ein beabsichtigtes, bis 1661 jedoch noch nicht erreichtes Aussehen oder aber, wie im Fall der Stiche Silvestres oder der Darstellungen Madeleine de Scudérys oder La Fontaines, einen imaginierten Zustand beschreiben. Der Garten selbst war zu der Zeit, als die graphischen und literarischen Zeugnisse entstanden, noch im Entstehen begriffen. Die Quellen spiegeln also eher einen Idealzustand wider, den der Bauherr verbreitet sehen wollte: »Ces gravures et cette ekphrasis [»Songe de Vaux«] ont été initialement réalisées pour représenter le jardin de Vaux, dans le but évident d'en diffuser la genèse et la splendeur anticipée «112. Da bei der Restaurierung ein großer Teil der den Garten so sehr prägenden Wasserspiele nicht wiederhergestellt worden ist (die allée d'eau wurde durch bepflanzte Marmorschalen ersetzt, verschiedene Brunnen fehlen, die Garbe hinter der Grotte wurde in einen Kranz aus niederen und höheren Strahlen verwandelt), gibt der heutige Garten nur unvollkommen den Eindruck wieder, der von Le Nôtre beabsichtigt gewesen war.

Der Garten, der dritte Raum von Vaux-le-Vicomte, sollte dem königlichen Besucher - nach dem Empfang im Vorhof und der Entledigung von politischer Verantwortung im Schlossinnern - ganz zur Zerstreuung und zum Vergnügen dienen. Zudem sollte er das Schloss mitsamt seinem ikonographischen Sinngehalt in Szene setzen. Bereits in den vorhergehenden Räumen ist der Garten präsent. Obwohl er vom Vorhof aus durch die Glastüren des Schlosses

château); Vue et perspective du parterre de fleurs; Vue sur la grille d'eau avec, au fond, le colombier (Paris, musée du Louvre, département des arts graphiques).

109 Hierbei handelt es sich um die »Veuë des petites cascades de Vaux« und »La Grotte de Vaux« (BN Estampes, Va. 77, Bd. XV; Louvre, Album Perelle, Nr.32312).

110 Bei beiden Texten handelt es sich um eine sogenannte Ekphrasis, eine literarische Beschreibung eines reellen oder imaginären Kunstwerks, die einer fiktiven Person in der Erzählung dargebracht wird.

111 Mémoires des travaux de menuiserie, in: Cordey, Vaux-le-Vicomte, Dokument V, S.202-208; Estimation des bustes de Vaux (1665), AN, $\mathrm{O}^{1}$ 1964, ${ }^{\circ} 5$, abgedruckt in: BonNAFFé, Foucquet, S. 69-72.

112 Poulin, Silvestre, S. 22. 


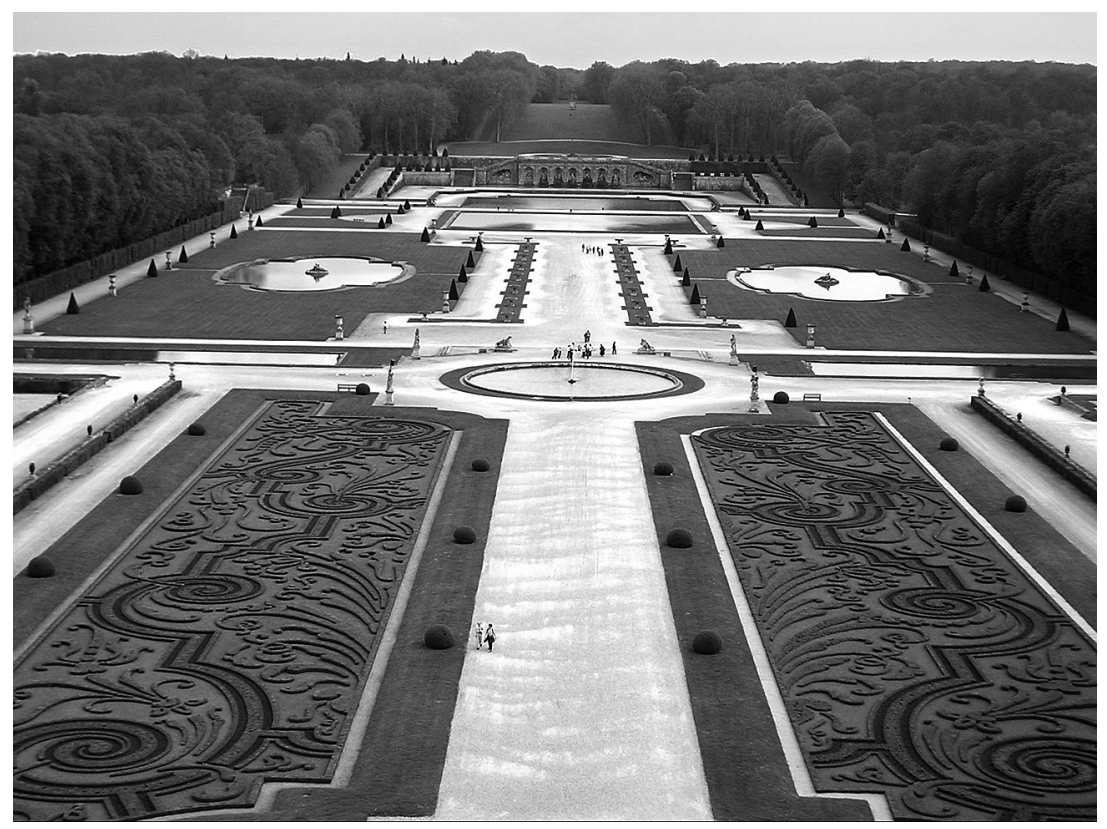

Abb.32: Garten von Vaux-le-Vicomte, Blick von der Schlossterrasse.

hindurch allenfalls zu erahnen ist, erscheinen seine Vorboten im ersten Raum in Form der Wasserspiele und der kleinen Rasenparterres. Im Schloss selbst nehmen die floralen Ornamente der Wandvertäfelung und Deckendekoration die nahe und gezähmte Natur vorweg. Die großen Fenster zur Gartenseite ermöglichen zudem noch vor dem Betreten der Grünanlage den Genuss wundervoller Ausblicke. Die Architektur schließlich entwickelt eine Dynamik, die den Besucher vom Schloss direkt in den Garten weist: »Le demy rond du salon pousse en dehors ${ }^{113}$.

Aus dem Salon heraustretend überblickt man erstmals den Garten, ohne ihn jedoch in Gänze erfassen zu können. Vor dem Besucher erstreckt sich die scheinbar bis zum Horizont reichende Hauptachse, zu seinen Füßen das Broderieparterre, rechts davon der Blumengarten, links das parterre de la Couronne, dessen Hauptbassin von einer goldenen Krone dominiert wird, die auf das nahegelegene appartement $d u$ Roi verweist. Weitere innovative Wasserspiele wie die grille d'eau erhöhen die östliche, königliche Seite, während die westliche, auf der das Appartement des Bauherrn liegt, von Nutzgärten bestimmt wird. Der Garten verliert sich zu beiden Seiten im angrenzenden Wald und geradeaus in der Ferne. Ein Eindruck von Weite dominiert den Blick. Fast schon am Horizont, am äußeren Ende der Anlage, erahnt

113 Scudéry, Clélie, Bd.X, S. 1127. 


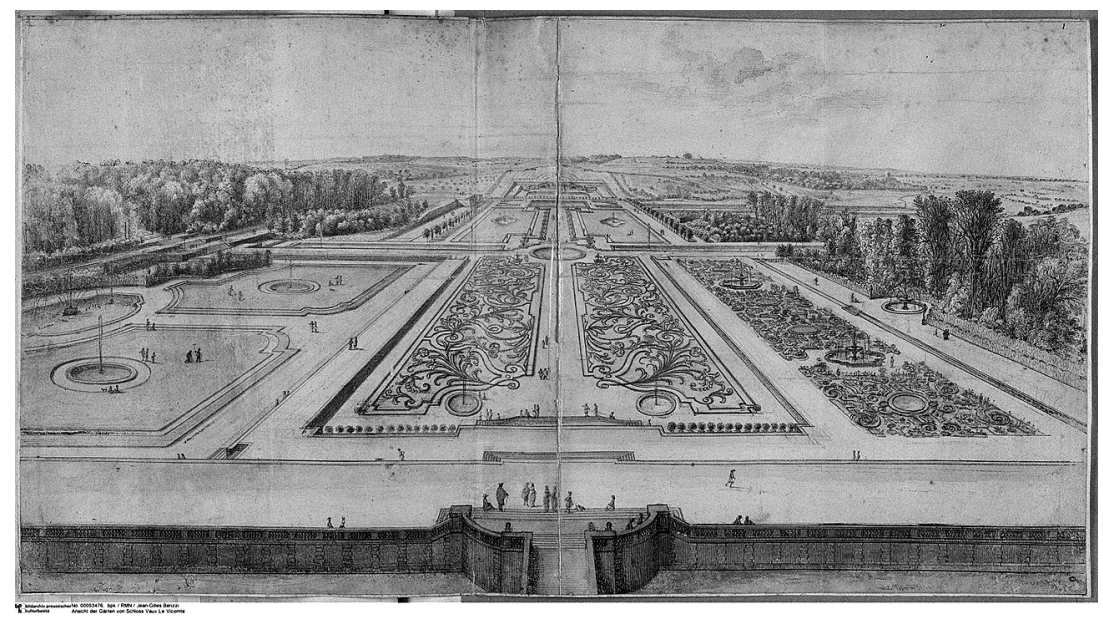

Abb.33: Erste Parterrezone: »Vue et perspective du jardin de Vaux-le-Vicomte« (Israël Silvestre, um 1659). Paris, musée du Louvre.

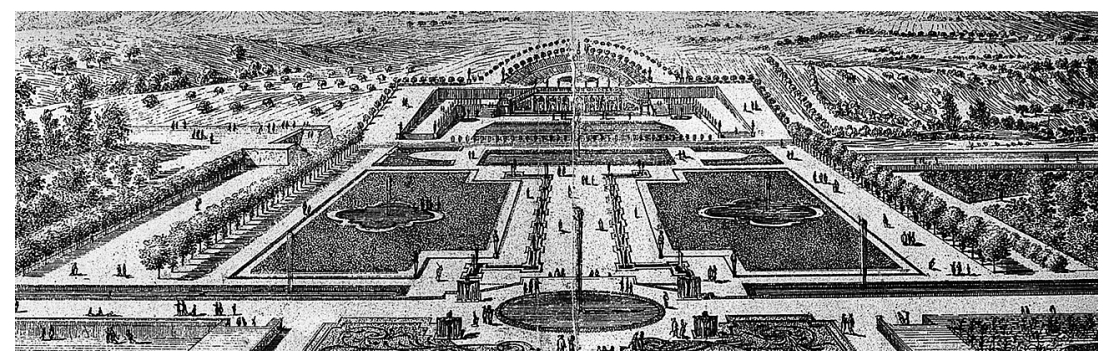

Abb.34: Zweite Parterrezone (Adam Pérelle, um 1665). Paris, Bibliothèque nationale de France.

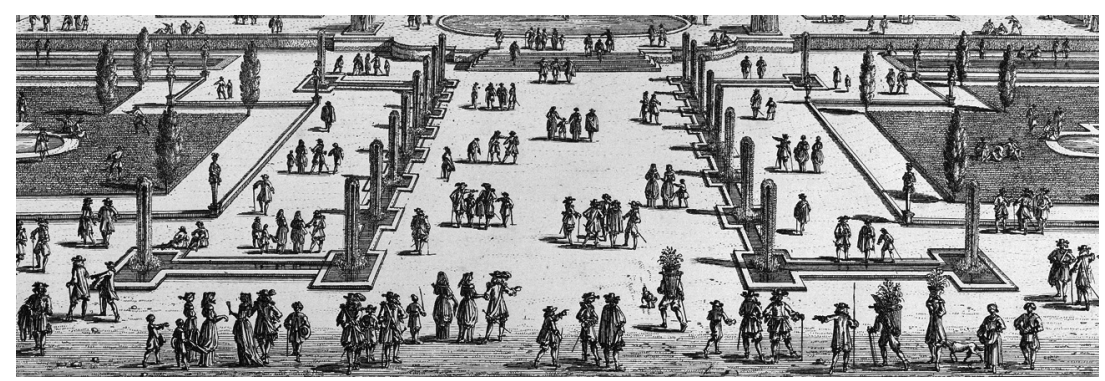

Abb.35: Zweite Parterrezone: Detail aus dem Stich »Vue de Vaux-le-Vicomte, côté jardins« (Adam Pérelle, um 1665). Versailles, château de Versailles et Trianon.

man eine Figur auf einer Anhöhe. Das wahre Ausmaß des Gartens mit all seinen Elementen bleibt auf der Schlossterrasse noch im Verborgenen. Erst beim Durchschreiten der Parkanlage wird man entdecken, dass sich entlang 
der Hauptachse mehrere zuvor verborgene Ebenen und Wasserspiele befinden ${ }^{114}$.

Das Broderieparterre erstreckt sich, wie in Frankreich üblich, im Bereich vor dem Schloss, der ersten Parterrezone in Vaux. Neu ist seine Komposition, die von Le Nôtre eingeführt wurde. Sich an der den Garten dominierenden Achse orientierend, wird das Parterre von dem Gartenarchitekten in die Länge gestreckt und zweigeteilt und vermittelt somit den Eindruck, dass es sich in die Tiefe des Gartens dränge ${ }^{115}$.

Hinter dem runden Bassin am Ende des Broderieparterres führen Stufen hinab auf eine neue Ebene, die zweite Parterrezone mit zwei großen quadratischen Wasserbecken, die entgegengesetzt der Hauptachse liegen. Die Flächen des zweiten Parterres wurden in ihrem Maßstab im Vergleich zur ersten Zone erheblich erweitert, so dass vom Schloss aus der Eindruck entstehen konnte, die beiden Flächen seien in ihrer Größe gleich. Das Element des Wassers, das den Garten von Vaux charakterisiert, gewinnt in der zweiten Zone an Dominanz. Hinter den Bassins, noch immer entlang der Hauptachse, traf der Besucher des 17. Jahrhunderts auf die allée d'eau, die heute verschwunden ist. Bei den Zeitgenossen hat die von mannshohen Wasserstrahlen gesäumte Allee einen starken Eindruck hinterlassen:

On voit une belle allée d'eau, qui occupe presque toute la largeur du iardin, d'où partent cent iets d'eau d'une esgale force, qui retombant dans le canal d'où ils partent, font un agréable murmure ${ }^{116}$.

Die Wasserallee führte auf ein quadratisches Bassin. Dahinter fällt das Gelände plötzlich steil ab. Ein längs verlaufender Kanal von einem Kilometer Länge liegt dem Betrachter zu Füßen, dahinter eine Grotte. Erst nachdem man auf diese unterste Ebene hinabgestiegen ist, kommen auch die grandes cascades zum Vorschein, die Le Nôtre an dem Abhang zwischen zweiter Parterrezone und Kanalebene anlegte. Aus grotesken Masken fließt Wasser in Muscheln und ergießt sich anschließend in ein großes Bassin. Das Motiv des Wassers hat sich, vom Schloss aus kommend, über die Springbrunnen zu Seiten der Broderie, die Querbecken, die Wasserallee und das große quadratische Bassin in der Gartenanlage mehr und mehr gesteigert, um sich am Kanal mit Grotte und Kaskade voll zu entfalten. Das Rauschen der Wasserspiele dominiert nun die Anlage und lässt sie zu einem verzauberten Ort werden. Der Kanal, die Querachse der Anlage, trennt den Besucher von der Grotte und dem dahinter, wieder auf höherer Ebene liegenden Teil des Gartens. Über der Grotte erhebt sich mannshoch ein weiteres Wasserwunder: die Garbe, über Rampen und Treppen zu erreichen. Sie bildet den Abschluss des

114 Hazlehurst, Gardens of Illusions, S. 31.

115 Das traditionelle Broderieparterre war quadratisch angelegt und in vier Beete unterteilt, in der Mitte befand sich ein Brunnen.

116 Scudéry, Clélie, Bd.X, S.1132f. André Le Nôtre erfand in Vaux dieses Gartenelement, das in späteren Gärten wiederholt Aufnahme finden sollte. 
Abb.36: Sphinx (Pfnorr, 1888).

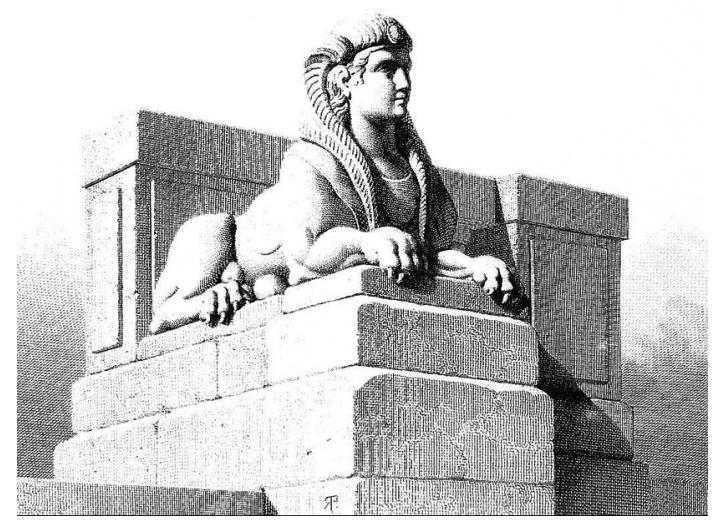

vom Wasser dominierten Gartens, wenngleich noch nicht jenen der gesamten Anlage.

In den Guiden des 17. Jahrhunderts wurden die Parkanlagen der Schlösser beurteilt nach ihrer Aussicht und ihrem Wasserreichtum ${ }^{117}$. Beide sind die Hauptcharakteristika des Gartens von Vaux-le-Vicomte und machen seine Besonderheit aus. Zugleich kennzeichnet den Garten der fortwährende Wechsel von Verbergen und Enthüllen, der zu einem Kennzeichen des französischen Gartens werden sollte. Dabei bedient sich Le Nôtre bestimmter illusionistischer Effekte, die er mit der Methode der abgeschwächten Perspektive (perspective ralentie) erzielt, bei der die Maßverhältnisse der Dinge auf das Auge des Betrachters zugeschnitten sind ${ }^{118}$. Le Nôtre manipuliert den Raum, indem er die Flächen und Skulpturen des Gartens unter Beachtung ihrer unterschiedlichen Entfernungen derart dimensioniert, dass sie sich vom Schloss aus in ihrer Größe nicht unterscheiden und somit der Effekt der Fluchtperspektive vermindert wird. Die Elemente gewinnen, je weiter sie vom Schloss entfernt sind, an Größe. Zugleich lässt die Detailgestaltung der einzelnen Elemente mit zunehmendem Abstand vom Schloss nach, ein Hinweis auf die hierarchische Ordnung der Anlage, deren Mittelpunkt immer das Schloss selbst bleibt. Die Wasserthematik wird beim Durchschreiten des Gartens präsenter. Bei den genau kalkulierten Wasserspiegelungen findet das Spiel mit den optischen Effekten ein weiteres Mal Anwendung. In dem quadratischen Bassin, dem ersten miroir d'eau des französischen Gartens am Ende der zweiten Parterreebene, in einem halben Kilometer Entfernung vom Schloss, spiegelt sich der Bau vollständig, im bassin de la Couronne auf der ersten Parterrezone in schräger Ansicht. Die Architektur vervielfältigt sich, das Schloss ist im Gar-

117 Krause, Maison de plaisance, S.12.

118 BRIX, Garten, S. 88. Die perspective ralentie wurde bereits in den 1630er Jahren im Garten von Richelieu angewendet. 


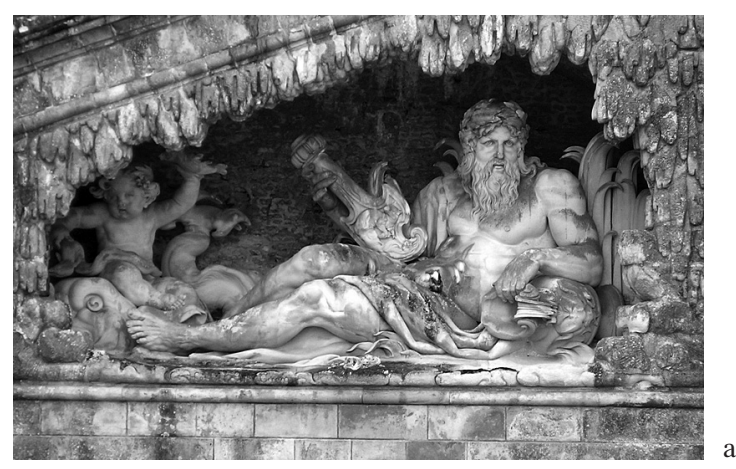

Abb.37 a-b: Figuren der Grottenhöhlen: Anqueuil und Tiber (Mathieu Lespagnandel, vor 1661).

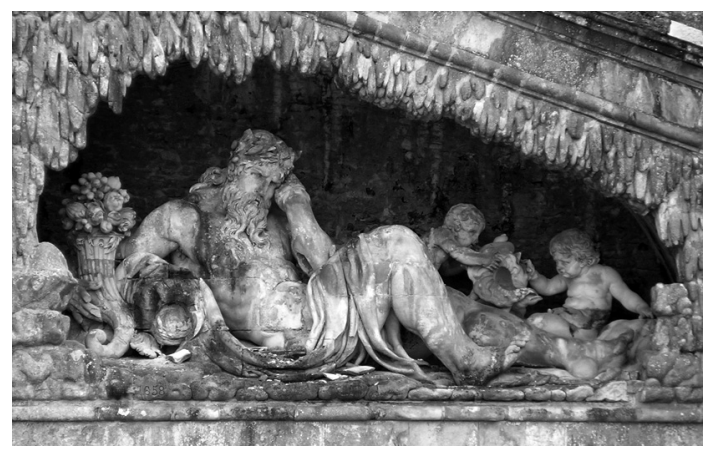

ten präsent, auch der Himmel spiegelt sich in den Wasserflächen und trägt zu einer bewussten Aufhellung des Gartens bei ${ }^{119}$.

Der Skultpurenschmuck der Anlage wurde zum größten Teil eigens für diese hergestellt und passt sich in das ikonographische und thematische Gesamtprogramm von Vaux-le-Vicomte ein ${ }^{120}$. Auf der Terrasse des Schlosses blicken zwei Sphingen in Richtung Garten (Abb.36). Sie sind die Hüter des Schlosses und seiner Geheimnisse und machen aus Vaux einen Ort der Diskretion $^{121}$. Den Garten selbst bevölkerten Götterhermen und Tierstatuen, die dem alltagsfernen und verspielten Charakter der Anlage Ausdruck verliehen und heute zum größten Teil nicht mehr existieren. Von Bedeutung für das ikonographische Programm von Vaux-le-Vicomte sind die Skulpturen, die sich noch immer am Ende der Anlage, bei und hinter der Grotte befinden. In Gestalt verschiedener Figuren von enormer Größe wiederholen sich hier The-

119 Bechter, Garten, S. 87.

$120 \mathrm{Zu}$ der Beauftragung und den Künstlern der Statuen: siehe Kapitel 3.2.

121 Nach RIPA, Iconologie, $1^{\text {re }}$ partie, S. 180 stehen die Sphingen für secret oder silence: »'Empereur Auguste prit à cet effet pour sa devise la figure d'un Sphinx, qui selon Pierius est le Ieroglyphe du Secret, comme l'Image d'Harpocrates l'estoit jadis du Silence«. 
men in übersteigerter Dimension, die bereits im Vorhof und im Schlossinnern eingeführt wurden.

In die beiden Grottenhöhlen unterhalb der Garbe wurde je ein Flussgott eingefügt (Abb.37a-b). In melancholischer Pose zur Rechten sitzt der römische Tiber. Er hat nachdenklich seinen Kopf auf die linke Hand gestützt und hält in seinem rechten Arm ein mit Blumen und Früchten gefülltes Horn. Zu seinen Füßen spielen zwei Putten mit einer Muschel, Zeichen einer vollendeten, aber vor langer Zeit entstandenen Schönheit. Der einheimische Flussgott Anqueuil auf der linken Seite der Grotte zeigt sich weit kraftvoller und munterer als sein Nachbar. Er stützt sich mit seinem linken Arm auf ein umgestürztes Tongefäß, aus dem eine unerschöpfliche Menge Wasser zu fließen scheint. $\mathrm{Zu}$ seinen Füßen sitzt ein mit Meerestieren spielender Putto. Zwar ist der einheimische Anqueuil nicht mit Früchten, Blumen oder Muschelwerk ausgestattet, doch trotzdem mit einem großen Reichtum gesegnet, den er aus seinem Fluss schöpft. Mit diesem Gegensatzpaar präsentiert sich Vaux-le-Vicomte in Abgrenzung zu Italien und diesem überlegen. Der die Anlage durchfließende und die unzähligen Wasserspiele unversieglich speisende Anqueuil zeigt sich üppiger und zufriedener als der römische Tiber, der sein Ansehen nur aus vergangener Schönheit zu schöpfen scheint. Auch Madeleine de Scudéry hebt den Triumph Anqueuils hervor: »Il [Tiber] paroist melancholique, comme estant fasché d'estre surpassé par le Fleuue du lieu«122. La Fontaine übersteigert den Anqueuil in seinem »Songe «, in dem er dem heimischen Fluss eine direkte Verbindung zum Ozean zuschreibt, dem er seinen Reichtum exotischer Meerestiere zu verdanken hat ${ }^{123}$. Félibien, dem die Festbeschreibung des 17. August zugeschrieben wird, thematisiert die Überlegenheit Vaux' gegenüber italienischen Anlagen anlässlich der Gartenpromenade des Königs. Als dieser, aus der Wasserallee tretend, vor dem miroir d'eau, dem großen Wasserbecken stehend auf die Grotte vor sich blickt, legt er ihm folgende Gedanken in den Kopf:

C'est icy où il faut que Tivoli et Frascati et tout ce que l'Italie se vante de posséder de beau, de magnifique et de surprenant avoue qu'elle n'a rien de comparable à Vaux. Ce n'est rien de dire que cent jets d'eau de plus de trente-cinq pieds de hauteur de chaque côté faisoient qu'on marchait dans une allée comme entre deux murs d'eau. Il y en avoit encore pour le moins plus de mille qui tombant dans des coquilles et des bassins merveilleusement bien taillés faisoient un si grand et si beau bruit que chacun juroit que c'étoit le trône de Neptune ${ }^{124}$.

Vier Löwenstatuen, je zwei an den beiden Aufgängen zur Garbe, nehmen die politische Botschaft Vaux-le-Vicomtes wieder auf. In der »Clélie« erwähnt Madeleine de Scudéry eine der beiden Zweiergruppen:

122 Scudéry, Clélie, Bd.X, S. 1136.

${ }^{123}$ La Fontaine, Euvres complètes I, Bd.VIII, S.268: Aventure d'un saumon et d'un esturgeon.

124 FÉLIBIEN, Relations, Relation des magnificences, S. 32. 


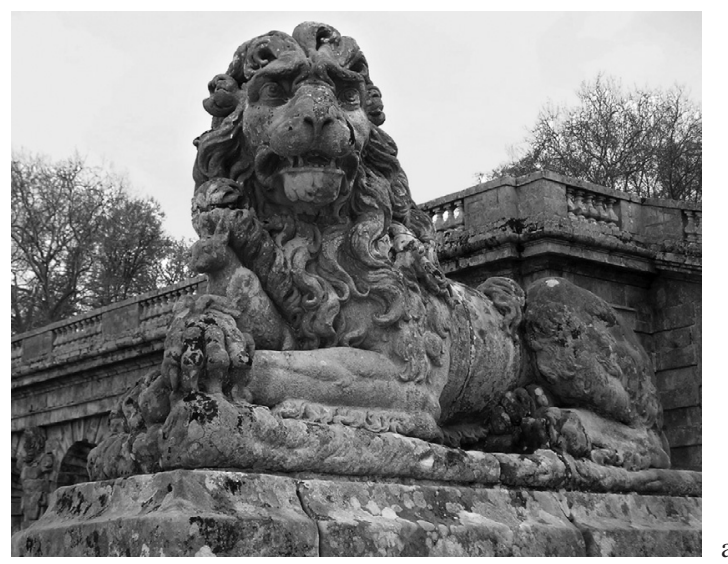

Abb.38 a-b: Löwengruppe am Aufgang zur Garbe (Mathieu Lespagnandel, vor 1661).

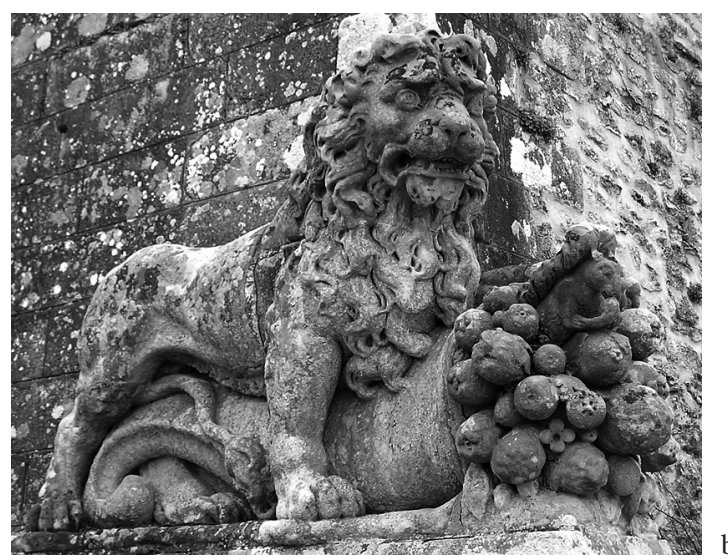

Au bas de la balustrade, on voit deux grands Lions, qui par l'industrie de Méléandre [Le Brun], montrent encore d'une façon toute particuliere les armes de Cléonime [Fouquet], car l'Escureuil y paroist entre les pates des Lions, mais de telle sorte qu'on voit assez que ces cruels animaux n'ont que de la douceur \& de l'amitié pour luy ${ }^{125}$.

125 Scudéry, Clélie, Bd.X, S.1137f. Madeleine de Scudéry nennt nur zwei Statuen der Vierergruppe. Dies mag dem Entstehungszeitpunkt ihres Werkes geschuldet sein, das etwa zeitgleich mit den Skulpturen um 1659/1660 entstand. Es ist zu vermuten, dass Madeleine de Scudéry - wie auch die anderen über Vaux schreibenden Autoren (siehe Kapitel 3.3) - die noch unfertige Schlossanlage auf der Grundlage von Berichten und Entwürfen beschrieb. Wie die »Mémoire des ouvrage de sculture quy convienne estre faicte au grotte de Monsaigneur le procureur generalle en son chateau de Vaux par moy Lespagnandelle, maistre sculteur « vom 16. April 1659 (CORDEY, Vaux-le-Vicomte, S. 224) vermuten lässt, wäre es darüber hinaus denkbar, dass zunächst nur eine Zweiergruppe für den Treppenbereich der Grotte vorgesehen war, der durch ein Basrelief ergänzt werden sollte. In dem Mémoire heißt es im ersten Eintrag:»Premiérement deux lions de gres pour mestre sur deux pied desthau au commancement des deux rampes des dicte grotte, lesquelle seront couché comme aussy deux aultres quy les regarde, quy sont debout tenant 


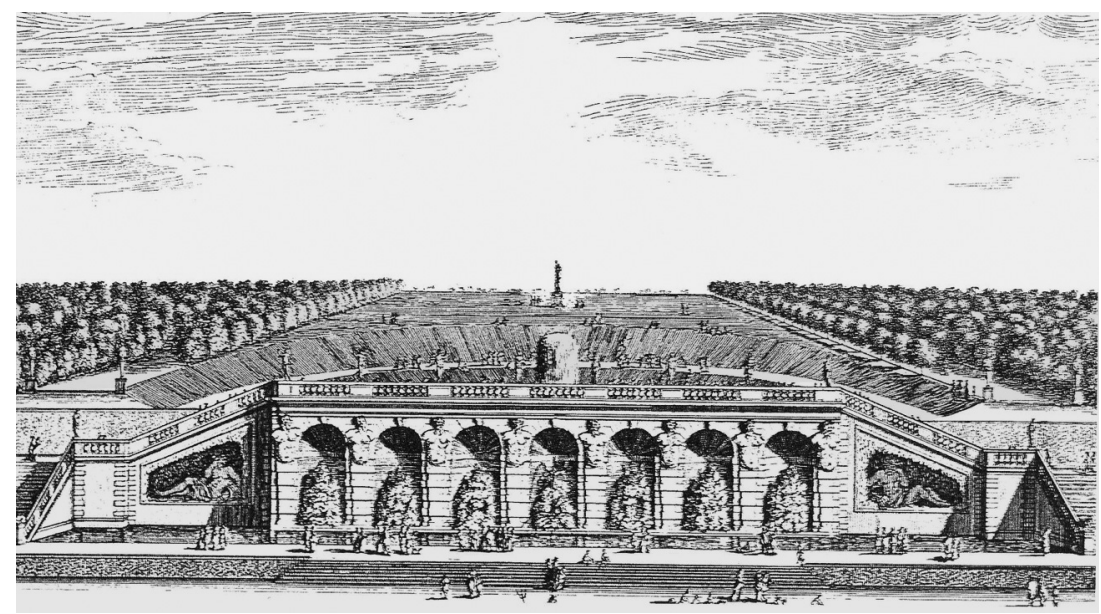

Abb.39: Detail aus dem Stich »Veue et perspective de la grotte et d'une partie du canal« (Israël Silvestre, um 1659). Paris, Bibliothèque nationale de France.

Beide Löwengruppen sind identisch. Nur innerhalb der Gruppen finden sich verschiedene Statuen. Die beiden äußeren Tiere (Abb.38b) stehen auf ihren vier Pfoten, zwischen ihren Beinen ein Füllhorn, das sich nach vorne hin öffnet. In seiner Mitte sitzt ein Eichhorn und labt sich an den Köstlichkeiten. Bei den beiden inneren Figuren (Abb.38a) handelt es sich um sitzende Löwen, zwischen deren Vorderpranken ein Eichhorn sitzt. Das bereits im skulpturalen Schmuck der Fassade sowie in den Schlossräumen im Stuckdekor und der Wanddekoration des cabinet des Jeux dargestellte Eichhorn findet sich erneut in diesen Figuren. Zum ersten Mal wird nicht nur ein indirektes Nebeneinander von Eichhorn und Löwe dargestellt, sondern ihr unmittelbares Miteinander. Blickte der Löwe im cabinet des Jeux noch aus der Distanz auf die Verfolgung des Eichhorns durch die Schlange, schien er in der Fassade des Schlosses vom Medaillon mit dem Eichhorn abgewandt dieses mit einer gewissen Distanz zu bewachen, so sind Löwe und Eichhorn am Ende des Gartens harmonisch vereint. Von der Schlange fehlt jede Spur. Die beiden Tiere zeigen sich in einem vertrauten Miteinander, bei dem sich das Eichhorn sorglos zwischen die Pranken des Löwen setzt.

Den hinter der Garbe liegenden Abhang erklimmend gelangt man zu der Statue des Herkules Farnese, der, lässig auf seine Keule gestützt, die Parkan-

des cornes d'abondance entre leur pate et quy sont demy basrelief contre le mur, quy auron huict pied de lon depuis la teste jusque a la croupe «. In einem ebenfalls bei CORDEY (Vaux-le-Vicomte, S. 225) abgedruckten Dokument vom 15. November 1661 führt Lespagnandel vier Löwenfiguren »quy sont sur des piedestaus« auf. Zwischen April 1659 und November 1661 muss also die Entscheidung gefallen sein, auf die Basreliefs zugunsten von Figuren zu verzichten. 


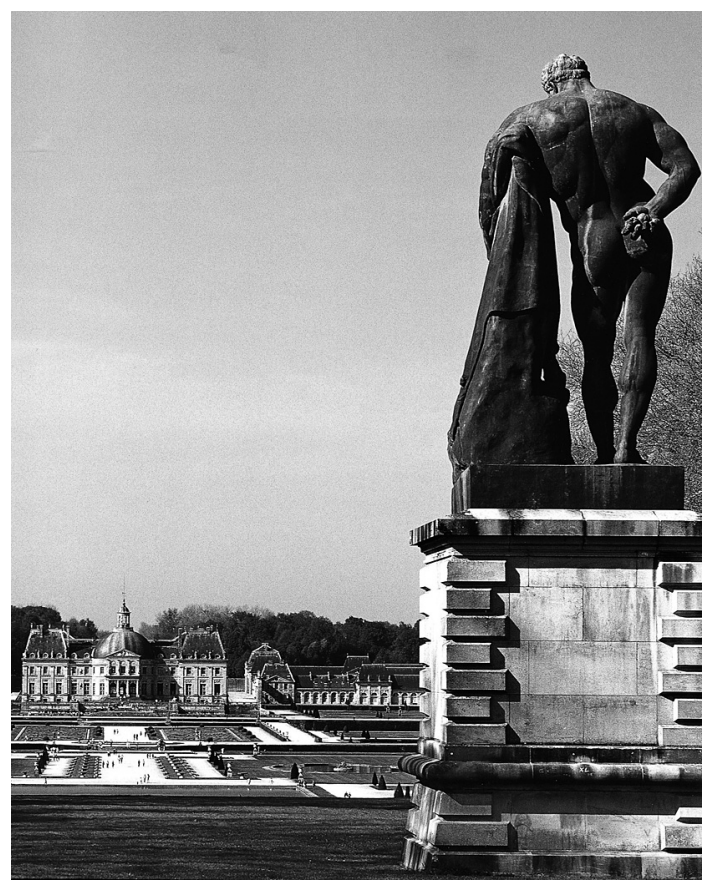

Abb. 40: Blick von der Herkules-Statue über den Garten zum Schloss von Vaux-leVicomte.

lage überblickt (Abb.40). Von nahem erkennt man seine imposante Größe, die vom Schloss aus nur mannshoch erscheint ${ }^{126}$. Mit dieser Sinnestäuschung wird der Besucher an die Ausmaße des Gartens erinnert. Die Statue wurde erst 1891 errichtet, ist aber auf einem Stich Silvestres (Abb. 39) zu sehen. Ihre Errichtung scheint von Le Brun geplant gewesen zu sein, denn in seinem Atelier im Schloss fand sich nach Fouquets Verhaftung »un modelle de cire d'un hercule ${ }^{127}$. Der Held blickt gen Osten, den in seiner Ausgestaltung stärker betonten Teil des Gartens, auf dessen Seite sich auch das appartement du Roi befindet. Die Herkulesstatue nimmt die Götterthematik wieder auf, die mit dem Hermengitter des Eingangs in Vaux eingeführt wurde. Sie bildet den Abschluss der Anlage und kennzeichnet damit ein weiteres Mal Vaux-le-Vicomte als einen von den Göttern bewohnten und bewachten Ort. Herkules bürgt für Sicherheit und Frieden in Vaux-le-Vicomte und im gesamten Königreich.

Von der Herkulesstatue aus gewinnt man erneut einen überraschenden Blick auf das Schloss. Das Bauwerk ist nun ganz und gar in den Vordergrund

${ }^{126}$ Die heutige Statue ist weit größer als ursprünglich geplant (siehe hierzu: Poulin, Silvestre, S.24, Anmerkung 58). Die von Puget zwischen 1663 und 1668 gefertigte Originalstatue, die sich heute im Louvre befindet (Inv. Nr.15345), hat lediglich eine Höhe von 1,56 m.

127 Inventaire de Vaux (1661), fol.132v. Poulin, Silvestre, S.17 bewertet die HerkulesStatue als »l'unique figure érigée par les >restaurateurs< qui corresponde à une intention des créateurs «. 
gerückt, die Nebengebäude scheinen dem Bau zugehörig und ihn zu einer riesigen Anlage zu erweitern, verbunden durch ein kurzes Mauerstück zwischen den Nebengebäuden und dem Hermengitter, das nun seinen architektonischen Sinn zu erkennen gibt. Kanal und Kaskaden sind von der Herkulesstatue aus erneut unsichtbar. Nicht mehr das Wasser und seine muntere Leichtigkeit, sondern der Schlossbau in seiner ganzen Pracht und Größe dominiert die Anlage. Die Perspektiven sind verkürzt, das viereckige Bassin scheint mittig in der Anlage zu liegen. Das Spiel der unterschiedlichen Ebenen ist verlorengegangen - alles erscheint in vollster Harmonie. Zudem hat ein Perspektivenwechsel stattgefunden: Es dominiert nun nicht mehr die zentrale Achse die Anlage, sondern die horizontale Stufung der Terrassen. Ein letztes Mal zeigt sich die Raffinesse der Planung Le Nôtres.

\subsection{Vaux-le-Vicomte: ein Fazit}

Vaux-le-Vicomte ist ganz auf die Bedürfnisse des jungen Ludwig ausgerichtet. Für ihn sollte der Bau eine Einladung zu divertissement und Sorglosigkeit sein. Der Vorhof ist für den triumphalen Empfang des Herrschers konzipiert. Das reich geschmückte Schloss ist wie geschaffen für Empfänge und Festlichkeiten, zur Bewirtung des Königs und seines Hofes. Für sein Wohlbefinden wurde in den besten Räumen des Schlosses ein Appartement eingerichtet. Seine Größe deutet darauf hin, dass man dem König einen privaten Raum für längere Aufenthalte bieten wollte. Das appartement du Roi gehörte im 17. Jahrhundert zwar bereits zum räumlichen Inventar eines ministeriellen Schlosses, bis dato ging seine Größe aber meist nicht über eine chambre hinaus $^{128}$. Vaux sollte dem jugendlichen Ludwig eine Heimstätte werden. Die Dekoration seines Appartements rühmte - in steter Präsenz des Eichhorns die Erfolge des Königs (Beilegung der Fronde und Ende des Krieges mit Spanien). Zugleich wird dem jungen, für seine Vergnügungssucht bekannten Herrscher die Aussicht auf einen nie versiegenden Reichtum verheißen, für den der Finanzminister Fouquet bürgt.

Die Ludwig von Fouquet verheißene Sorglosigkeit zeigt sich nicht allein in der Ikonographie der Innendekoration. Sie wird von der Architektur der gesamten Anlage reflektiert. Diese präsentiert dem Besucher noch vor ihrem Betreten ihre Verspieltheit und Raffinesse: Der Vorhof ist zur Straße offen und zugleich von dieser durch ein Gitter getrennt. Der Blick auf das Schloss kann sich frei entfalten, doch erst wenn man darauf zuschreitet, werden verborgene Elemente sichtbar und es entfaltet sich ein zuvor ungeahntes Spiel der Perspektiven. Dieses setzt sich beim Durchschreiten des Gartens fort und wirft immer wieder neue, überraschende Einblicke auf: Das Schloss wirkt einmal nah, dann wieder fern. Der Garten einmal weit und breit, dann wieder

128 In Maisons ist eine chambre für den König eingerichtet. In Richelieu findet sich neben einem Prunkappartement für den König ebenfalls eines für den Minister. 
klein und überschaubar, je nachdem, wie das Schloss, stets der Protagonist der Anlage, gerade inszeniert werden soll. Es ist die Raffinesse von Vaux-leVicomte, ein innovatives Zusammenwirken der Künste (Architektur, Malerei, Skulptur) zum einen und der Baukunst und Natur zum anderen in immer neuen Spielarten zu bieten. Der Garten von Vaux und die dahinterliegenden Wälder gaben dem Hofstaat genug Möglichkeiten und Platz für mannigfaltige Vergnügungen, die durch den einfallsreichen Hofkünstler Le Brun und den erfinderischen maître d'hôtel Vatel erdacht und umgesetzt werden konnten. Der königliche Besuch blieb denn auch nicht aus: Am 14. Juli 1659 kam Ludwig XIV. erstmals in Begleitung seiner Mutter. Am 19. Juli 1660 lud Fouquet den König und seine Gemahlin zu einem Empfang, noch bevor das junge Paar seinen triumphalen Einzug in Paris gehalten hatte. Auch andere königliche Gäste kamen nach Vaux-le-Vicomte. Bereits im September 1656 besuchte Christina von Schweden die Baustelle. Noch vor dem Einweihungsfest vom 17. August erschien Henrietta Maria von Frankreich, die Witwe König Karls von England am 12. Juli 1661.

Doch Vaux-le-Vicomte diente nur zu einem Teil dem reinen Vergnügen. Es sollte zudem der Öffentlichkeit die Tugenden und Fähigkeiten Fouquets anpreisen. Die Deckengemälde stellen einen vernünftigen, umsichtigen und seinem König völlig ergebenen Bauherrn dar, der seine politische Unentbehrlichkeit kenntlich machen will. Fouquet sah sich als einen Minister, der dem Staat zu Ruhm und Reichtum verhelfen konnte. Dem jungen Ludwig präsentierte sich der Finanzminister in dem östlichen appartement mittels eines die Decke tragenden Eichhornfrieses als Stütze des Staates. Der König, der es gewohnt war, einen starken Premierminister an seiner Seite zu haben, sollte davon überzeugt werden, dass Fouquet alle Qualitäten für dieses Amt mitbrachte. Die Chronologie der Innenausstattung weist darauf hin, dass Fouquets wichtigste Botschaft in seinem Prunkappartement $\mathrm{zu}$ finden ist. Wie sonst ließe sich erklären, dass er sein appartement noch vor jenem des Königs gestalten ließ und man nahezu ausschließlich seine Beschreibung in der zeitgenössischen Literatur findet?

Die Financiers der Krone sind als weitere Adressaten des Baus zu nennen. In Zeiten chronischen Geldmangels war es für den Finanzminister, der sich um die Liquidität der Krone zu kümmern hatte, ein kluges Mittel, die Solidität seines Finanzsystems und damit die Kreditwürdigkeit des Staates durch die Zurschaustellung von Pracht und Reichtum zu suggerieren. So konnte er den Kreditgebern den Glauben erhalten, dass die Rückzahlung ihrer Darlehen eine sichere Sache sei:

Les dépenses de l'Estat n'eussent pû estre faites, ni les deniers fournis à temps, pour les besoins et les necessitez plus urgentes, si je ne les eusse fait fournir, \& je n'eusse pas pû les faire fournir, si l'apparence de mon bien, la dépense, l'éclat, la libéralité, joints à l'observation inviolable de mes paroles, ne m'en eussent donné le crédit ${ }^{129}$.

129 Fouquet, Euvres, Bd. V, S. 324. 
In seiner Anlage zeigte sich das Schloss als Ort des Vergnügens, in seiner Ikonographie zielte es auf öffentliche Wirkung. Die Öffentlichkeit, die Fouquet als Rückhalt für seine Ambitionen benötigte, wurde bei der Planung des Schlosses mitbedacht. Um le public zu erreichen, gab Fouquet 1659 - als sich seine akute politische Gefährdung nach dem Bruch mit seinem Bruder in der Überarbeitung seines Notfallplans von Saint-Mandé niederschlug - die literarische Propagierung von Vaux in Auftrag. Die Ikonographie des Schlosses wollte verstanden werden, wenn sie nicht auf die Exzellenz ihrer Ausführung reduziert werden sollte. Dies war umso notwendiger, da in Vaux-le-Vicomte die althergebrachten Bilder mit neuen Inhalten und zeitgenössischen Bezügen versehen worden waren. Die erklärenden Texte von André Félibien, Jean de La Fontaine und Madeleine de Scudéry sollten die Ikonographie des Schlosses verstehen helfen und zugleich allen Fouquets Rolle als tragende Säule des Königreichs vor Augen führen.

Die Schriftsteller halfen dem Finanzminister nicht allein, den Lesern die Botschaft der Bilder von Vaux zu entschlüsseln. In ihren Schriften wird neben der Glorifizierung des Bauherrn auch eine Abgrenzung gegenüber den italienischen Vorläufern vorgenommen ${ }^{130}$. Diese war nicht zuletzt auch eine Abgrenzung gegen den Italiener Mazarin, den Fouquet nicht nur hinsichtlich seines eigenen Schicksals fürchtete, sondern dem er auch die Verantwortung für die politischen Wirrnisse Frankreichs anlastete: »Sous un Ministre étranger, fort absolu, fort interessé, fort ignorant de nos formes, \& qui ne vouloit estre contredit de personne, n'y s'assujettir aux Loix du Royaume, il y avoit beaucoup à craindre en cas de violence \& d'opression « 131 .

Mit Hilfe der Ikonographie von Vaux und deren Verbreitung durch verschiedene Medien trat Fouquet in einen künstlerischen Kampf gegen seine hauptsächlichen Widersacher Colbert und Mazarin ein. Keine Widrigkeiten sollten das Vorankommen seines Bauprojektes verhindern. Um Nachahmung und Sabotage (zum Beispiel in Form von gegenwirkender Propaganda) vorzubeugen, versuchte er jeden ungeladenen Besuch zu verhindern. Dass Fouquets Befürchtungen nicht grundlos waren, zeigt ein Fall von Bauspionage, von dem der maître d'hôtel Vatel dem Verwalter Courtois berichtet:

J'oubliois à vous mander que Monseigneur a témoigné qu'il seroit bien-aisé de sçavoir quand M. Colbert a esté à Vaux, qui fut un jour ou deux aprés qu'il en fut party; en quels endroits il a esté, \& qui l'a accompagné \& entretenu, pendant sa promenade, \& même ce qu'il a dit; ce qu'il faut tâcher de sçavoir sans affection, \& même les personnes à qui il a parlé132.

Der Bau besaß bereits lange vor seiner vorläufigen Fertigstellung eine große politische Brisanz und eine enorme Ausstrahlung auf die Zeitgenossen. Ihr

130 Nach der Besichtigung von Vaux wird in Félibiens »De l'origine...« [Relations, S. 28] die Frage gestellt: »Hé bien! serez-vous encore de ceux qui ne trouvent rien de comparable à ce qui se voit en Italie?«

131 Fouquet, Euvres, Bd. X, S.37.

132 Ibid., Bd.IV, S. 267; BN ms. fr. 10976, fol. 5r. 
Interesse an Schlossbauprojekten ist nicht ungewöhnlich, die Reaktion des Bauherrn auf die Neugierde zeigt jedoch, dass Fouquet durchaus verbergen wollte, was in Vaux im Entstehen war. Auch in Kreisen des Hofes zeigte man größtes Interesse an dem Bauprojekt:

Un Gentilhomme du voisinage, qui s'appelle Villeserin, a dit à la Reine qu'il a esté ces jours icy à Vaux, \& qu'il a compté à l'Astelier neuf cens hommes. Il faudroit (pour empécher cela autant qu'il se pourra) executer le dessein que l'on avoit fait, de mettre des Portiers \& tenir les portes fermées; je serois bien aise que vous avanciez tous les ouvrages le plus que vous pourrez avant la saison que tout le monde va à la campagne, \& qu'il y ait en veüe le moins de gens qu'il se pourra ensemble ${ }^{133}$.

Doch nicht allein die unerwarteten Besuche drohten das Geheimnis zu lüften. Auch offiziellen Besuchern sollte der Bauaufwand und die Dimension von Vaux nicht frühzeitig preisgegeben werden. Vor allem vor dem Premierminister, der wahrscheinlich bereits 1656 erstmals nach Vaux reiste, galt es, das Ausmaß der Arbeiten zu verbergen, indem man die Zahl der Arbeiter reduzierte: »Son Éminence ira mercredi coucher à Vaux; faudra congédier les journaliers et massons du grand canal, en sorte qu'il y en ait peu; faut les employer pendant ce temps là dans les fermes et à Maincy «134.

Zwischen 1656 und 1661 verschlechterte sich Fouquets politische Situation zusehends. Die Rivalität mit Colbert wurde von diesem geschürt, der kränker werdende Mazarin machte sich dies für seine eigene Politik zunutze und ließ Fouquet in der ständigen Furcht seines nahenden Sturzes. Um einem Ende seiner Karriere vor Fertigstellung seines neuen Schlosses entgegenzuwirken, ließ er die Arbeiten in Vaux eiligst vorantreiben. Die von dem Spion der Königin genannte Anzahl von neunhundert Arbeitern soll, so Grésy, einer von Fouquet am 21. November 1660 geschriebenen note zufolge, »par laquelle il exigeait qu'on en doublât le nombre «135, auf die erstaunliche Anzahl von 1800 Arbeitern erhöht worden sein ${ }^{136}$. Die große Zahl von Arbeitern und die sich häufenden Arbeitsunfälle führten im Herbst 1660 zur Gründung des Krankenhauses La Charité im benachbarten Maincy ${ }^{137}$. Das rasante Bautempo erforderte eine ausgefeilte Logistik, die von der Beherbergung der meist ortsfremden Arbeiter einschließlich ihrer medizinischen Versorgung bis hin zum Bau einer für die Schlossausstattung produzierenden Tapisseriemanufaktur in Maincy reichte.

133 Fouquet, CEuvres, Bd. IV, S.265f.

134 Zitiert nach: GrÉsY, Documents, S.2. Zu den Besuchen Mazarins in Vaux vergleiche: Fouquet, Euvres, Bd. V, S.90f. und Bd. IX, S.130.

135 GRÉsY, Documents, S. 4.

136 Der Brite Sir Christopher Wren, Late Surveyor-General of the Royal Buildings, reiste im Jahre 1665 nach Paris und stellte dort mit großem Erstaunen fest, dass am Louvre »no less than a thousand Hands are constantly employ'd in the Works « (Wren, Parentalia, S.261). Gemessen daran muss die Zahl der in Vaux beschäftigten Arbeiter gigantisch gewesen sein.

137 Brief Ludovico Vigarinis an den Kardinal Rinaldo d'Este vom 25.06.1660, abgedruckt in: RouchÈs, Inventaire, S.29f. 
Die Wahl der drei aufsteigenden, bereits in königlichen Diensten stehenden Künstler Le Vau, Le Brun und Le Nôtre zeigt die Wichtigkeit des Bauprojekts für Fouquet, der zwar während des Prozesses immer wieder beteuerte, dass er an einen schnellstmöglichen Verkauf des Schlosses dachte ${ }^{138}$, sich aber aufgrund der auf ihn bezogenen Innendekoration selbst zu widersprechen scheint. Auch die Briefe Louis Fouquets aus Rom verraten die Dringlichkeit des Bauprojektes und seiner Ausgestaltung für den Finanzminister, der sich 1655 mit der Gestaltung der neuen Anlage intensiv auseinandersetzte und sich von seinem Bruder entsprechende Unterlagen übersenden ließ. Dieser schrieb im August 1655 an den Finanzminister: »J'ay recherché soigneusement dans Rome toutes les estampes d'architecture, fontaines et palais; je vous les ay envoiés par Saint-Malo et j'en ay fait descrire un mémoire que je vous envoie. Il s'en trouvera encore quelques unes pour les ornements particuliers des maisons ${ }^{139}$.

Vaux-le-Vicomte ist ein Bau, mit dem Nicolas Fouquet sein Mäzenatentum für seine Selbstdarstellung einspannte, um seine wankende Stellung zu festigen und sich vor dem politischen Absturz zu retten. Das Schloss ist Ausdruck des grenzenlosen Ehrgeizes des Finanzministers, der mit der neuen Anlage nicht nur protzen, sondern auch Stil zeigen wollte. Nicht zuletzt ist Vaux ein Bau, der auch der Repräsentation und Kennzeichnung seiner gesellschaftlichen Stellung diente: »C'estoit une terre que je considérois comme mon établissement principal avant que j'eusse Belle-Isle, et où je voulois laisser quelque marque de l'estat où j'avois esté «140.

\section{Kunst und Kuriositäten für Vaux-le-Vicomte}

Fouquets Sammelverhalten der Jahre nach 1656 war völlig auf die Ausstattung des neuen Anwesens ausgerichtet. Die Bibliothek wurde zu einem Ort für die das neue Schloss und seinen Bauherrn verherrlichenden Dichter und Denker. Die Kuriositätensammlung wurde im Hinblick auf eine einzigartige Ausstattung der Anlage vergrößert, auch wenn es zu einem Umzug von SaintMandé nach Vaux-le-Vicomte nicht mehr kam. Der skulpturale Schmuck wurde bei französischen Künstlern in Auftrag gegeben. Eine eigens gegründete Tapisseriemanufaktur sollte die Bildwirkerserien für Vaux produzieren. Skulpturen und Tapisserien fügten sich so in das Bildprogramm des neuen Schlosses ein.

138 Fouquet, Euvres, Bd. XII, S. 90.

139 Brief Louis Fouquets an Nicolas Fouquet vom 2. August 1655, in: FouQuet, Lettres, S. 290 .

140 Fouquet, Euvres, Bd. IX, S. 124. 


\subsection{Bibliothek und Kuriositätensammlung}

Wenngleich die Bücher- und Kuriositätensammlung des Finanzministers in Saint-Mandé verblieb, ist auch ihr weiterer Aufbau (siehe Kapitel 2.2.) in Verbindung mit der neuen Schlossanlage zu bringen.

Für die Unterbringung der Bibliothek war in Vaux-le-Vicomte kein Raum vorgesehen. In Saint-Mandé aber verdoppelte sich der Bestand ab 1655 nahezu. Die Erweiterung der Büchersammlung steht in Zusammenhang mit der Literaturförderung durch Fouquet und dem Bau des neuen Schlosses. Denn erst die Lobpreisung und Deutung durch die Dichter - allen voran Félibien, La Fontaine und Scudéry - konnte der Anlage die entscheidende öffentliche Wirkung geben.

Die Belassung der Bibliothek in Saint-Mandé macht die unterschiedlichen Aufgaben der beiden Anwesen Fouquets deutlich. Vaux-le-Vicomte war ein öffentlicher Raum, der in seiner Ikonographie und Ausstattung auf die Person des Königs ausgerichtet war. Einer viel Raum in Anspruch nehmenden Bibliothek wollte sich der von seiner Grundfläche her eher kleine Bau architektonisch nicht unterwerfen. Saint-Mandé blieb der private Raum Nicolas Fouquets. Hierhin zog er sich zum Arbeiten zurück. Hier empfing er die von ihm Geförderten, die seinen Ruhm vermehren und Vaux-le-Vicomte literarisch erhöhen sollten.

Die ab 1655 forcierte Erweiterung seiner Bibliothek sowie die Einstellung Pierre de Carcavys lassen das Anliegen des Finanzminister zutage treten: Er wollte eine Bibliothek, die ihresgleichen suchte. Sie erst entsprach den Bedürfnissen und Ansprüchen eines Ministers, der hoch hinaus wollte.

Auch die Kuriositätensammlung blieb in Saint-Mandé und wuchs nach 1655 stetig an. Aus der zeitgenössischen Literatur wissen wir, dass eine Unterbringung der Raritätensammlung in der neuen Schlossanlage geplant war und dass Le Brun hierfür zwei besondere Bauten entworfen hatte, die für einen Garten des 17. Jahrhunderts noch recht ungewöhnlich waren:

On voit $[\ldots]$ vis à vis du quarré d'eau [...] une chose qui a esté heureusement inuentée par le fameux Méléandre [Charles Le Brun]: car comme Cleonime [Fouquet] a plusieurs curiositez antiques, \& particulierement deux de ces figures de pierre, qu'on dit qui ont seruy à la sepulture des premiers Roys de Lybie; il a fait bastir en vn petit coin de terre assez irregulier, deux Pyramides à l'imitation de celles qui sont aupres de Memphis, afin de mettre tout ce qu'il a de ces sortes de raretez ${ }^{141}$.

Die bereits erwähnten Mumien, die den Glanz- und Mittelpunkt der Sammlung ausmachten, wurden demnach 1659 wahrscheinlich für Vaux-le-Vicomte erworben. Der weitere Ausbau der Sammlung sollte La Fontaine zufolge in Vaux erfolgen:

Nous fûmes envoyés par le maître des vents Pour offrir de sa part, en termes obligeants, 
Au possesseur de Vaux, Oronte [Fouquet] son intime,

Ce que dans ses pays on voit de raretés,

Ambre, nacre, corail, marbre, diversités,

Enfin tous les trésors de la cour maritime ${ }^{142}$.

Die Bibliothek als Ort der Gelehrsamkeit passte nicht so recht in das Programm von Vaux. Die Kuriositätensammlung allerdings sollte der neuen Anlage dazu verhelfen, sich noch stärker von anderen Schlössern abzuheben.

\subsection{Kunstsammlung}

\subsubsection{Skulpturen}

In welchem Maße bereits die römischen Sendungen von 1656 für das im Entstehen begriffene Vaux-le-Vicomte bestimmt waren, lässt sich heute nicht mehr feststellen. Da die Inventare von Vaux jedoch auch einige antike Statuen nennen, kann man davon ausgehen, dass ein Teil dieses Bestandes von den italienischen Einkäufen Louis Fouquets stammte. ${ }^{143}$ Darüber hinaus ist eine Skulpturensendung bekannt, die im August 1657 Vaux-le-Vicomte erreichte. Die Sendung enthielt Marmorfiguren aus einem alten Haus in der Nähe Lyons, die Fouquet von Le Tellier kostenlos überlassen worden waren ${ }^{144}$.

Der größte Teil der skulpturalen Ausschmückung von Schloss und Garten stammt jedoch von Künstlern, die im Auftrag Fouquets und wahrscheinlich unter der Direktive Le Bruns arbeiteten. Bereits seit 1655 war Michel Anguier (1614-1686) für den Finanzminister in Saint-Mandé tätig gewesen. 1658 kam er nach Vaux-le-Vicomte, um auch hier an der Gestaltung des Anwesens mitzuwirken. Dem Inventar von 1665 zufolge können Anguier zehn Skulpturen zugeschrieben werden: ein Hund und eine Hündin aus Hartgestein, ein Wildschwein aus gleichem Material, vier Köpfe »pour poser sur des guesnes«, zwei Sphingen aus Hartgestein (Zuschreibung nicht gesichert) und eine Figur »représentant une géométrie moderne de quatre pieds assise « aus weißem Marmor ${ }^{145}$. Die »Mémoire de Michel Anguier portant énumération de travaux exécutés par lui pour Fouquet et qui n'ont pas encore été payés« aus

142 La Fontaine, CEuvres complètes I, Bd. VIII, S. 270.

143 Insgesamt befanden sich den Inventaren zufolge acht antike Figuren, eine Büste und mindestens zwei Masken in Vaux-le-Vicomte (siehe Anhang 2).

144 Fouquet, Euvres, Bd. IV, S. 266f.: »La troisième [lettre écrite par Fouquet ou ses commis sur le fait des bâtiments et décorations de la maison de Vaux], datée du 21 Août 1657, [...] écrite auparavant par ledit Sieur Fouquet, contenant entr'autres choses ces mots: Celle-cy est pour vous avertir qu'il doit arriver à Melun demain, ou après, des balots \& caisses de figures de marbre, qui viennent de Lyon par terre; il est importannt [...] de les faire mener jusqu'à Vaux«. Und in einer Randbemerkung Fouquets heißt es auf S.266: »Que Monsieur Le Tellier m'a données gratuitement, provenant d'une demolition de quelque vieille maison en ce pais-là «.

145 Estimation des bustes de Vaux (1665), AN O ${ }^{1} 1964, \mathrm{n}^{\circ} 5$, fol. 3, abgedruckt in: BonNAFFÉ, Fouquet, S. 70. 
dem Jahr 1660 verzeichnet zudem zum einen die Entwurfszeichnung für eine Skulptur der Göttin Rea (hierbei handelt es sich mit der Figur Apollons um die beiden auf dem Tympanon des Eingangsportals sitzenden Figuren), und zum anderen den Transport auf dem Wasserweg von Vernon nach Medun einer Clémence und einer Justice, der vermuten lässt, dass auch diese beiden Figuren von Anguier geschaffen worden sind ${ }^{146}$. Guillet de Saint-George schreibt Anguier zudem die Figur des neben Rea auf dem Tympanon des Eingangsportals sitzenden Apollon zu sowie drei antike Philosophen und zwölf Hermen »qui figurent les douze dieux principaux ${ }^{147}$.

Die Doppelhermen am Eingangsgitter wurden von Mathieu Lespagnandel (1616-1689) entworfen ${ }^{148}$. Seine Arbeit in Vaux-le-Vicomte ist ab 1659 belegt ${ }^{149}$. Die doppelköpfigen Büsten auf einem Fußgestell zeigen insgesamt acht Götter, die nur zu einem Teil klar herausgearbeitet sind ${ }^{150}$. Der Sturz Fouquets verhinderte die Fertigstellung der Hälfte der Hermen, die jedoch trotz ihres unfertigen Zustandes an dem für sie vorgesehenen Platz aufgestellt wurden, wo sie sich noch heute befinden. Ebenfalls Lespagnandel zugeschrieben werden die sitzenden Figuren des Tiber und Anqueuil, die sich in den Grottenhöhlen befinden, sowie die vier Löwenstatuen aus Sandstein mit einer Länge von 2,60 Metern, die linker- und rechterhand der beiden Aufgänge zur Ebene der gerbe d'eau aufgestellt sind.

Eine weitere für das ikonographische Konzept der Anlage von Vaux-leVicomte wichtige und von Nicolas Fouquet in Auftrag gegebene moderne Skulptur ist die Herkules-Statue von Pierre Puget (1620-1694), die jedoch nicht mehr vor dem Sturz des Finanzministers fertiggestellt wurde. Da sie sowohl von Madeleine de Scudéry in ihrem Roman erwähnt wird als auch auf den Stichen Silvestres abgebildet ist, wurde sie wohl um 1659 in Auftrag gegeben. Die Arbeit Pugets an der Skulptur mag von einem weiteren Auftrag Fouquets unterbrochen worden sein, der sich bis zum September 1661 hinzog: Um 1660 sandte der Finanzminister den Künstler für die Auswahl und den Kauf von Marmor für Vaux-le-Vicomte nach Italien ${ }^{151}$. Souchal vermutet, dass die Herkulesstatue schließlich erst in den Jahren 1663-1668 zur Aus-

\footnotetext{
146 Abgedruckt in: CoRdeY, Vaux-le-Vicomte, S.221.

147 Guillet de Saint-George, Mémoires, Bd. I, S. 440.

148 CoRdey, Vaux-le-Vicomte, Dokument IX, S. 223: Mémoires et devis concernant les travaux de sculpture exécutés à Vaux-le-Vicomte par Mathieu Lespagnandel, I: Mémoire des ouvrages dont je n'ay de marché que verbalement (30 septembre 1662). Siehe auch: AN, Fonds d'Ormesson, 156 MI 18, fol. 86r.

149 Cordey, Vaux-le-Vicomte, Dokument IX, S. 224: Mémoires et devis concernant les travaux de sculpture exécutés à Vaux-le-Vicomte par Mathieu Lespagnandel, II: Mémoire des ouvrages de sculture quy convienne estre faicte au grotte de Monseigneur le procureur generalle en son chateau de Vaux par moy Lespagnandelle, maistre sculteur (16 avril 1659).

150 Zur Identifizierung der Gottheiten siehe S.91, Anm.39.

151 Petitfils, in: Cornette, Versailles, S. 67 datiert die Reise Pugets nach Rom auf das Jahr 1660. SouchaL, French Sculptors, Bd. II, S. 187 datiert sie auf das Jahr 1661.
} 
führung kam. Ihre Planung für Vaux-le-Vicomte ist durch ein Wachsmodell belegt, dass sich in Le Bruns Räumen im ersten Obergeschoss von Vaux-leVicomte befand ${ }^{152}$. Die heutige überlebensgroße Herkulesstatue überragt die von Puget ausgeführte (und später von Colbert für Sceaux erworbene) Figur bei weitem.

Einzigartig ist der Auftrag, den Fouquet bereits 1655, also noch vor dem endgültigen Entwurf für Vaux-le-Vicomte, an den in Rom lebenden Maler Nicolas Poussin erteilte ${ }^{153}$. Obwohl für die nächsten zwei Jahre mit Arbeit ausgelastet, entwarf der alternde Künstler eine Gruppe von Hermen für den Garten von Vaux-le-Vicomte - und lieferte damit sein erstes und einziges skulpturales Werk: »Il fit de ses mains les modèles de terre, de la grandeur des statues au naturel, qu'exécutèrent divers sculpteurs, dans la maison desquels je l'ai vu plusieurs fois travailler la terre avec l'ébauchoir et modeler avec grande facilité «154. Es sind keine Entwurfszeichnungen Poussins überliefert, so dass man davon ausgehen kann, dass der Maler direkt am Modell gearbeitet hat, wie er es von seinen Studienstatuetten für die Gemälde gewohnt war $^{155}$. Im Frühsommer 1656 dürften zumindest die Modelle Poussins für die Hermen fertiggestellt gewesen sein, denn am 7. März 1656 schreibt Louis aus Rom, dass die Arbeit an den Hermen den Meister noch gute zwei Monate beschäftigen würde ${ }^{156}$. Nicht überliefert ist die Anzahl der Hermen für Vauxle-Vicomte sowie ihr genauer Aufstellungsort. Die »Estimation« von 1665 verzeichnet dreizehn Hermen einer zusammengehörigen Gruppe aus weißem Marmor mit einer Größe von sechseinhalb Fuß (= 2,11 m), zehn davon im grand parterre, eine »encore enquaissé estant dans l'un des passages du chasteau« und zwei weitere »posez a costé de la gerbe au dessus de la grande cascade ${ }^{157}$. Die 1672 publizierte Biographie Poussins aus der Feder Giovanni

152 Ibid.

153 Louis spricht erstmalig in dem Brief vom 27. Dezember 1655 die Arbeit Poussins an den Hermenentwürfen an: »Il [Poussin] vous fera faire des Termes admirables; ce seront des statues qui vaudront celles de l'antiquité. Jusques à présent on a travaillé aux modèles, aptitudes, etc (Fouquet, Lettres, S.297). In einem Brief vom 23. August 1655 weist er Fouquet noch darauf hin, dass der Maler vorzugsweise für den Finanzminister zu arbeiten bereit ist (Fouquet, Lettres, S.295). Der Auftrag muss also zwischen September und Dezember 1655 an Poussin erteilt worden sein.

154 Bellori, Poussin, S.79. Poussin hatte es sich zwar zur Angewohnheit gemacht, die Haltung der Figuren seiner Gemälde sowie den Faltenwurf ihrer Kleider vorab an eigenen Skulpturen aus Wachs oder Ton zu erproben, auch hatte er sich mit seinem Freund François Duquesnoy bereits in der Kunst der Skulpteure versucht, über ein Entwurfsstadium waren diese Versuche jedoch bisher nicht hinausgekommen. Bellori berichtet über den Hermenauftrag hinaus von einer anderen Arbeit für Fouquet, die aus den Briefen Louis Fouquets nicht ersichtlich wird. Es handelt sich um zwei Vasen »à l'antique, grands d'environ quatres palmes, avec les anses enroulées de serpents, qu'il fit travailler et exécuter en marbre africain antique (ibid., S. 80).

155 Kerspern, Termes de Poussin, S. 272.

$156 »$ Vos Termes l'occuperont bien encore deux mois« (in: FouQueT, Lettres, S. 300).

157 Estimation (1665), in: BonnafFé, Foucquet, S. 70. 
Pietro Belloris, die einzige zeitgenössische Quelle neben den Inventaren, berichtet von dem Thema der Hermen:

Il représente les divers génies des fleurs et des fruits de la terre en figures humaines et de femmes, avec toute la poitrine humaine, et élevées sur des Termes, ou Hermès, que l'on devait disposer dans les allées du jardin. Voici le dieu Pan, couronné de pin, avec un rameau en main; le dieu Faune riant, le torse enguirlandé de lierre; Pallas dont le heaume est entouré d'oliviers, avec le rameau dans la droite et le serpent; Cères, Bacchus, avec les épis et les raisins, et d'autres nymphes et divinités, avec des corbeilles de fleurs et de fruits, et une corne d'abondance, en signe de la fertile et délicieuse villa ${ }^{158}$.

Es sind nahezu alles Gottheiten, die den Charakter Vaux' als Ort der Zerstreuungen und Feste in Ausgelassenheit und Überfluss kennzeichnen sollten.

Bei dem Großteil der Skulpturen von Vaux-le-Vicomte handelt es sich um Auftragsarbeiten. Die Ikonologie der Statuen durfte nicht dem Zufall überlassen werden. Ihr materieller Wert war - im Gegensatz zu Saint-Mandé, das den gesellschaftlichen Aufstieg Fouquets manifestieren sollte und wo der Hauptteil der antiken und wertvollen Statuen des Finanzministers untergebracht war - zweitrangig. Für Vaux-le-Vicomte war es vielmehr von Bedeutung, dass sich die Skulpturen in das ikonographische Programm der Schlossanlage einfügten, denn diese war das Mittel einer eher politischen als gesellschaftlichen Distinktion. Aus diesem Grund wurden die Figuren in die bildliche und literarische Inszenierung der Anlage einbezogen. Silvestre zeigt in seinen Zeichnungen und Stichen die Hermen Poussins im Wechselspiel mit Natur, Wasser und Perspektiven und hebt zudem Pugets Herkulesstatue als visuellen Schlusspunkt von Vaux hervor. Madeleine de Scudéry konzentriert sich in ihrer »Clélie« auf die Darstellung der Figurengruppen am Ende des Gartens: die Flussgötter und Löwen von Lespagnandel und die Herkulesstatue von Puget, und greift damit die wichtigsten Themen der Anlage auf.

\subsubsection{Gemäldekäufe zwischen 1656 und 1661}

Für die Zeit zwischen Sommer 1656 (Ende der Kunstmission Louis Fouquets in Rom) und März 1661 (Reise Maucroix' in die Ewige Stadt) sind keine Kunstkäufe Fouquets im Ausland bekannt. Welche der von Louis Fouquet bis zum Sommer 1656 in Rom erworbenen Gemälde für Vaux-le-Vicomte bestimmt waren, lässt sich mit Hilfe des 1661 erstellten Inventars und der königlichen séquestre von 1671 ermitteln. Beide Quellen nennen vierzehn hochrangige Bilder, die sich im Appartement Le Bruns in der ersten Etage des Schlosses befanden: »lesquels tableaux appartenants audit sieur Fouquet et dit Le Brun s'y avait chargé pour les conservé «159. Es sind dies Gemälde namhafter Künstler: Lambert Sustris, Jan Brueghel d. Ä., Anthonis Mor, Paolo Veronese und der Familie Bassano. Es ist wahrscheinlich, dass es sich bei den Bildern um die vierzehn von Louis in seiner zweiten Sendung aus Rom ge-

$159 \mathrm{AN} \mathrm{V}^{6} 577$, fol 3. 
Abb. 41: »Die Schönheit stutzt die Flügel Amors" (Charles Le Brun, vor 1661). Vaux-leVicomte.

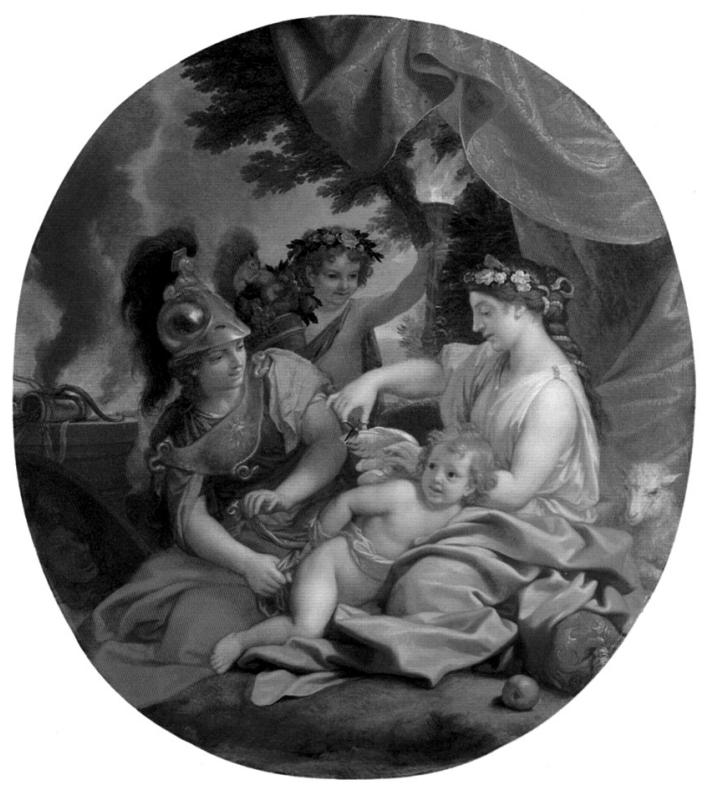

schickten Gemälde handelt. Die berühmtesten und wertvollsten Stücke der Gemäldesammlung Fouquets wurden demnach in Vaux-le-Vicomte aufbewahrt, wo sie die Exklusivität der Ausstattung erhöhten. Das Inventar von 1661 nennt des Weiteren dreizehn Gemälde, die jedoch nicht näher bestimmt werden können (siehe Anhang 2).

Über diesen Bilderbestand hinaus sind drei Auftragsarbeiten bekannt, die von Charles Le Brun wahrscheinlich zur Bauzeit von Vaux-le-Vicomte für Fouquet ausgeführt wurden. Es handelt sich um drei Porträts, die das ikonographische Programm ergänzten und wohl eigens aus diesem Grund in Auftrag gegeben wurden: Ein Bildnis Ludwigs XIV., eines Mme Fouquets und ein weiteres, das den Hausherrn von Vaux zeigt. Zwei der drei Bilder wurden auch von den zeitgenössischen Literaten rezipiert. Ihre Aufnahme in die Werke Félibiens und Nivelons macht die Wichtigkeit der Porträts für das Bildprogramm Vaux-le-Vicomtes deutlich.

Das Porträt von Marie-Madeleine de Castille wird in der »Troisième relation« von André Félibien in aller Ausführlichkeit behandelt. Das kleinformatige Gemälde mit dem Titel »La Beauté et la Sagesse rognant les ailes de l'Amour « (Abb.41) befindet sich seit einigen Jahren wieder im Schloss selbst. Es hängt im cabinet des appartement von Mme Fouquet im ersten Obergeschoss.

Das Bild zeigt vier Personen, von denen die beiden rechten durch eine besondere Lichtführung hervorgehoben werden. Es sind dies die Figur der 
Schönheit, »une belle femme assise [...] vestuë d'une robe blanche \& d'un manteau bleu, ayant sur sa teste une guirlande de roses ${ }^{160}$, und auf ihren Knien Amor, dem sie die Federn stutzt, damit er auf ewig bei ihr bleibe. Das Kind wird von der Allegorie der Weisheit und Vernunft in Gestalt der Minerva gehalten. Hinter ihr beleuchtet ein ebenfalls blumenbekränzter Knabe die Szene, der in seiner zweiten Hand ein mit Blumen und Früchten gefülltes Horn als Zeichen des Reichtums emporhält. Mit diesem Gemälde wurde auch die Hausherrin über die Präsenz ihrer Initialen und Wappen im Dekor des Schlosses hinaus in die Ikonographie von Vaux-le-Vicomte eingebunden. Sie steht für die Schönheit der Anlage. Sie ist es, die - mit Unterstützung der Weisheit und Vernunft - die Liebe in Vaux erhält. Sie wird damit zum notwendigen Gegenpart ihres Mannes. Indem sie für Harmonie im Hause sorgt, gibt sie ihrem Gemahl die Möglichkeit, sich um die Staatsgeschäfte zu kümmern. Beide stehen im Dienste des Königs, für dessen Wohlergehen sie - mittels einer geschlechtlichen Aufgabenverteilung - auf privater und staatlicher Ebene Sorge tragen.

Das Gegenstück zu diesem Gemälde, das Porträt Nicolas Fouquets, befindet sich heute ebenfalls in Vaux-le-Vicomte. Es hängt dort, wo es sich aufgrund seines Bildgehalts am besten in das Bildprogramm des Schlosses einfügt: in der den Staatsgeschäften vorbehaltenen Chambre carrée. Im Gegensatz zum Porträt Mme Fouquets und den Deckendarstellungen des appartement d'apparat des Finanzministers handelt es sich bei dem Abbild Fouquets um keine allegorisierte Darstellung.

Das Gemälde (Abb.42) zeigt den auf einem Stuhl sitzenden, dem Betrachter rechts zugewandten Finanzminister in der Amtsrobe eines Magistrats ${ }^{161}$, mit einer Feder in seiner rechten und einem gefalteten Blatt Papier in seiner linken Hand. Fouquet blickt den Betrachter offen, aber bescheiden an. Der Hintergrund liegt in fast völligem Dunkel. Trotzdem ist das kostbare Mobiliar zu erahnen: Sessel und angrenzender Tisch sind mit Gold- und Silberelementen reich verziert. Auf dem Tisch befindet sich eine rote Kassette. Hinter Fouquet ist ein gold umrahmtes Gemälde fast in Gänze von einem samtenen Vorhang verdeckt. Das Porträt zeigt einen mit dem seiner Position angemessenen Wohlstand umgebenen Finanzminister, der sich jedoch nicht von den Verlockungen von Kunst und Kostbarkeiten ablenken lässt. Er widmet sich allein den Staatsgeschäften (Dokument und Schreibgerät) und blickt dem politischen Alltag voller Erwartung und mit großer Selbstgewissheit entgegen. Die bei ihm liegende Kassette ist ein Symbol seiner Diskretion: Bei ihm ist jedes Geheimnis in guten Händen. Fouquet lässt sich als einen vertrauenswürdigen und diskreten Staatsmann darstellen. Seine in diesem Porträt formulierten Regierungstugenden (Kompetenz und Diskretion) lassen sich in den Dienst des dritten für Vaux von Le Brun angefertigten Porträts stellen, das sich im Esszimmer des Schlosses befand.

160 FÉLIBIEn, Relations, Troisième relation, S.48f.

161 Zur Kleiderordnung der Zeit siehe: Mansel, Costume, S. 7. 
Abb.42: Porträt Nicolas Fouquets (Charles Le Brun, vor 1661). Vaux-le-Vicomte.

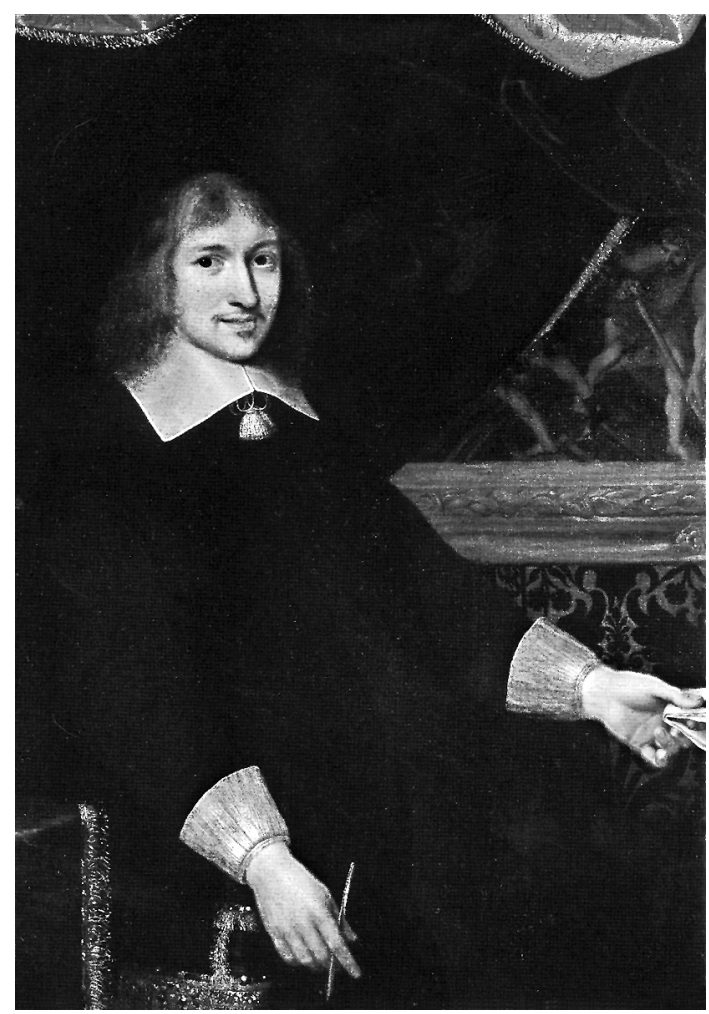

Das Bildnis Ludwigs XIV. war über dem Kamin der salle à manger angebracht ${ }^{162}$. Von den drei Autoren Félibien, La Fontaine und Scudéry wird es nicht beschrieben. Doch Claude Nivelon, der erste Biograph Le Bruns, erwähnt es. Das Gemälde vervollständigt das in Vaux zusammengeführte Trio aus König, Hausherrn und Gemahlin. Es gilt heute als verschollen ${ }^{163}$. Seine Beschreibung kann einzig durch die Augen Nivelons erfolgen:

[Le tableau] représente Louis XIV assis sur son lit de justice, revêtu des habits royaux, ayant en main les marques de la puissance royale; au bas se voient des armes brûlantes, l'Amour qui enchaîne la Rébellion et des trophées de peinture et de tous les arts confusé-

162 Die Wahl des Ortes für die Bildaufhängung folgt einer Tradition des 17. Jahrhunderts. Das Porträt des Königs (entweder ein Basrelief, eine Wandmalerei oder ein Gemälde) wurde in der Regel über einem Kamin angebracht (zum Beispiel: Fontainebleau, Reiterrelief Heinrichs IV.; Maisons, Gemälde Ludwigs XIV. im salon d'Hercule).

163 Jouin, Le Brun, S. 119 schließt nicht aus, dass es sich bei dem Bild um ein Wandgemälde gehandelt hat, welches bei der Übernahme des Schlosses durch Claude Louis Hector, Duc de Villars im Jahre 1705 und der Zerstörung der Malereien des Speisesaals zugunsten der Anbringung von Tapeten vernichtet wurde. 
ment mêlés ensemble, parmi lesquels se voit un tableau dressé représentant le grand Henri, aïeul de Louis XIV ${ }^{164}$.

Ludwig XIV. wird als gerechter König präsentiert, der das Erbe seines Großvaters fortführt und seinem Reich Frieden bringt. Die ihm zu Füßen liegenden Symbole für Malerei und Künste machen kenntlich, dass er seinem Land eine kulturelle Blüte - die von einer erfolgreichen Friedenspolitik abhängt bringen wird. Fouquet ließ das Gemälde nicht ohne Grund für sein neues Schloss anfertigen. Vaux-le-Vicomte zeigte sich als Ausgangspunkt und Vorbild der zukünftigen Prosperität. Hier war der Idealzustand bereits erreicht.

Es ist nicht bekannt, zu welchem Zeitpunkt die drei Porträts für Vaux entstanden sind. Da das Bildnis Mme Fouquets von Félibien beschrieben wird, kann man davon ausgehen, dass es vor 1660 angefertigt wurde. Kurz nach der Hochzeit des Monarchen wurde, so Nivelon, das Bild Ludwigs fertiggestellt. Es ist demnach auf das Jahr 1660 zu datieren. Das Porträt von Nicolas Fouquet wird von keinem der zeitgenössischen Autoren erwähnt. Es wurde wohl also erst nach 1660 angefertigt ${ }^{165}$. Die Gemälde von Vaux-le-Vicomte dienten zum einem seiner luxuriösen Ausstattung und zum anderen der Komplettierung seiner ikonographischen Botschaft. Letztere wurde durch gezielte Auftragsarbeiten gewährleistet.

Bemühungen um den Erwerb von Gemälden auf dem freien Kunstmarkt durch Fouquet sind ab dem Jahr 1660 wieder belegt. Doch handelte er nach 1656 bei Gemäldekäufen nicht in eigener Sache. In Zeiten zunehmender politischer Instabilität scheint die (vielleicht wenige Jahre zuvor noch intendierte) Vergrößerung seiner eigenen Sammlung von untergeordneter Bedeutung gewesen zu sein. Vielmehr wollte sich der Finanzminister dieses Sammlungsgebiet nun auf eine andere Weise für die Festigung seiner politischen Position zunutze machen. Durch Kunstkäufe für den großen collectionneur Mazarin, der zum Zeitpunkt seines Todes eine Sammlung von mehr als achthundert Gemälden besaß, und die königliche Familie, suchte er sich zum Favoriten der Stunde zu erheben.

1660 war Nicolas Fouquet an den Verhandlungen zu dem berühmten Gemälde »Charité de saint Roch" von Annibale Carracci beteiligt, die er wahrscheinlich im Namen des Königs ausführte ${ }^{166}$. Zu Beginn des Jahres 1661 schließlich erwarb Fouquet aus der Sammlung des Kölner Bankiers Everhard Jabach für 240000 Livres einundsechzig hochrangige Gemälde, die er jedoch nicht für die Vergrößerung seiner eigenen Sammlung vorsah. Aus den Aufzeichnungen des in Paris weilenden Christiaan Huygens vom 27. Januar 1661

164 Nivelon, Le Brun, S. 260.

165 Cordey, Portraits, S. 220 geht hingegen davon aus, dass das Porträt von Nicolas Fouquet bereits viel früher entstanden ist. Er datiert es auf die Zeit vor 1654. Da Le Brun aber erst ab 1655 in Fouquets Diensten stand, ist dies unwahrscheinlich. Nivelon erwähnt das Porträt Fouquets in seiner Biographie Le Bruns nicht.

166 SchnAPPER, Curieux, S. 217. 
wissen wir, dass die Gemälde bereits Ende Januar in der Bibliothek des Kardinals hingen, wohin sie auf Veranlassung Le Bruns geliefert worden waren ${ }^{167}$. Im März desselben Jahres, kurz vor dem Tod des Kardinals, wurden sie in den königlichen Besitz übergeben. Unklar bleibt, ob der Finanzminister die Gemälde im Namen Mazarins erstand, damit dieser sie dem König zum Geschenk machen konnte, oder ob Fouquet sie dem Premierminister schenkte mit der Absicht »à obtenir et à se conserver les faveurs du Cardinal « ${ }^{168}$, dieser sie aber an Ludwig weitergab.

Im März 1661 sandte Fouquet ein weiteres Mal einen Kunstagenten nach Italien. War der Romaufenthalt Louis Fouquets der Jahre 1655/1656 zum Aufbau einer eigenen Sammlung bestimmt gewesen, konzentrierten sich nun seine Kunstkäufe auf den Erwerb für Dritte. Wie bereits Louis Fouquet, so kam auch der neue Kunstagent François Maucroix, ein Jugendfreund Jean de La Fontaines, kurz nach dem Tode Mazarins im März 1661 mit einer doppelten Mission nach Rom. Unter dem Pseudonym Abbé de Crécy sollte er diplomatisch tätig werden und mit Zustimmung des Königs die von Mazarin vernachlässigte Beziehung zwischen dem Papst und dem französischen Hof verbessern, war zudem aber damit beauftragt, »d'acquérir pour le surintendant tableaux et objets d'art «169. Dass Fouquet nach dem Tod Mazarins und der Vakanz des Amtes des Premierministers nicht die Absicht hatte, in Italien für seine eigenen Sammlungen anzukaufen, zeigen die Maucroix vor seiner Abreise gegebenen Instruktionen: »M. Maucroix s'informera aussi des curiositez et raretez du païs qu'on pourroit envoyer soit pour Monsieur ou pour Madame, soit pour faire de petits présens de temps en temps au Roi ou aux Reines «170. In Rom gab sich Maucroix als allseits interessierter Geistlicher ohne Ziel und Reiseauftrag, traf Kardinäle »\& paroistra là comme un Ecclesiastique, qui n'a autre affaire que de voir le monde. Et pour cét effet, il fera aussi des habitudes avec les Peintres celebres, comme le Poussin, le Chevalier Bernin, le Chevalier del Pozzo, \& les autres curieux de ce pays-là, chez qui les honnestes gens s'assemblent ${ }^{171}$. Kein Geringerer als der Abbate Elpidio Benedetti, ehemaliger Kunstagent Mazarins in Rom, diente Maucroix in der heiligen Stadt als Ansprechpartner. Die Kunstmission sollte jedoch diskret behandelt werden. Über die Preise der erworbenen Kunstobjekte durfte nicht gesprochen wer-

167 »Ménage me vint prendre, et me mena voir la Bibliothèque de M. le Cardinal ou l'on avait estalé quantité de beaux tableaux Italiens appartenant à Jabach. [En marge non daté: M. Fouquet les a achetez pour 80000 écus (= 240000 Livres)]« (zitiert nach: ScHNAPPER, Louis XIV, S.85).

168 Michel, Mazarin, S. 137.

169 Maucroix, Lettres, S. 23.

170 BN ms. fr. 18423, fol. 52v.

171 Extrait de l'inventaire de production de Monsieur le Procureur General de la Chambre de Iustice; Contenant les inductions qu'il a tirées de l'Escrit de Mr Fouquet, dont la copie figurée est cy-devant transcrite, BN FOL-LB37-3341, S. 33. 
den ${ }^{172}$. Besondere Vorsichtsmaßnahmen sollten zudem bei der Verschickung der Einkäufe walten, eine Sendung an den Finanzminister nicht auf direktem Wege, sondern über mindestens zwei Mittelsmänner erfolgen ${ }^{173}$. Über Käufe durch Maucroix ist indes nichts überliefert. Dies dürfte seinen Grund darin haben, dass die Romreise, die als außenpolitischer Schachzug Fouquets geplant worden war und vielleicht durch den Wunsch des Finanzministers nach der Nachfolge Mazarins genährt wurde, mit dem plötzlichen Sturz des Ministers ein schnelles Ende fand.

\subsubsection{Tapisserien}

Ein Schwerpunkt der Kunstsammlung Fouquets lag bei den Tapisserien. Diese galten als ausgesprochene Luxusgüter und waren ein künstlerisches Medium, das wie kein anderes repräsentative Zwecke erfüllte ${ }^{174}$. Die Sammlung des Finanzministers umfasste nicht nur besonders berühmte und wertvolle, mit Gold und Silber durchwirkte Serien, für die Ausstattung von Vaux-le-Vicomte gründete er sogar eine eigene Manufaktur in unmittelbarer Nähe des neuen Schlosses, die den Stellenwert der aufwendigen und kostbaren Kunstwerke innerhalb seiner Sammlung kenntlich macht. Fouquet besaß sowohl flämische als auch französische und englische Teppichfolgen. Da keine Quellen überliefert sind, die Auskunft geben über das Kaufverhalten des Finanzministers vor der Einrichtung der Manufaktur von Maincy, können Rückschlüsse auf die Zusammenstellung seiner Sammlung nur mit Hilfe der Inventare und allgemeiner Informationen über den französischen Tapisseriemarkt im 17. Jahrhundert gezogen werden.

Die Sammelleidenschaft für Tapisserien blühte im 17. Jahrhundert. Die größte Nachfrage bestand nach den luxuriösen, mit Gold und Silber durchwebten Historienfolgen aus dem flandrischen Raum, deren Einfuhr seit Heinrich IV., der die Produktion dieser Luxusgüter im eigenen Land durch die

\section{BN ms. fr. 18423 , fol. 52r.}

173 Auf Seite 37f. des »Extrait de l'inventaire de production de Monsieur le Procureur General« wird der zu verfolgende Weg bei der Versendung der Kunstobjekte wie folgt beschrieben: »Quant à l'adresse de ses pacquets, il peut les recommander tousiours par une lettre ou autrement, à M. du Lieu maistre des Courriers à Lyon, pour qui on luy donnera une lettre. Se servir par chaque Ordinaire, de divers noms pour mettre au dessus du pacquet; par exemple, il peut m'appeller de trois noms differens, M. de Saint Val; M. de Boisvert, M. le Cointe: Plus mettre une autre enveloppe par dessis celle-là, tantost à M. Tallement Boisvert, rue des Fossez Montmartre; tantost à M. Estrang Banquier, rue S. Honoré; tantost à M. Dumas Advocat au Conseil, rue des vieux Augustins; lesquels seront advertis chacun, de me rendre les Lettres qui viendront sous leur enveloppe, avec un tel nom. Par exemple, M. Dumas sera adverty pour celuy de M. de Boisvert; M. Tallement, pour Saint Val; M. Estrang, pour M. le Cointe. Il peut aussi se servir pour le dessus des Lettres, tantost de la main d'un valet, tantost de la sienne, \& de differens cachets, dont nous sommes convenus. Tout cela pour faire perdre la trace à ceux qui voudroient intercepter les Lettres, \& descouvrir ses correspondances«.

174 Brassat, Tapisserien, S.11f. 
Gründung von Manufakturen förderte, verboten war. Ihr Erwerb war auf legalem Weg nunmehr ausschließlich über private Verkäufe, häufig Nachlassverkäufe möglich. Die Beauftragung der französischen Tapisseriemanufakturen mit der Herstellung der preziösen Stücke war auch unter privaten Sammlern gebräuchlich. Bei einer Produktionsgeschwindigkeit von einem Meter pro Monat und Person - eine mehrteilige Serie konnte damit eine Herstellungszeit von bis zu zehn Jahren erreichen - sowie einem drastischen Anstieg der Nachfrage nach Tapisserien seit Anfang des Jahrhunderts musste jedoch mit langen Wartezeiten bei der Herstellung von Auftragswerken in den Manufakturen gerechnet werden.

Um sowohl die langen Wartezeiten für französische Tapisserien als auch den aufwendigen Erwerb der hochwertigen flämischen Produkte zu umgehen, gab es seit der Mitte des 17. Jahrhunderts im französischen Raum einige wenige private Manufakturgründungen. Nur selten sind sie - wie im Falle Fouquets - auf den Wunsch zurückzuführen, vorrangig für die Ausstattung einer einzigen Schlossanlage zu produzieren ${ }^{175}$. Fouquets Bauprojekt erforderte eine rasche Fertigstellung, da ihn die politischen Umstände unter hohen zeitlichen Druck setzten. Die große Ungeduld bei der Errichtung seiner Schlossanlage brachte den Finanzminister (oder seinen künstlerischen Leiter?) wenige Jahre nach dem Beginn der Arbeiten am Schloss auf die Idee, eine eigene Werkstatt zu gründen und damit die Ausstattung des Baus mit den hochwertigen Wandbehängen selbst kontrollieren und dem Bautempo entsprechend anpassen zu können. Die Manufaktur von Maincy wurde im September 1658 gegründet. In zwei Ateliers entstanden hier bis 1662 (die dortige Arbeit wurde auch nach der Verhaftung des Finanzministers weitergeführt) zahlreiche Tapisserieserien an Hoch- und Niedrigschaftstühlen. Grésy schätzt die Zahl der in Maincy beschäftigten Bildwirker zwischen 1658 und 1662 auf 290. Die Arbeiter kamen überwiegend aus Flandern und Frankreich ${ }^{176}$. Die Ernennung Le Bruns zum Direktor der Manufaktur von Maincy kann im doppelten Sinne nicht verwundern. Zum einen war es in den Tapisseriemanufakturen allgemein üblich, mit Malern zusammenzuarbeiten, die Entwürfe und Vorlagen lieferten. Zum anderen war Le Brun mit der gesamten künstlerischen Leitung von Vaux-le-Vicomte beauftragt, in die das Atelier von Maincy als wesentlicher Bestandteil gehörte. Charles Le Brun führte in der neuen Manufaktur bedeutende Neuerungen im Herstellungsablauf der Tapisserien ein, die

175 HeInz, Europäische Tapisseriekunst, S. 165 nennt nur einen vergleichbaren Fall: das in Cadillac im ersten Drittel des 17. Jahrhunderts gegründete Privatatelier des Herzogs von Épernon. In den meisten Fällen kam die Initiative für eine Manufakturgründung entweder von den Gemeinden oder den Bildwirkern selbst.

176 Grésy, Documents, S.15f. führt neunzehn Arbeiter namentlich auf, unter ihnen Jean und Claude Lefebvre, bei denen es sich - wie Cordey, Tapisserie, S. 40 vermutet - um den Sohn und den Neffen des haute-lissier Pierre Lefebvre handelt, der 1648 vom König aus Florenz nach Paris geholt wurde, um hier bis zur Einrichtung der Gobelins in der Manufaktur des Louvre zu arbeiten. 
ab 1662 in der königlichen Gobelinmanufaktur übernommen wurden. Er gestaltete den Arbeitsablauf durch eine neue Hierarchie unter den Webern und deren Spezifizierung effizienter ${ }^{177}$ und führte eine neue Vorlagentechnik für die Tapisserien ein, die nicht nur den Arbeitsprozess erleichterte, sondern auch die gewebten Produkte in ihrer Bildlichkeit präziser werden ließ. War es bislang üblich, dass die in Deckfarben oder Tempera kolorierten, auf Papier ausgeführten Vorlagenzeichnungen von den Webern mit einem gewissen Interpretationsspielraum auf ihr Medium übertragen wurden, so wurden die Entwürfe nun von den Künstlerateliers in Öl an die Manufaktur gegeben. Damit gewannen die Vorlagen an die Weber sowohl in ihrer Darstellung als auch der Farbgebung an Präzision.

Im Mai 1660 erhielt das Tapisserieatelier von Maincy ein königliches Privileg (lettre patente), wodurch es in den Rang einer königlichen Manufaktur erhoben wurde. Mit Verweis auf die Entfernung zu Paris übertrug Ludwig XIV. die Leitung der Manufaktur ihrem Begründer Nicolas Fouquet. Ihre Produkte sollten von nun an mit einer Bleiplombe gekennzeichnet und ihre Nachahmung verboten werden. Die aus Flandern stammenden Arbeiter und ihre Familien wurden eingebürgert; zudem sollten in Maincy zwanzig Lehrlinge eine Ausbildung finden, so dass der Fortbestand der Ateliers gesichert war. Die lettre patente rühmt die Manufaktur als »un etablissement si utile et avantageux au public « und erinnert an Heinrich IV., der die Tapisseriemanufakturen in Frankreich gefördert hatte »pour en faire l'espreuve à la maniere de Flandres «178.

Die »Histoire de Constantin « ist die bekannteste Tapisserieserie aus Maincy und eine der berühmtesten Folgen überhaupt, die nicht nur zu dem Bestand der größten Kunstsammlungen der Zeit (wie zum Beispiel derjenigen Mazarins) gehörte, sondern - noch unvollendet - rund dreißig Jahre zuvor von Ludwig XIII. als diplomatisches Geschenk an Kardinal Francesco Barberini überreicht worden war ${ }^{179}$. In Maincy wurde sie nach Vorlagen Le Bruns in fünf Stücken gefertigt (die ursprüngliche Folge umfasste zwölf Motive) und ist im Inventar von $1665 \mathrm{im}$ Besitz von Fouquet nachgewiesen. Der hohe Prestigewert der Konstantinfolge sollte das Ansehen der neuen Schlossanlage steigern.

177 Über die Arbeitsaufteilung in der Manufaktur von Maincy ist nichts bekannt. In der Gobelinmanufaktur erfolgte eine Aufteilung in Figuren (Baudouin Yvart), Blumen und Früchte (Monnoyer), Tiere und Vögel (Pierre Boel), Architekturen (Guillaume Anguier) und Landschaften mit kleinen Figuren (van der Meulen) (Heinz, Europäische Tapisseriekunst, S. 145).

178 Lettres patentes accordées par le roi au surintendant Fouquet établissant une manufacture de tapisseries de haute et basse lisse dans le village de Maincy, Saint-Jean de Luz, mai 1660 (Archives de Vaux-le-Vicomte), zitiert nach: CoRdEY, Tapisserie, S. 48f.

179 Der Nepot Papst Urbans VIII. war 1625 nach Paris gekommen, um Ludwig XIII. auf eine konsequent katholische Außenpolitik zu verpflichten. Kurz vor seiner Ankunft hatte man jedoch soeben durch die Heirat der jüngeren Schwester Ludwigs dynastische Verbindungen mit dem Anglikaner Karl I. geknüpft. Mit der diplomatischen Gabe bekundete Ludwig XIII. Rom gegenüber seine besten Absichten (siehe: BRASSAT, Tapisserien, S. 92). 
Auch die »Histoire de Méléagre « ist eine der Serien, die nach den neuen Entwurfsmethoden in Maincy hergestellt wurde. Sie besteht aus fünf Stücken, die in basse-lisse (Verfahren am Webstuhl mit waagrechtem Webrahmen) gefertigt wurden, und war bis zur Überführung der Manufaktur von Maincy in die Gobelinmanufaktur im Jahre 1662 noch nicht in Gänze fertiggestellt. Es ist unklar, ob sie im Auftrag des Finanzministers gefertigt worden ist ${ }^{180}$. Entworfen wurde die Serie von Charles Le Brun und François Bellin, der in Maincy für die Landschaftsdarstellungen zuständig war ${ }^{181}$. Mit ihrer Jagdthematik hätte sich die Serie hervorragend in das Ambiente Vaux-le-Vicomtes eingepasst.

Von den Türvorhängen (portières) aus Maincy waren bis 1662 die »Renommées « mit den Wappen Fouquets, ein Vorhang zu »Mars« und die »Portière du char de triomphe « vollendet ${ }^{182}$. Zudem ist eine Verdüre mit Tierdarstellungen zu nennen, von der fünf Stücke vor 1662 in Maincy hergestellt wurden ${ }^{183}$, sowie ein »soubzbassemens de tapisserye « aus sechs Stücken in Wolle und Seide, welches in basse-lisse hergestellt war und sowohl im Inventar von 1661 als auch 1665 genannt wird.

Cordey zufolge lagen in Maincy außerdem Entwürfe für eine »Histoire de Moïse « und eine »Histoire des muses« sowie für einen Türvorhang mit der Fabel des Einhorns bereit, zu deren Ausführung es aber nicht mehr kommen sollte ${ }^{184}$.

Neben den Wirkteppichen aus Maincy gehörten zu der Sammlung des Finanzministers weitere Tapisserien aus dem französischen Raum. Mindestens zwei Teppichserien aus Fouquets Besitz stammen aus Pariser Manufakturen:

180 Nivelon bezweifelt dies. In seiner Biographie Charles Le Bruns schreibt er: »De ce même temps de 1658, M. Le Brun étant lié d'inclination avec un illustre ami, M. Valdor, qui était beaucoup en honneur et estimé à la cour et qui faisait de nobles entreprises, comme il a paru en plusieurs choses très curieuses, fit six grands tableaux pour être exécutés de tapisserie représentant l'histoire de Méléagre«. Überliefert sind drei Ölgemälde von 3,05 x 3,10 Metern, bei denen es sich mit großer Wahrscheinlichkeit um Entwürfe zu der Serie handelt: die im Louvre aufbewahrten Gemälde »La Chasse de Méléagre« und "La Mort de Méléagre « sowie die der Walker Art Gallery von Liverpool gehörende »Offrande de la hure « (ReYNiès, in: Lisses et délices, S. 268). Reyniès nennt zudem folgende Skizzen, die als Entwürfe für die »Histoire de Méléagre « aus der Hand Le Bruns identifiziert wurden: Skizzen zu der »Rencontre de Méléagre« (Darmstadt, Hessisches Landesmuseum), zwei Hundeskizzen zu »Offrande de la hure« und »Mort de Méléagre« (Paris, Louvre) (ibid.).

181 »Les dessins de ses tableaux se voient de sa [Le Brun] main, dessinés à la plume et rehaussés d'or de la même manière sans changements, et les paysages sont de l'habile M. Belin, qui vivat dans ce temps« (Nivelon, Le Brun, S. 238).

182 SAUNIER, in: Lisses et délices, S.286. Inwieweit der Vorhang »Lion« zur Ausführung kam, lässt Saunier offen. Die Vorlagen wurden auch in den Gobelins genutzt, so dass die Entwürfe wiederholt zur Ausführung kamen - im Falle des »Char de triomphe« einundsiebzig Mal.

183 CoRdey, Tapisserie, S. 43.

184 Ibid. 
die in haute lisse (Verfahren am Webstuhl mit senkrechtem Webrahmen) rehaussée d'or gefertigte sechsteilige Serie mit den Taten der Apostel, die im Inventar von 1665 als ein Produkt aus dem Pariser Raum kenntlich gemacht und auf 1500 Livres geschätzt wird, und die sechsteiligen mit Gold durchwirkten »Mois de l'année« nach Zeichnungen von Lucas van Leyden. Sie gehören mit einem Schätzwert von 3000 Livres im Jahr 1665 zu den wertvollsten Stücken der Sammlung Fouquets. Zudem gehörten zu ihr mehrere Tapisserien aus Rouen (die in den Inventaren nicht genauer beschrieben werden) und Verduren aus der Auvergne.

Nur zwei Tapisserieserien aus Brokatelle aus der Sammlung Fouquets stammten aus Italien. Es ist nicht auszuschließen, dass es sich dabei um Stücke handelt, die entweder von Louis Fouquet oder aber von Maucroix in Rom erworben wurden. Quellenbelege für diese Vermutung existieren allerdings nicht. Bei den fünf in dem Inventar von 1661 als »tapisserie de Bergame« bezeichneten Teppichfolgen ${ }^{185}$ handelt es sich - entgegen ihrer Bezeichnung nicht um Wirkereiarbeiten aus dem italienischen Raum. Sie stammen vielmehr aus Frankreich selbst und wurden in Rouen, Lille, Roubaix, Amiens oder Tournai angefertigt. Die auch als tapisseries de Rouen bezeichneten Teppiche (unter diesem Namen verzeichnet das Inventar zehn weitere Tapisseriefolgen dieser Art) wurden aus einfachen Materialien hergestellt und waren »mainly intended for secondary rooms and offices in important buildings «186. In Vaux-le-Vicomte finden sie sich überwiegend in den Räumen der in Vaux arbeitenden Künstler Le Nôtre und Le Vau und in jenen des Arztes La Rivière sowie in Gängen und Vorzimmern ${ }^{187}$.

Auf welchem Weg die sieben aus Flandern stammenden Bildteppichserien von Vaux-le-Vicomte erworben wurden, ist ungewiss. Möglich wäre ein Nachlasskauf oder ein Erwerb über französische Händler. Bedenkt man die politische Stellung Fouquets, wäre aber auch eine direkte Einfuhr aus Flandern denkbar. Die Inventare kennzeichnen sechs Teppichserien aus Brüsseler Ateliers: die »Histoire d'Abraham « in zehn Bildern, ein Einzelteppich mit der Geschichte von »Suzanne et les vieillards«, die »Histoire d'Iphigenye« in zehn Bildern, »Apollon et les Quatre Saisons« (oder: »Les Grotesques«) aus fünf Teppichen nach Zeichnungen von Giulio Romano, die achtgliedrigen »CEuvres de miséricorde« sowie die »Histoire de Salomon«, ebenfalls nach einer Vorlage von Giulio Romano. Die Brüsseler Werkstätten galten als die besten Tapisserieateliers, aus denen der größte Teil der sehr hochwertigen mit Gold

\footnotetext{
185 Inventaire de Vaux (1661), abgedruckt in: BonnAfFé, Foucquet, S. 86-96.

186 Thornton, Interior Decoration, S. 108.

187 Thornton bezeichnet die tapisseries de Bergame auch als "poor man's tapestry [...] for a middle-class clientèle that could not afford real tapestries « (ibid.). Dass sie in Vaux-leVicomte nicht in den repräsentativen Räumen des Erdgeschosses oder den Privaträumen des Bauherrn und seiner Frau im ersten Obergeschoss zu finden sind, erklärt sich durch die mindere Qualität der Teppiche, die der gesellschaftlichen Stellung Fouquets widersprochen hätte.
} 
und Silber durchwirkten Teppichserien stammte. Auch die Folgen von Vauxle-Vicomte, hergestellt aus einem Seiden-Woll-Gemisch, sind mit Gold durchwirkt und erreichen unter den 1665 geschätzten Tapisserien aus der Sammlung Fouquets Höchstwerte. Die Geschichte Salomos steht mit einem Schätzwert von 8000 Livres an erster Stelle. Ihr folgt mit 5000 Livres die Serie mit den »Euvres de miséricorde« und die »Histoire d'Iphigenye « mit 4000 Livres. Aus der besonders für ihre Verduren, nicht aber für eine hohe Qualität bekannten Bildwirkerstadt Oudenaarde stammt eine achtteilige »Histoire de Gédéon«, die 1665 auf 1800 Livres geschätzt wurde und damit weit hinter den Brüsseler Produkten zurückbleibt. Sie ist jedoch aufgrund ihrer Historie interessant. Der Gideon-Zyklus wurde ab 1448 im Auftrag Philipps des Guten hergestellt und galt lange Zeit als kostbarste Teppichfolge und Verkörperung der kulturellen Identität der Burgunderherzöge ${ }^{188}$. Seine Stellung unter den großen Bildwirkereien mag Fouquet dazu motiviert haben, eine Neuauflage der Folge zu kaufen, um das Ansehen seiner Sammlung zu steigern.

Aus England stammen fünf Tapisserieserien: »Les Vertus « (Wolle/Seide) in acht Bildern, »La Fable de Vulcain« nach Raffael in acht Bildern, die vierteilige »Histoire de saint Jean ${ }^{189}$ sowie die Einzelteppiche $»$ Les pèlerins d'Emhaus « nach Tizian ${ }^{190}$ und »Le Christ en croix«. Wahrscheinlich handelt es sich um Tapisserien aus der 1619 von Jakob I. gegründeten Manufaktur von Mortlake, die die älteren Ateliers verdrängt hatte und den englischen Markt beherrschte. Die sorgfältige Auswahl der Materialien sowie die fachmännische Ausführung durch namhafte niederländische Wirker brachte den Produkten aus dem Londonder Vorort bald europaweites Ansehen ${ }^{191}$. Auf welchem Weg Fouquet die Teppiche erhalten hat, ist nicht überliefert. Denkbar wäre ein Erwerb über Agenten vor Ort oder ein englischer Nachlassverkauf in Frankreich, die sich Anfang der fünfziger Jahre häuften.

Die Themen der Bildteppichserien aus Fouquets Sammlung weisen keinen Bezug zu der politisierten Ikonographie von Vaux-le-Vicomte auf. Selbst die Arbeiten aus der Manufaktur von Maincy verfügen, bis auf die Wappen Fouquets, über keinen aktuellen Bildgehalt. Dies entspricht durchaus der ikonographischen Tradition der Bildwirkerarbeiten, die aufgrund ihrer langen Herstellungszeit »an Prozessen der gesellschaftlichen Kommunikation meist nur mit einer gewissen Verzögerung « teilnehmen konnten und sich daher nicht aktueller, sondern vielmehr zeitloser, allgemeingültiger Sujets annahmen ${ }^{192}$. Erst Ludwig XIV. setzte zahlreiche Tapisserieserien motivisch in Bezug zu seinem Wirken und verwendete damit eine aktuelle Ikonographie. Die Tapis-

188 Brassat, Tapisserien, S. 189.

189 Schnapper, Curieux, Anm. 165 vermutet hinter dieser Serie ein Produkt aus Brüssel.

190 Hierbei handelt es sich um eines der beliebtesten Themen aus der Manufaktur von Mortlake, deren sehr feine dichte Technik oft für die Kopie berühmter Gemälde genutzt wurde (HeInZ, Europäische Tapisseriekunst, S.184).

191 Ibid., S. 180.

192 BRASSAT, Tapisserien, S. 14. 
serien des Finanzministers dienten vorrangig der Nobilitierung von Vaux-leVicomte. Sie waren ein Zeichen von Luxus und Wohlstand und damit Ausdruck des Repräsentationsbedürfnisses des Finanzministers. Auch in die literarische Inszenierung der Schlossanlage sollten die wertvollen Folgen aufgenommen werden. In seinem »Songe de Vaux« beschreibt La Fontaine zumindest eine der Serien von Vaux ${ }^{193}$. Die Darstellung der »Fable de Vulcain « blieb jedoch unvollendet, so dass man über sie keine Rückschlüsse auf die ikonographische Funktion der Tapisserien innerhalb der Raumdekoration von Vaux-le-Vicomte ziehen kann.

Die Gründung der Tapisseriemanufaktur von Maincy könnte auch mit dem Hintergedanken erfolgt sein, ihre Erzeugnisse als diplomatische Geschenke zu verwenden. Diese waren vor allem auf dem Gebiet der internationalen Politik ein wichtiges Mittel der Sympathiewerbung. Für den Premierminister gehörten außenpolitische Gespräche und Verhandlungen zum Alltagsgeschäft. In diese Rolle wünschte sich Nicolas Fouquet.

\section{Vaux-le-Vicomte und die Dichter}

Die Förderung der Literatur durch die ersten Minister des Königreiches begann mit dem Kardinal Richelieu, der die Zurschaustellung königlicher Herrschaft mit Hilfe der Poesie auch zur Steigerung seiner Autorität einzusetzen wusste und den Großteil seiner Aktivitäten als Mäzen im Dienste Ludwigs XIII. der Mehrung seines eigenen Ruhmes widmete. Er förderte das Theater sowohl im Namen des Königs als auch durch Aufführungen im eigenen Hause ${ }^{194}$, rief ausländische Gelehrte ins Land und setzte mit seiner Kulturpolitik, die mit der Gründung der Académie française im Jahre 1635 ihren Anfang nahm, neue Maßstäbe. Der Kardinal entwickelte einerseits eine neue Strategie zur Stärkung sowohl der königlichen als auch der eigenen Macht und andererseits eine neue Form der Kunstförderung: die protection constante ${ }^{195}$.

Als Schützling Richelieus erkannte Fouquet vermutlich schon sehr früh den Nutzen der Literaturpatronage. Als ehrgeiziger Aufsteiger war es für ihn unerlässlich, jene zu unterstützen, die ihm zu einem glänzenden Ruf und gesellschaftlichem Ansehen verhelfen konnten. Um seine Macht nach außen darzustellen, benötigte er die Lobesreden und Widmungsbriefe der Dichter: »Tout obligeait le surintendant à être un mécène attentif, constant, libéral, qui par adresse, par générosité et par complaisance régnât sans conteste sur tous les esprits ${ }^{196}$.

193 La Fontaine, CEuvres complètes I, Bd. VIII, S. 295: Songe de Vaux, Fragment IX (Les Amours de Mars et de Vénus).

194 Im Kardinalspalast befand sich das Privattheater Richelieus, wo regelmäßig Theateraufführungen stattfanden (vgl. Harouel, »Mécénat«, in: DGS, S. 1004).

195 Chatelain, Foucquet, S. 146.

196 Ibid., S. 152. 
Doch mit der Übernahme des Amtes des Finanzministers waren es zunächst die Dichter selbst, die in Form von Buchwidmungen ihr Interesse an einer Förderung durch Fouquet zeigten. Nachdem sich Fouquet im Dezember 1654 mit der Aufgabenverteilung zwischen den beiden Finanzministern in seinem Amt behauptet hatte, stieg die Zahl der ihm gewidmeten Bücher kontinuierlich an.

Mit der Zeit verband sich das Interesse der Literaten an einer Förderung durch den Minister mit einem verstärkten Bedürfnis Fouquets, die Dichter mittels Gratifikationen und Pensionen an sich zu binden, um sie in ihren Buchwidmungen zu seinen Gunsten sprechen zu lassen. Nachdem sein politischer Erfolgskurs wegen der Spannungen mit Mazarin und Colbert ins Stocken gekommen war, wurde diese Art des Prestigegewinns für ihn immer wichtiger. Parallel zum Bau von Vaux-le-Vicomte wurde die Förderung von Literaten ab 1657 regelrecht institutionalisiert. Ihre Protegierung, der Aufbau sowie die Pflege eines weiten Kreises von Protegés wären undenkbar gewesen ohne die Unterstützung durch Paul Pellisson, der 1657 als secrétaire und premier commis in die Dienste des Finanzministers trat ${ }^{197}$.

Der aus einer hugenottischen Magistratsfamilie stammende Paul Pellisson (1624-1693) war 1645 nach einem Jurastudium für einen ersten Aufenthalt nach Paris gekommen. Neben der Chambre bleue der Marquise de Rambouillet hatte sich hier um 1640 eine société d'amis von jungen und gebildeten Schriftstellern um Gédéon Tallement des Réaux gebildet, unter ihnen François Maucroix und Jean de La Fontaine, die eine Welle amouröser und galanter Poesie auslösten und damit die Schwere der herkömmlichen Dichtung ironisierten. Zu ihnen stieß der junge Schriftsteller und Advokat Paul Pellisson aus Castres. 1650 ließ er sich endgültig in der Stadt an der Seine nieder und bildete fortan mit seinen Dichterfreunden eine feste Gemeinschaft. Die Gruppe, die sich Académie de la Table ronde nannte, trat regelmäßig in seinem Haus zusammen, um hier zu lesen, zu diskutieren und zu produzieren, unterstützt von dem Schriftsteller und Gelehrten Valentin Conrart, dessen 1629 gegründeter literarischer Zirkel als Vorläufer der Académie française gilt. Im August 1653 lernte Pellisson durch seine Freunde Madeleine de Scudéry kennen, mit der ihn bis zu seinem Tod eine »amitié tendre « verband ${ }^{198}$.

In Paris hatte sich Pellisson zunächst als historiographe der Académie française einen Namen gemacht (1650 erschien seine Geschichte der Akademie) und war von dieser mit dem Supernumerar der Académie bedacht wor-

197 Vgl. Niderst, Scudéry, S.303, 353f. Sowohl DonnÉ, Parnasse, S. 203 als auch Niderst, Scudéry, S. 353 geben das Jahr 1657 als Eintrittsjahr Pellissons in die Dienste Fouquets an. Chatelain, Foucquet, S. 88 hingegen legt es bereits in das Jahr 1656. Zwischen dem ersten Kontakt mit Fouquet und dem Eintritt in seine Dienste liegt eine Phase, in der Pellisson überwiegend antike Texte übersetzt hat (NIDERST, Scudéry, S.304).

198 Die »Carte de Tendre « war von Madeleine de Scudéry eigens konzipiert worden »pour expliquer à Pellisson comment il pouvait devenir un `tendre ami« (NIDERST, Scudéry, S.35). 
den. Die Bekanntschaft mit Fouquet machte der junge Dichter im Jahr 1655, nachdem er dem Minister im Namen von Madeleine de Scudéry für eine Gratifikation gedankt hatte. Mit diesem Gedicht erlangte Pellisson selbst eine Förderung durch Fouquet, die ihn erneut zu einer Danksagung veranlasste ${ }^{199} .1657$ wurde Pellisson schließlich zum Sekretär des Finanzministers und leitete fortan die täglichen Geschäfte des surintendant: Er beantwortete Depeschen, gab Gesandten, wie dem 1661 von Fouquet nach Rom geschickten Maucroix, genaue Instruktionen, kümmerte sich um Zahlungen an Fouquets Spione und korrigierte die poulets (Liebesbotschaften) des die Frauen verehrenden Finanzministers. Zu seinen Aufgaben gehörte schließlich die Auswahl förderungswürdiger Künstler und die Bildung einer cour poétique um Fouquet: »Pellisson fut donc mêlé à toutes les affaires du surintendant: emprunts, pensions, intrigues politiques, services du roi, ambitions personnelles ${ }^{200}$. Pellissons gute Verbindungen zu den Pariser Dichterzirkeln erlaubten einer neuen Generation von Poeten den Zutritt zum Kreise Fouquets. Dieser setzte sich zusammen aus Freunden des Sekretärs, die von der Großzügigkeit Fouquets und der Möglichkeit, Pellisson für ihre Interessen einsetzen zu können, zu profitieren suchten: André Félibien, Charles Perrault, Philippe Quinault und Jean Loret waren einige, die dank der Fürsprache Pellissons eine Pension erhielten. Daneben gab es auch Dichter, die bereits vor $1657 \mathrm{zu}$ den Schützlingen des Finanzministers gehörten, unter ihnen Paul Scarron und François Le Métel de Boisrobert.

Mit der Einstellung Pellissons erhielten die Dichter eine neue Möglichkeit, ihren Anliegen bei dem Finanzminister Gehör zu verschaffen. Schriftlich oder mündlich wandten sich die Dichterfreunde an Pellisson, der die Bittgesuche an seinen vielbeschäftigten Herrn weitertrug. Scarron bedankt sich in einem Brief an Fouquet, dass dieser sein von Pellisson vorgetragenes Bittgesuch erhört habe:

Monseigneur,

Je ne puis mieux récompenser Monsieur Pellisson, de la bonté qu'il a eue de vous parler de mon affaire, \& de me faire voir l'obligeante réponse que vous lui avez faite, qu'en vous faisant voir le billet qu'il m'en écrit. Il est mal-aisé de parler de vous, quand ce seroit à vous-mesme, sans vous donner des louanges, mal-aisé de vous en donner sans vous déplaire, \& plus mal-aisé encore de s'empescher de vous en donner. Je voudrois donc bien que quelqu'un vous dit pour moi; que vous estes le plus genereux homme du monde, \& que toutes les graces que vous me faites, vont toujours au de-là de toutes les prieres que je vous faits ${ }^{201}$.

199 Arsenal, ms. 3135, fol. 267: »A M. Fouquet Procureur Général au Parlement \& Surintendant des finances«. In dem Brief gibt der Autor an, ihm sei Apollon erschienen und habe ihn in die Welt der Fiktion eingeführt. Er verspricht weiterhin, die von seinem Adressaten wenig geschätzte Prosa zu rehabilitieren und zitiert Malherbe: »En Prose on dit ce que l'on veut, en vers on dit ce que l'on peut«.

200 Niderst, Scudéry, S. 356.

201 Scarron in einem undatierten Brief an Nicolas Fouquet (SCARron, Dernières Euvres, S. 88f.). 
Tabelle 2: Buchwidmungen an Fouquet. Buchwidmungen an Mme Fouquet in eckigen, an Pellisson in runden Klammern ${ }^{202}$.

\begin{tabular}{lc}
\hline Jahr & Anzahl der Dedikationen \\
\hline 1652 & 1 \\
1653 & $/$ \\
1654 & {$[1]$} \\
1655 & 3 \\
1656 & 4 \\
1657 & $2[1]$ \\
1658 & 7 \\
1659 & $9[2]$ \\
1660 & 1 \\
1661 & $2(1)$ \\
o. J. & 2 \\
\hline
\end{tabular}

Die Hoffnung auf eine Förderung durch den Finanzminister schlägt sich in der Zunahme der Buchwidmungen an Fouquet nach 1657 nieder (siehe Tabelle 2). Manchmal richteten die Dichter ihre Widmungsbriefe nicht direkt an den Minister, sondern an seinen Sekretär, um auf diesem Weg ans Ziel zu gelangen ${ }^{203}$.

Die regen Kontakte Pellissons zu den Dichtern schufen beste Voraussetzungen, die Literaten und ihre Werke für die politischen Zwecke Nicolas Fouquets einzuspannen. Die Buchwidmungen enthielten allerdings neben (meist) allgemeingültigen formelhaften Lobeshymnen auf den Buchpaten keine individuellen Botschaften und waren daher kein Sprachrohr ihres Adressaten. Texte über sich und sein neues Schloss aber benötigte der Finanzminister, um die in der Ikonographie von Vaux-le-Vicomte versteckten Botschaften entschlüsseln zu helfen und an die Öffentlichkeit zu tragen. Zwei Jahre nach der Einstellung Pellissons hatte man einen Kreis von Dichtern gefunden, die in ihren Werken für den Finanzminister die literarische Inszenierung von

202 Eine ausführliche Tabelle mit genauer Aufführung von Autoren und ihren Fouquet gewidmeten Werken findet sich im Anhang 3.

${ }^{203}$ LeINER, Widmungsbrief, S. 156: »Wo die Autoren nicht mutig genug sind, mit einer Zueignung den Kontakt zu einer hochgestellten Persönlichkeit herzustellen, der sie selbst unbekannt sind, wenden sie sich in einer Zuschrift an eine minder bedeutende Standesperson, um diese um Fürsprache zu bitten «. In einer anonymen Schrift (Arsenal, ms. 5418, fol. 510) heißt es in diesem Sinne:

Tu sais agir, généreux Pellisson;

J'en suis Instruit, \& c'est mon propre exemple

Qui m'en fournit une preuve assez ample.

Aupres de toy, je suis presqu'inconnu,

Et cependant, j'y suis le bien-venu,

Mais qui pis est, l'estat de ma fortune,

Comme tu vois, veut que je t'importune,

Et tu reçois mes Importunitez,

Tu me confons par tes civilitez. 
Vaux bewerkstelligen sollten. Die wahrscheinlich nach Pellissons Anregungen entstandenen Texte trugen die politische Botschaft von Vaux an die Öffentlichkeit und ergänzten somit »die Anlage von Vaux-le-Vicomte um ein Modell ihrer adäquaten Rezeption $\ll^{204}$.

\subsection{Die Schriften zu Vaux-le-Vicomte}

1659 hatte Nicolas mit der alleinigen Übernahme der surintendance des Finances sowohl einen beruflichen Sieg errungen und zugleich infolge des endgültigen Bruchs mit seinem Bruder Basile und der unüberbrückbaren Differenzen mit Colbert einen politischen Tiefpunkt erreicht. Hatte er bereits seit 1656 bei dem Bau von Vaux die Künste dafür genutzt, eine Botschaft und ein Bild seiner selbst zu entwerfen und auf diese Weise die Kunstproduktion auf sich selbst abgestimmt, so nahm er ab 1659 auch die Literatur für die Inszenierung seiner Person in Anspruch ${ }^{205}$. Bis zu seinem Sturz arbeiteten drei Autoren an Werken zu Vaux-le-Vicomte: André Félibien, Jean de La Fontaine und Madeleine de Scudéry. Ihre Schriften stehen in einem engen Bezug zueinander. Sie bilden, so Germer, »ein sorgfältig geplantes intertextuelles Netz. [...] Sie waren nicht äußerlicher Zusatz, sondern integraler Bestandteil der propagandistischen Gesamtkonzeption von Vaux «206. Die Schriften setzen in ihrer Darstellung der Anlage je eigene Akzente und heben dadurch verschiedene Aspekte von Vaux-le-Vicomte hervor.

Den Ausgangspunkt der literarischen Inszenierung von Vaux-le-Vicomte und seines Erbauers bilden die Texte André Félibiens (1619-1695). Seit seiner Rückkehr aus Italien im Jahr 1649 hatte er versucht, sich in Frankreich als Schriftsteller zu etablieren. Auf welchem Gebiet er zu veröffentlichen gedachte, hatte er bereits vor seinem Italienaufenthalt deutlich gemacht. Die Übersetzungen von »Caída «207 und Leonardos Malereitraktat hatten seine politischen und kunsttheoretischen Ambitionen zu Tage gebracht. Ein Forum für derlei Schriften gab es in Frankreich jedoch noch nicht. Kunsttheoretische Traktate waren allein den Künstlern vorbehalten, die auch die Leser dieser

\footnotetext{
204 Germer, Félibien, S. 179.

205 Auffällig ist zudem die zunehmende Berichterstattung über das Haus Fouquet, die Jean Loret ab 1656 in seiner »Muze historique « lieferte. Ob dies alleine mit der zunehmenden gesellschaftlichen und politischen Bedeutung des Finanzministers in Verbindung zu bringen ist oder ob Loret dem surintendant aufgrund einer finanziellen Unterstützung besonders verpflichtet war, muss offen bleiben.

206 Germer, Félibien, S. 171.

207 Bei Camillo Guidis »Caída del Conde-Duque de Olivarez« handelt es sich um den Augenzeugenbericht zu dem spektakulären Sturz des spanischen Ministers Gaspar de Guzman, Conde-Duque de Olivarez (1587-1645). Der Bericht wurde 1643 (unmittelbar nach dem Fall) von dem Gesandten des Herzogs von Mantua publiziert und fand in zahlreichen Übersetzungen in ganz Europa einen reißenden Absatz. Félibiens Übersetzung erschien 1650 bei Augustin Courbé in Paris unter dem Titel »Relation de ce qui s'est passé en Espagne à la disgrâce du Comte-Duc d'Olivares« (siehe auch: Germer, Félibien, S.112).
} 
Texte waren. Félibien wollte eine neue Form der kunsttheoretischen Schrift schaffen, die ein breites Publikum ansprechen sollte.

Wann und durch wen der Kunsttheoretiker und der Finanzminister miteinander bekannt wurden, ist nicht überliefert. Das Journal des Sçavans vom 28. November 1695 gibt an, dass sich Félibien und Fouquet erstmals kurz nach der Hochzeit des Schriftstellers, also bereits im Frühsommer 1653 getroffen haben ${ }^{208}$. Da André Félibien dem Kreis der Literaten verbunden war, dem auch Pellisson angehörte, ist jedoch ebenso eine spätere Bekanntschaft über den Sekretär des Ministers denkbar. Auch eine Verbindung über Charles Le Brun ist nicht auszuschließen, mit dem Félibien seit seinem Italienaufenthalt bekannt war.

Drei Schriften Félibiens der Jahre 1660-1661 stehen in unmittelbarem Bezug zu Vaux-le-Vicomte ${ }^{209}$ : In der 1659 konzipierten und im folgenden Jahr veröffentlichten »De l'origine de la peinture et des plus excellens peintres de l'Antiquité «210 finden sich eine Beschreibung der Gartenanlage von Vaux und einige allgemeine Bemerkungen zum Schloss. Die wohl im Anschluss daran verfassten Briefe über Vaux ${ }^{211}$ liefern eine Beschreibung der dekorativen Ausgestaltung des Schlosses selbst, die im August 1661 verfasste »Relation des magnificences faites par Monsieur Fouquet a Vaux-le-Vicomte lorsque le Roi y alla, le 17 août 1661, et de la somptuosité de ce lieu « ${ }^{212}$ bildet den Ab-

208 Journal des Sçavans vom 28. November 1695, S. 459: »Peu de temps après [le mariage de Félibien], ses amis le présentérent à M. Foucquet, qui témoigna beaucoup d'estime de son mérite «. Félibien heiratete am 28. April 1653.

209 Es ist nicht eindeutig geklärt, in welcher Reihenfolge Félibien die Schriften zu Vaux verfasste. Lange Zeit war seine Autorenschaft selbst umstritten. Jacques Thuillier schreibt die Briefe in der Einleitung zum 11. Band der von der Société des amis de Jean de La Fontaine im Jahre 1999 herausgegebenen Ausgabe ihrer Revue »Le Fablier« mit dem Thema »Avec La Fontaine chez Foucquet: André Félibien à Vaux-le-Vicomte (16601661)« eindeutig Félibien zu. Er geht jedoch davon aus, dass Félibien zunächst die Festbeschreibung verfasste und erst im Anschluss daran die beiden Briefe zu der Innendekoration des Schlosses schrieb. Im »Journal des Sçavans« vom 28. November 1695 (S. 495) heißt es dazu: »Ce Surintendant des Finances ayant donné bien-tôt après une fête et des divertissements à Vaux, M. Félibien, qu'il y avoit invité, en donna la relation, qui plut extrêmement à toutes les personnes d'esprit et qui fut suivie de deux lettres contenant la description de la maison de Vaux«. Aufgrund der Kürze der Zeit, die zwischen dem Fest vom 17. August 1661 und der Verhaftung Fouquets am 4. September liegt, ist es unwahrscheinlich, dass die Festbeschreibung der Beginn der Vaux gewidmeten Literatur ist.

210 De l'origine de la peinture et des plus excellens peintres de l'Antiquité, Paris (Pierre Le Petit) 1660, in-4º 50p. (ohne Angabe des Verfassers). Der Text wurde 1666 mit kleinen Änderungen in den ersten Teil der »Entretiens« Félibiens übernommen.

211 Die Briefe sind in einer undatierten und anonymen Fassung in der Bibliothèque nationale überliefert ( $\left.\mathrm{Lk}^{7} 10117\right)$. Über die Autorschaft Félibiens besteht jedoch aufgrund der im Nachruf des »Journal des Sçavans« gemachten Angaben kein Zweifel.

212 Diese Schrift ist ebenfalls ohne Angabe des Datums und Verfassers überliefert und existiert heute nur mehr als Kopie in dem Recueil Thoisy der Bibliothèque nationale (402, fol. 714-722). Auch im Falle der »Relation« ist eine Autorschaft über den Nachruf im »Journal des Sçavans« nachgewiesen. Mehr zur Festbeschreibung Félibiens: siehe Kapitel 4. 
schluss der Arbeiten für Nicolas Fouquet. Den Anstoß für eine kunsttheoretische Beschreibung von Vaux-le-Vicomte könnte der Text Ascanio Amalteos (1630-ca. 1689) zu dem Gemälde Romanellis im Appartement Anna von Österreichs im Louvre gegeben haben. Fouquet war diese Beschreibung bekannt, da er einer derjenigen war, denen Amalteo zu Beginn seines Textes huldigte ${ }^{213}$.

Die »Origine « ist sowohl die erste eigenständige kunsttheoretische Veröffentlichung Félibiens als auch seine erste Huldigung an den Mäzen Fouquet ${ }^{214}$. Sie bildet den Auftakt der literarischen Inszenierung von Vaux-le-Vicomte und ist zugleich der Vorläufer der »Entretiens« von 1666 (Herausgabe des ersten Bandes), die Félibien zum führenden Kunsttheoretiker seiner Zeit machen sollten. Der Definition der Bestandteile der Malerei, der Diskussion der Qualitäten und Kenntnisse des guten Malers sowie der Bestimmung, was ein gutes Bild ausmache, folgt die Beschreibung eines Spazierganges durch den Garten von Vaux-le-Vicomte und die Lobpreisung seines Erbauers. Das Werk wird mit der Geschichte der Entwicklung der Malerei seit ihren Anfängen und der Erörterung der Leistungen ihrer wichtigsten Vertreter beendet. Die Schrift ist angelegt als der Brief eines nicht identifizierten Autors an einen ebenfalls namenlos bleibenden »Monsieur«. Darin gibt der Autor ein Gespräch wieder, das er mit seinem Freund Pymandre in Vaux-le-Vicomte geführt hat. In der »Origine« entfaltet Félibien seine Theorien am Beispiel von Vaux-le-Vicomte, das den Rahmen für die kunsttheoretischen und kunstgeschichtlichen Ausführungen bildet. Zugleich rühmt er die Einzigartigkeit der Anlage im Vergleich zu anderen zeitgenössischen Bauten und italienischen Vorbildern $^{215}$.

213 Germer, Félibien, S.147. Der Titel des Werkes von Ascanio Amalteo lautet: »La Regia Habitazione dell'Augustissima Regina Christianissima, coiè le quattro camere della Francia, delle virtù, degli Eroi romani e d'Apollo e Diane, illustremente figurate dal signor Giovanni Francesco Romanelli« (Paris 1657).

214 Félibien betrat mit der »Origine« literarisches Neuland der homme de lettres. Wie bereits erwähnt waren kunsttheoretische Schriften zuvor den Künstlern selbst vorbehalten gewesen. Die Übertragung des Genres auf einen Schriftsteller brachte Félibien zugleich in das Spannungsfeld der Interessen, und so ist es nicht verwunderlich, dass er in der »Origine« beständig eingrenzt und abschwächt. Félibien besetzt mit seinem ersten kunsttheoretischen Werk eine neue akademische Position und richtet sich zugleich an einen neuen, vorher wenig beachteten Leserkreis: den Laien.

215 »Pymandre me dit, Hé bien! serez-vous encore de ceux qui ne trouvent rien de comparable à ce qui se voit en Italie? Pourquoy vouelez-vous, luy repliquay-je, que je sois si desraisonnable? Il ne faut qu'avoir des yeux \& du sens commun pour estimer tant de riches Palais que nous avons aujourd'huy en France; Et sans sortir de celuy-cy, en quel lieu, je vous prie, avez-vous veu tant de diuerses beautez r'assemblées? Il est vray aussi que c'est une entreprise singuliere; Car pourriez-vous bien m'en remarquer de semblables? Ie n'ay garde de m'y engager, dist Pymandre, car toutes les Personnes puissantes n'ont pas les inclinations aussi nobles que sont celles du Ministre de ce Palais « (FÉLIBIEN, Origine, S.15, abgedruckt in: Relations, S.28). 
Anders verhält es sich mit den auf die »Origine« folgenden Briefen zu Vaux-le-Vicomte. Auch sie richten sich an den namenlosen »Monsieur« und erscheinen dadurch als Fortführung der ersten Schrift zu Vaux. In ihrem Fall bildet die Anlage des Finanzministers jedoch den eigentlichen Gegenstand des Textes ${ }^{216}$. Die Beschreibungen beschränken sich auf die Deckengemälde zweier Räume und das Bildnis Mme Fouquets von Charles Le Brun. Gegenstand der sogenannten »Seconde relation « ist die chambre des Muses; in der »Troisième relation « wird der salon d'Hercule sowie »La Beauté et la sagesse rognant les ailes de l'Amour« beschrieben. Darüber hinaus findet die Anlage von Vaux keine Erwähnung. In den Briefen werden sowohl die Tugenden Fouquets als auch die Kunstfertigkeit Le Bruns gerühmt. An erster Stelle steht jedoch die Beschreibung der Gemälde, die Aufdeckung des in den Malereien verborgenen Sinns sowie Anmerkungen zu den verwendeten Darstellungstechniken, die wiederum in Zusammenhang mit dem Gemalten selbst stehen. Die Briefe sollten dem Leser bei der Entschlüsselung der Ikonographie helfen. Félibiens Schriften zu Vaux sind somit keine literarischen, sondern kunsttheoretische Texte. Dadurch heben sie sich von den Texten La Fontaines und Scudérys ab.

Jean de La Fontaine (1621-1695) gehört zu jenen Poeten, die bereits kurz nach dem Dienstantritt des neuen Sekretärs eine Förderung durch Fouquet erfuhren: 1658 wurde er auf Empfehlung seines alten Freundes Pellisson in den Kreis der geförderten Künstler aufgenommen ${ }^{217}$ und widmete seinem neuen Mäzen zum Dank sein Kleinepos »Adonis « ${ }^{218}$ mit einer Dedikation in

${ }^{216}$ Im ersten der beiden Briefe, der »Seconde relation«, schließt der Autor direkt an die erste Schrift zu Vaux an, wenn er schreibt: »Monsieur, J'apprens par vostre dernière Lettre que vous n'estes pas entièrement satisfait de ce que je vous ay escrit touchant la maison de Vaux. Vous auriez souhaitté peut estre que je me feusse estendu davantage à descrire ce qu'il y a de plus remarquable, \& principalement les belles Peintures dont elle est ornée, comme une des choses pour lesquelles vous avez le plus de curiosité« (FÉLIBIEN, Relations, Seconde relation, S.35).

$217 \mathrm{Ob}$ La Fontaine tatsächlich von Pellisson in den Kreis Fouquets eingeführt wurde, ist nicht geklärt. Clarac behauptet, dass die Bekanntschaft La Fontaines mit Fouquet auf Initiative der Frau des Dichters, der Nichte des in Fouquets Diensten stehenden Jannart, erfolgte. Als Quellenbeleg führt er eine handschriftliche Notiz »sur la copie de la >Relation de l'entrée de la reine < qui figure dans les portefeuilles Tallemant « an (CLARAC, in: La Fontaine, Euvres complètes II, S. XXVIII). Da La Fontaine Jacques Jannart, den er nach dem Sturz Fouquets ins Exil nach Limoges begeleitete, sehr verbunden war, ist auch eine Einführung durch diesen selbst denkbar. Einige Autoren vertreten darüber hinaus die Meinung, Mme de Sévigné hätte den Dichter bei Fouquet eingeführt (Hislaire, Sévigné, S.17).

218 Das Manuskript wurde dem Minister in einer besonders edlen Ausgabe präsentiert: Kein Geringerer als der Kalligraph Nicolas Jarry, der im Jahr 1642 bereits »La Guirlande de Julie« illustriert hatte, war mit der Gestaltung der Handschrift beauftragt worden. Die Form war ganz auf den Empfänger ausgerichtet: »chiffre de Fouquet, et cartouche formé d'un entrelacement de rubans, de rameaux de myrte et de chêne, où jouent des écureuils, qui reprend le frontispice gravé par François Chauveau « (Lesage, Sous le signe de Fouquet, in: Dies. [Hg.], La Fontaine, S.38). 
Versform $^{219}$. Die Handlung des »Adonis«, die das Thema von Freundschaft und Liebe aufgreift, bettet La Fontaine in eine naturverbundene Szenerie, die das Gartenthema seiner späteren Werke, so auch der Schrift zu Vaux-leVicomte, vorwegnimmt ${ }^{220}$.

Mit La Fontaine vereinbarte Fouquet 1659 eine besondere Form der Förderung: Für eine regelmäßige Pensionszahlung versprach der Dichter ihm eine pension poétique in Versform:

À la Saint-Jean je promets madrigaux,

Courts et troussés, et de taille mignonne:

Longue lecture en été n'est pas bonne.

Le chef d'octobre aura son tour après;

Ma Muse alors prétend se mettre en frais:

Notre héros, si le beau temps ne change,

De menus vers aura pleine vendange;

$\mathrm{Ne}$ dites point que c'est menu présent,

Car menus vers sont en vogue à présent.

Vienne l'an neuf, ballade est destinée:

Qui rit ce jour, il rit toute l'année;

Or la ballade a cela, ce dit-on,

Qu'elle fait rire ou ne vaut un bouton.

Pâques, jour saint, veut autre poésie:

J'envoirai lors, si Dieu me prête vie,

Pour achever toute la pension,

Quelque sonnet plein de dévotion ${ }^{221}$.

Fouquet, l'unique but des faveurs d'Uranie,

digne objet de mes chants, vaste et noble génie,

Qui seul peux embrasser tant de soins à la fois,

Honneur du nom public, défenseur de nos lois;

Toi dont l'âme s'élève au-dessus du vulgaire,

Qui connais les beaux-arts, qui sais ce qui doit plaire,

Et de qui le pouvoir, quoique peu limité,

Par le rare mérite est encor surmonté,

Vois de bon œil cet œuvre, et consens pour ma gloire

Qu'avec toi l'on le place au temple de Mémoire;

Par toi je me promets un éternel renom;

Mes vers ne mourront point, assistés de ton nom.

$\mathrm{Ne}$ les dédaigne pas, et lis cette aventure

Dont pour te divertir j'ai tracé la peinture

(zitiert nach: Chéruel, Mémoires, Bd. I, S.452).

220 Vorbild für La Fontaines »Adonis« ist »L'Adone« von Giambattista Marino, das 1623

in Paris erschien - »deux ans après la naissance de La Fontaine, et qui jouissait pendant toute la jeunesse de ce dernier d'une très grande renommée dans les milieux littéraires français« (Lesage, Sous le signe de Fouquet, in: Dies. [Hg.], La Fontaine, S. 38). Über das Hauptsujet hinaus finden sich weitere wichtige Parallelen zwischen dem Werk La Fontaines und seinem Vorbild. In seinem »Adone« entwickelt Marino ein Thema, das sich bei La Fontaine durch das Gesamtwerk zieht: der Garten als eine Metapher des plaisir (bei Marino: 6. Gesang »Il giardino del piacere«) (ibid.). Zur Gartenthematik im Werk La Fontaines siehe auch: Michel Conan, Les jardins chez La Fontaine, in: ibid., S. 48-53.

$221 » \mathrm{M}^{\prime}[$...] ayant dit que je lui devais donner pension pour le soin qu'il prenait de faire valoir mes vers, j'envoyai quelque temps après cette lettre-ci à $\mathrm{M}$ « (in: LA FontaIne, Euvres 
Der Dichter hielt sich ein Jahr lang an den Rhythmus ${ }^{222}$, danach kam es zu Verzögerungen, die er mit der Arbeit an einem großen Werk zu Ehren des Mäzens entschuldigte: der »Songe de Vaux«. Dieser wurde, wie auch die erste Schrift Félibiens zu Vaux-le-Vicomte, um das Jahr 1659 begonnen ${ }^{223}$. Um das noch unfertige Schloss beschreiben und rühmen zu können, legte der Dichter seinen Fragmenten die Entwürfe und Beschreibungen der Künstler von Vaux zugrunde, die er persönlich kannte ${ }^{224}$. Im Text selber findet sich ein direkter Verweis auf die Stiche Silvestres, die dem Dichter als Vorlage dienten ${ }^{225}$. Im Juni 1659 reiste La Fontaine erstmals selbst nach Vaux, so dass seine Arbeit am »Songe« nicht nur auf eine theoretische Unterrichtung zurückzuführen ist $^{226}$. Im »Songe « werden Prosa und Poesie kombiniert mit Versatzstücken aus der Architekturbeschreibung und der galanten Konversationskultur. Die Handlung spielt überwiegend im Garten von Vaux und wird nur zu einem kleinen Teil auch in das Schloss verlegt. Auf eine Beschreibung der Ikonographie der Anlage verzichtet La Fontaine völlig. Er entwirft vielmehr das Bild eines Ortes der galanten und göttlichen Phantasien. Im Vordergrund steht die Inszenierung des Gartens als lieu enchanté.

complètes II, S.494). Clarac datiert den Text »peu avant juin 1659« (ibid., S. 882), so dass wir den Beginn der pension poétique auf den Sommer 1659 legen müssen.

${ }^{222} \mathrm{Im}$ Sommer 1659 lieferte La Fontaine die Mme Fouquet gewidmete »Ballade pour le premier terme « (ibid., S. 496f.), zum Oktober desselben Jahres eine »imitation du rondeau de Voiture: Ma foi, c'est fait« (ibid., S. 497f.) und zum Januar des Jahres 1660 die Ballade "Sur la paix des Pyrénées et le mariage du roi« (ibid., S.498f.). Im Anschluss an die ersten drei »Pensionszahlungen « gibt es nur mehr spärliche Informationen zu entsprechenden Literaturlieferungen durch La Fontaine an Fouquet. Clarac vermutet, dass der Mme Fouquet gewidmete »Dizain« (ibid., S.499f.), den er mit den Worten »Je devais donner des madrigaux en d'autres temps, et voici ce que j'envoyai pour un de ces termes « überschrieb und deren Entstehungszeitraum er zwischen Juni 1659 und September 1661 annimmt (ibid., S. 886), für einen Sommer oder Herbst-Termin geschrieben wurde. Ebenso der Fouquet gewidmete »Dizain« (ibid., S.500), der Clarac zufolge »semble donc avoir été envoyé à Fouquet pour compléter le terme de juin, en 1660 ou en 1661 (ibid., S. 887).

${ }^{223}$ Im Jahr 1671, als Teile des »Songe de Vaux« in einer Sammlung La Fontaines veröffentlicht wurden, schrieb La Fontaine im avertissement: »Le lecteur verra trois fragments d'une description de Vaux, laquelle j'entrepris de faire il y a environ douze ans. J'y consumai près de trois années«.

224 »Vous savez mon ignorance en matière d'architecture, et que je n'ai rien dit de Vaux que sur des mémoires « (Brief La Fontaines an seine Frau vom 12. September 1663, in: La Fontaine, Euvres complètes I, Bd. IX, S.259).

225 »C'étoit aussi cette maison magnifique, avec ses accompagnements et ses jardins, lesquels Silvestre m'avoit montrés, et que ma mémoire conservoit avec un grand soin, comme étant les plus précieuses pièces de son trésor « (ibid., Bd.VIII, S.246). Zur Bekanntschaft La Fontaines mit Le Brun siehe: Brief an Maucroix vom 26. Oktober 1693, in: LA Fontaine, Euvres complètes II, S.729.

${ }^{226}$ Ballade pour le premier terme (Juni 1659): »Je viens de Vaux, sachant bien que sur tous, les Muses font en ce lieu résidence (ibid., S.496f.). 
La Fontaine schildert in seiner Lobrede auf Vaux die Schönheiten der Schlossanlage in Form eines Traumes, in dem Götter und Heroen den verzauberten Ort bevölkern und rühmen:

Des lieux que pour leurs beautés

J'aurois pu croire enchantés,

Si Vaux n'étoit point au monde :

Ils étoient tels qu'au Soleil

Ne s'offre au sortir de l'onde

Rien que Vaux qui soit pareil227.

Hauptgestalt des »Songe« ist Acante, der - von Ariste und Gélaste begleitet - das Schloss im Traum besucht ${ }^{228}$. Hier begegnet er nicht nur Schönheit und Überfluss, sondern auch Göttern und Getier. Zwei Tage und eine Nacht dauert Acantes Besuch in Vaux. Seinen ersten Tag im Schloss beginnt der träumende Gast im Schlossinneren, wo er den salon des Muses erkundet (Fragment V) und lernt, warum es die Musen an diesen Ort verschlagen hat: »Oronte [Fouquet] [...] occupe leurs esprits: Tantôt dans les forêts, tantôt sous les lambris «229. Im Verlauf des Tages lernt er die Schönheiten von Vaux weiter kennen: Er betrachtet die Wandteppichfolge mit der Geschichte von Mars und Venus (Fragment IX), lauscht dem Gesang eines sterbenden Schwans (Sinnbild für den Gesang des verliebten Jupiter) und erfährt Vaux als einen Ort der Musik und der Metamorphose, der von keinem Geringeren als dem Musenbegleiter Apollon geleitet und gelenkt wird: »Apollon a juré de ne plus faire de vers que quand Oronte et Sylvie [Mme Fouquet] le souhaiteront. Il gouvernera leurs troupeaux, il sera contrôleur de leurs bâtiments; il conduira la main de nos peintres, de nos statuaires, de nos sculpteurs $\ll^{230}$. Er hört die Rede eines Störs (esturgeon), der dank einer direkten Verbindung zwischen dem Ozean und dem Fluss Anqueuil nach Vaux kommen konnte und vorhersagt, dass noch weitere Raritäten aus der Meereswelt ihren Weg zu den Wassern von Vaux finden werden (Fragment III). Auch die Unterredung von Neptun und seinen Tritonen weist auf den Wasserreichtum der Anlage hin (Fragment VIII). In der auf den ersten Tag folgenden Nacht ist Acante Zeuge des Tanzes der Liebe im Wald von Maincy (Fragment VI). Seinem Erwachen am nächsten Morgen folgt die Begegnung mit Aminte, einer lieblichen Nymphe, die aus Vaux einen Ort der Liebe und Freundschaft machen will (Fragment VII). Der Aufenthalt Acantes in Vaux endet mit einem zweiten Besuch im salon des Muses, wo er einem Wettstreit zwischen der Archi-

227 Ausschnitt aus dem 1. Kapitel des »Songe de Vaux« (LA Fontaine, Euvres complètes I, Bd. VIII, S. 246).

${ }^{228}$ Im einführenden ersten Fragment heißt es: »Acante s'étant endormi une nuit du printemps, songea qu'il étoit allé trouver le Sommeil, pour le prier que, par son moyen, il pût voir le palais de Vaux avec ses jardins: ce que le Sommeil lui accorda, commandant aux Songes de les lui montrer« (ibid., S.243).

${ }^{229}$ Ibid., Fragment V, S. 278.

230 Ibid., Fragment IV, S. 277. 
tektur, Malerei, Gartenkunst und Poesie beiwohnt, der von Letztgenannter gewonnen wird: »La dernière main n'y sera que quand mes louanges l'y auront mise; et vous-même, ne devriez-vous pas consentir que j'eusse l'écrin, comme le plus digne prix de la gloire que mes ouvrages vous ont donnée? «231 Der »Songe de Vaux« blieb unvollendet, das Gedicht liegt uns lediglich in den vorgestellten neun Fragmenten vor $^{232}$. Diese lassen den Inhalt des geplanten Werkes erahnen. La Fontaine spricht in ihnen alle Themen an, die Vaux zu einem besonderen Ort machen: die Omnipräsenz der Künste, der Wasserreichtum der Anlage, der Neptun und einer direkten Verbindung zum Ozean geschuldet ist, die ungeheuren Schätze von Vaux - wie die Tapisseriefolge (die im Inventar von Vaux mit einem Schätzwert von über 11000 Livres als die wertvollste Teppichserie aus dem Besitz Fouquets gekennzeichnet wird) oder die maritimen Raritäten - und die Allgegenwart der Liebe, die bereits in dem Gemälde Le Bruns von Mme Fouquet thematisiert worden war. Aus dem Vorwort erfahren wir, dass sogar ein Abschnitt zu den Abenteuern eines Eichhorns für den »Songe « geplant war - so dass selbst die Geschichte Fouquets am Ende nicht fehlen sollte ${ }^{233}$.

Jean de La Fontaine inszeniert Vaux-le-Vicomte als einen Ort der Musen und Götter. Diese sind in seinem »Songe « nicht in Kunstwerke gebunden, sie werden nicht analytisch betrachtet, sondern im lebendigen Miteinander erfahren. Die Lobpreisung des Schlossherrn geschieht bei La Fontaine nicht in explizierter Form. Sie ergibt sich vielmehr aus dem ehrfurchtsvollen Verhalten der göttlichen Bewohner der Schlossanlage gegenüber Fouquet und der Tatsache, dass Vaux von ihnen als perfekter Aufenthaltsort erkoren wurde. Die von Le Brun entworfenen Bilder von Vaux leben bei La Fontaine, so dass die Schlossanlage zu einem erfahrbaren Ort der göttlichen Erhabenheit wird.

Ein Bezug zu den anderen Werken zu Vaux, besonders zu der Beschreibung Madeleine de Scudérys, findet sich im zweiten Fragment des »Songe«: »Plusieurs personnes avoient déjà fait la description de quelques endroits de ce beau séjour; surtout qu'il [Gélaste] m'en vouloit montrer une du salon, laquelle on ne pouvoit assez estimer « ${ }^{234}$.

Bereits im Jahre 1655 hatte Madeleine de Scudéry (1607-1701) eine erste Gratifikation von Fouquet erhalten, für die sie sich mit Hilfe Pellissons in dem »Remerciment du siècle« bedankt hatte. Als enge Freundin Pellissons (und Mme Fouquets?) war sie dem Hause Fouquet seit dessen Eintritt in die Dienste des Finanzministers noch enger verbunden. Im Jahr 1659 erhielt auch sie den Auftrag zu einer literarischen Überhöhung der neuen Schlossanlage, die die Romanautorin ihrem neuesten Werk einfügte. Der Romanzyklus »Clélie.

231 Ibid., Fragment II, S. 266.

2321967 erschien ein Nachdruck bei der Genfer Librairie Droz: JeAn de La Fontaine, Le Songe de Vaux, hg. von Eleanor Tiтсомв, Genf 1967.

233 La Fontaine, Euvres complètes I, Bd. VIII, S. 243.

234 Ibid., Fragment II, S. 266. 
Histoire romaine « erschien seit 1654 und umfasste bis 1659 bereits neun Bände. Bei dem Opus handelt es sich um einen Abenteuerroman, der im vorchristlichen Rom spielt und die Liebesgeschichte von Clélie und Aronce zum Thema hat. Die Helden müssen Trennung und Krieg überwinden, bis sie endlich nach vielen Abenteuern zueinander finden. Scudéry projiziert in ihrem Roman das zeitgenössische höfische Leben mit seinen Festlichkeiten und seiner Konversationskultur in die Antike und unterbricht die Rahmenhandlung mit unzähligen Nebenerzählungen, in denen vor allem die Besucher ihrer »samedis« porträtiert werden. In den zehnten und letzten Band des Romans, der im März 1660 erschien, fügte Sapho (alias Madeleine de Scudéry) die Beschreibung von Vaux-le-Vicomte (Valterre) und die Lobpreisung seines Erbauers Cléonime (Fouquet) durch eine ihrer Romanfiguren (Teanor) ein. Diese umfasst nicht nur ausgewählte Teile der Anlage, sondern geht - in dieser Reihenfolge - auf alle drei Räume von Vaux ein: den Vorhof, das Schlossinnere und den Garten. Besonderes Augenmerk legt sie auf die künstlerische Ausstattung und die Ikonographie der Deckenmalereien. Für die Erläuterung der nicht ausgeführten Salonbemalung muss Madeleine de Scudéry Einsicht in die Entwurfszeichnung Le Bruns erhalten haben. Dies lässt vermuten, dass sie auch darüber hinaus Unterstützung von den Künstlern von Vaux erhielt. In Bezug auf ihre anderen Beschreibungen der Werke Le Bruns verweist die Autorin zudem ausdrücklich auf die Schriften Félibiens und stellt damit einen Zusammenhang zu den anderen Werken zu Vaux her:

I'en ay veu une si belle $\&$ si admirable description, que ie ne l'entreprens qu'en tremblant. [...] Ie n'ay iamais rien veu de si beau que ce qu'un fort honneste homme a escrit sur ce sujet là; car il fait voir les choses qu'il descrits, \& quoy qu'il employe presque tous les termes de l'art, son discours ne laisse pas d'estre clair, fleury, eloquent, \& naturel235.

Die Darstellung Teanors beginnt mit der Geschichte der Familie Fouquet und der Erklärung, wie sie zu ihrem Wappentier kam. Es wird berichtet, dass dieses als Auszeichnung des Königs an die Familie gegeben wurde, die damit als langjährige und loyale Diener der Krone dargestellt werden - ein Topos, der den in Vaux gezeigten Anspruch des Finanzministers auf unmittelbare Nähe zum König legitimieren soll. In der Beschreibung des Vorhofes finden sich sowohl Hinweise auf die Triumphbögen, die Erhabenheit des Baus, die Löwenthematik der Fassade als auch die Transparenz der Schlossarchitektur - all dies für die ikonographische Botschaft der Anlage wichtige Details. Die Beschreibung des Schlossinnern beschränkt sich auf das appartement d'apparat des Hausherrn, schließt jedoch auch die Erläuterung der Deckengestaltung des Salons mit ein. Die Aufnahme des Eichhorns in den Götterhimmel beschreibt Madeleine de Scudéry als Zentrum der gesamten Anlage. Wichtige Anmerkungen finden sich außerdem zu der Arbeit und Meisterschaft Le Bruns (Méléandre) und der Besonderheit der Darstellungstechniken in Vaux, 
die für das allgemeine Verständnis der Ikonographie der Anlage grundlegend sind. In der Beschreibung des Gartens geht Teanor zunächst auf den Wasserreichtum und die vielen Überraschungseffekte ein, die die Anlage zu bieten hat: »Au delà du grand quarré d'eau, on descend encore, \& l'on voit alors un obiet tout à fait surprenant «236. Anschließend werden die für das bildliche Programm von Vaux entscheidenden Skulpturen erläutert: die Götterhermen, die Flussgötter Tiber und Anqueuil, die Löwenstatuen und die Herkulesstatue am Ende des Gartens. Die Beschreibung schließt mit einer erneuten Lobrede auf den Erbauer der Anlage, »qui donnant toute sa vie au service de son Roy $\ll 37$.

Wenngleich ihre Darstellung in eine historisierte Rahmenhandlung eingebettet ist, liefert Madeleine de Scudéry damit die umfassendste (wenn auch nicht die detaillierteste und phantasievollste) Beschreibung der Schlossanlage und bildet so die Grundlage für ein allgemeines Verständnis von Vaux-leVicomte, das durch die anderen beiden Texte vertieft werden kann. Die Beschreibung Madeleine de Scudérys stellt den Basistext der literarischen Inszenierung von Vaux dar. So sind die drei Schriften zu Vaux nicht allein durch wechselseitige Verweise miteinander verbunden. Auch in ihrer Form und ihrem Inhalt ergänzen sie sich und bilden ein Beziehungsgeflecht, das den verdeckten Sinn der Deckenmalereien des Schlosses enthüllt, die kulturelle Erhabenheit der Anlage manifestiert und den Schlossherrn selbst als den Mittelpunkt von Kunst und Pracht inszeniert - nicht ohne dies von König und Göttern legitimieren zu lassen.

Auf den ersten Blick gleicht Fouquets Mäzenatentum der Jahre 1656-1661 dem anderer Minister des 17. Jahrhunderts. Wie sie ließ er sich einen pompösen Landsitz bauen, vereinte in umfangreichen Sammlungen Gelehrsamkeit, Kunst und Kuriositäten seiner und vergangener Zeiten und förderte die literarische Produktion. Doch bei genauer Betrachtung ging Fouquets Engagement weit über das Übliche hinaus. Um seinen Karriereambitionen ein Medium zu geben, verknüpfte er die einzelnen Gebiete seiner Kunstförderung und schuf damit eine neue Form der propagandistischen Kulturpatronage und eine innovative Möglichkeit der Selbstinszenierung.

Die Jahre von Vaux dienten dem Mäzen Nicolas Fouquet nicht mehr zur gesellschaftlichen Etablierung, sondern zur Sicherung der erreichten Position und Festigung seiner Macht sowie zur Vorbereitung eines weiteren Aufstiegs. 